\title{
Proteomic Profiling of the Brassicaceae and Poaceae Mature Stigma
}

\author{
Nazila Nazemof \\ M. Sc. Carleton University \\ A Thesis Submitted to the Faculty of Graduate and Post-Doctoral Affairs in Partial \\ Fulfilment of the Requirement for the Degree of
}

Doctor of Philosophy
Department of Biology

Carleton University

Ottawa, Ontario, Canada

(C) Copyright 2014, Nazila Nazemof 


\section{Abstract}

The stigma, the specialized apex of the gynoecium plays a critical role in pollen capture, discrimination, hydration, germination, and guidance. Species of the Brassicaceae and Poaceae possess dry stigmas as opposed to the wet stigmas found for example in the Solanaceae and Liliaceae. The global proteome underlying stigma development and function remains largely unknown. A total of 2184 and 2275 proteins were identified in triticale and B. napus mature stigma respectively using a combination of 1D SDS PAGE LCMS/MS, 2D IEF/SDS PAGE LC-MS/MS and OFFGEL Electrophoresis (OGE) LC-MS/MS. Two search engines, Mascot version 2. 3. 0 (http://www.matrixscience.com) and X! Tandem version 2007.01.01.1 (www.thegpm.org/tandem), were used to search against the Universal Protein Resource (UniProt) Viridiplantae database. Scaffold version 4.0.4 (Proteome Software Inc., Portland, OR, USA) was used to validate MS/MS based peptide and protein identifications. The potential role of identified proteins involved in triticale stigma development (e.g. CRABS CLAW (CRC), STYLISH (STY), and PEPPER (PEP)), pollenstigma interactions (e.g. FIDDLEHEAD (FDH), SECRETION-ASSOCIATED RAS1 (SAR1) and FERONIA (FER)), as well as protection against biotic and abiotic stresses (e.g. PROTEIN KINASE INTERACTOR1 (PTI1), STRESS ACTIVATED PROTEIN KINASE 7 (SAPK7), and PROTEIN DISULFIDE ISOMERASES (PDIs)) was discussed. Proteins were often found in multiple spots indicating a significant degree of post-translational modification. Comparisons between triticale stigma transcriptomic and proteomic data also revealed post-translational as well as post-transcriptional regulation in this tissue. 
In triticale, comparing the functional distribution of mature stigma proteins and most abundantly expressed genes showed that structural and metabolic processes had high protein to mRNA ratios, whereas regulatory processes and transport had low protein to mRNA ratios, probably reflecting the need for rapid protein production and turnover in response to pollination. The B. napus stigma was found to express many proteins with a wide variety of roles in cellular and organ development (e.g. ANGUSTIFOLIA (AN) 3, SHORT VALVE (STV) 1, and SHAVEN3-LIKE (SVL)1). Approximately 8\% of the B. napus and triticale mature stigma proteins were predicted to contain a signal peptide and this low percentage suggests that many of the proteins involved in extracellular interactions with the pollen are probably synthesized after pollination. Comparative proteomic analysis of Brassicaceae and Poaceae stigmas revealed very similar global functional trends despite being very different morphologically, but also demonstrated evident differences in protein composition in particular with respect to glucosinolate and isoprenoid metabolism, photosynthesis and self-incompatibility. To our knowledge, this study represents the first high throughput characterization of the stigma proteome. This work should serve as a solid base for future research meant to investigate the function of these proteins in stigma development and function. 


\section{Acknowledgements}

I would like to thank my supervisor, Dr. Laurian Robert, for his support, patience, and assistance through my study. He has been always available to guide me and contribute in the completion of this thesis.

I would also like to thank my co-supervisor, Dr. Tim Xing, and my committee advisory member, Dr. Douglas Johnson, for their valuable advice.

Thanks to all of my fellow lab members, past and present, in particular, Madeleine Lévesque-Lemay, John Chan, Frances Tran, and Kevin Vali.

I want to extend to my acknowledgments to Philippe Couroux for his help and donating his time to solve computational issues throughout this research.

Special thanks to my husband, Mehrdad, for his understanding and specially his patience during this journey.

I would like to dedicate this thesis to the most important people in my life, my parents, brother and my niece. They have been the light and inspiration in my life.

Finally and most importantly, I want to give a special dedication of this thesis to my beloved son, Arman, for being such a wonderful child during my study. 


\section{TABLE OF CONTENTS}

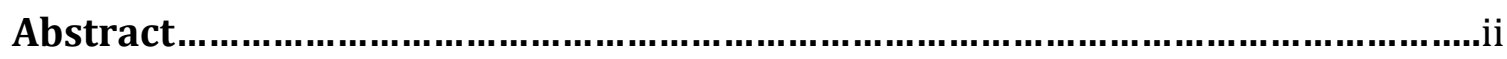

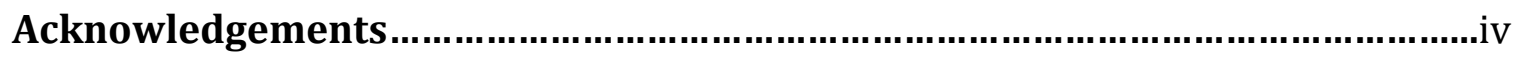

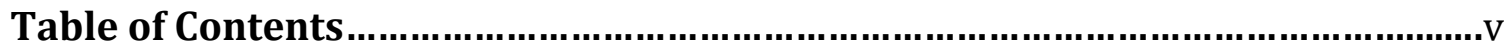

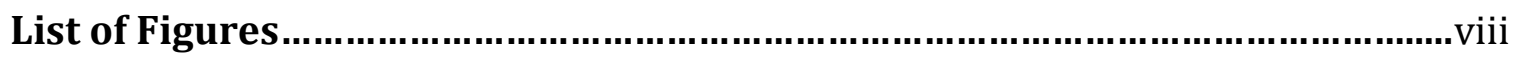

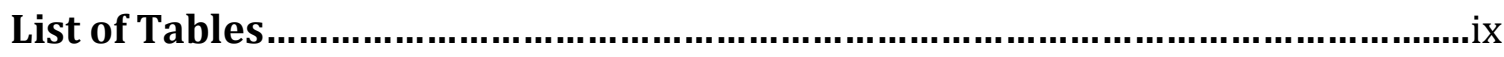

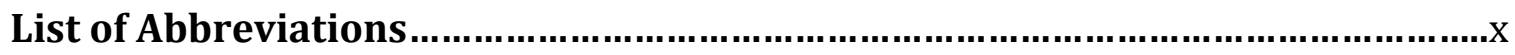

\section{Chapter 1. General Introduction}

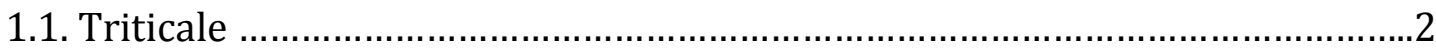

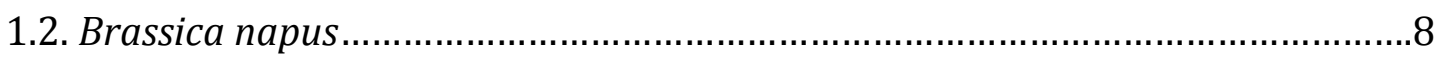

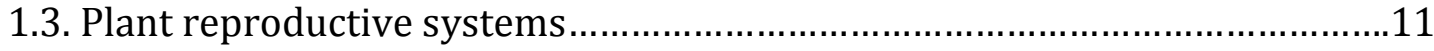

1.4. Sexual plant reproduction ....................................................................11

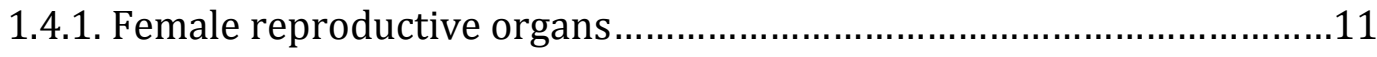

1.4.2. Male reproductive organs................................................................14

1.5. Pollen-Stigma interactions in species with dry stigmas...................................16

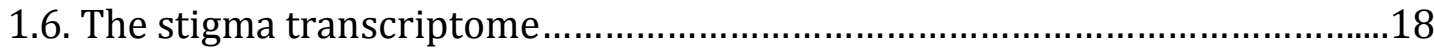

1.7. The stigma proteome

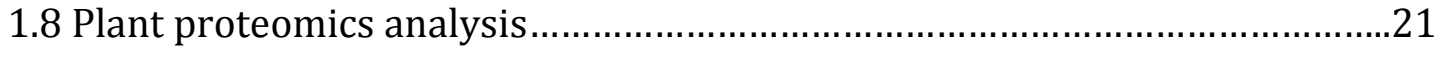

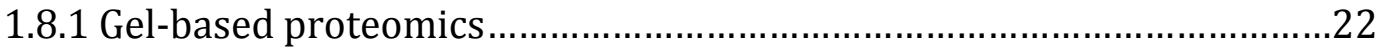

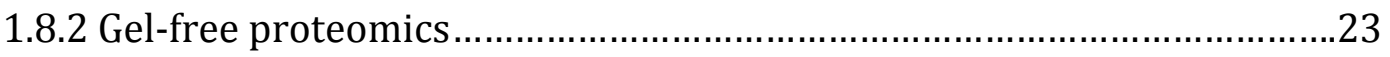

1.8.3 Label- based or label- free Proteomics …….......................................24

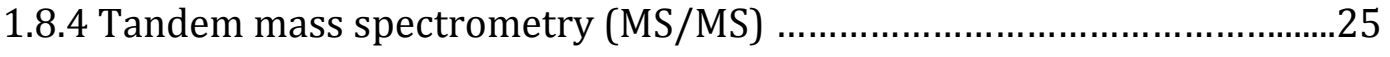

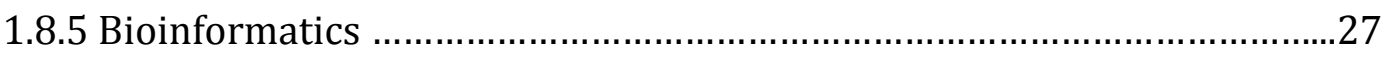

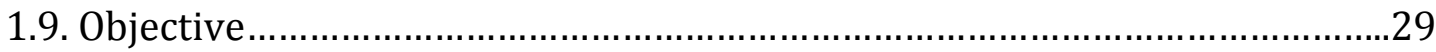




\section{Chapter 2. Proteomic Profiling Reveals Insights into Triticeae Stigma Development and Function}

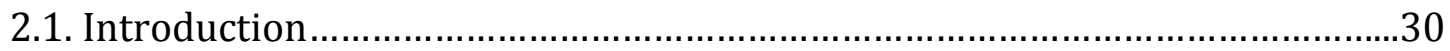

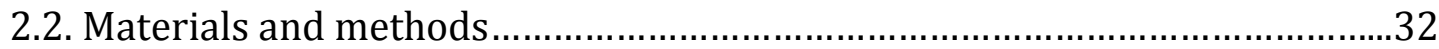

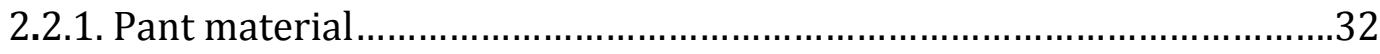

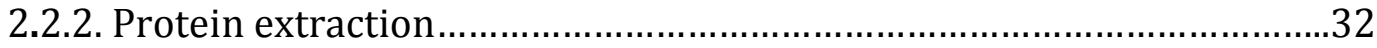

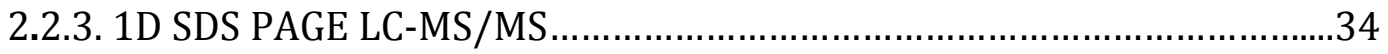

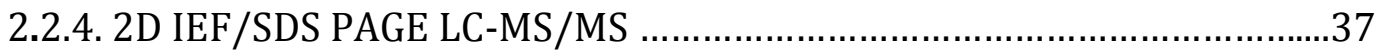

2.2.5. OFFGEL Electrophoresis (OGE) LC-MS/MS ............................................38

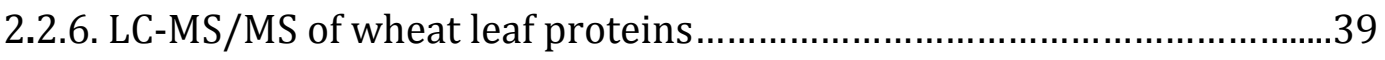

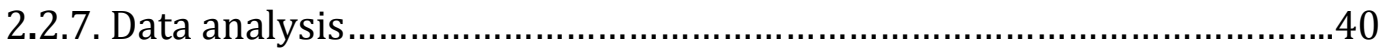

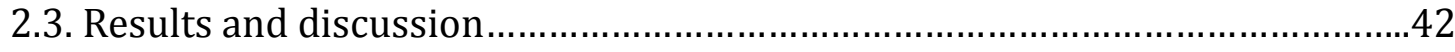

2.3.1. Comparison of 1D LC-MS/MS, 2D LC-MS/MS and OGE LC-MS/MS.......42

2.3.2. Functional classification of triticale mature stigma proteins..................44

2.3.3. Proteins involved in stigma development..............................................4

2.3.4. Proteins involved in pollen-stigma interactions.....................................48

2.3.5. Proteins involved in biotic and abiotic stress........................................53

2.3.6. Comparison of the stigma and leaf proteome .........................................55

2.3.7. Stigma proteins with single peptides....................................................55

2.3.8. Correlation between triticale mature stigma mRNA and protein

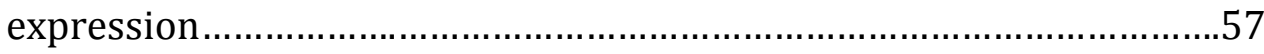

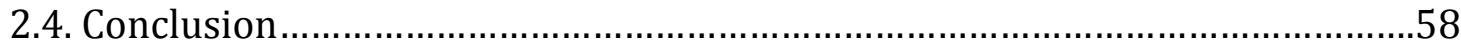


Chapter 3. Analysis of the Brassica napus Stigma Proteome Reveals Numerous Proteins Involved in Cellular and Organ Development

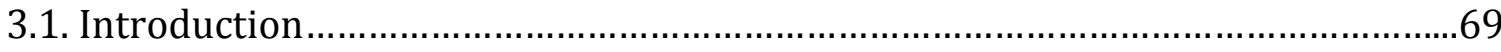

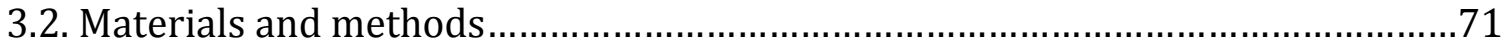

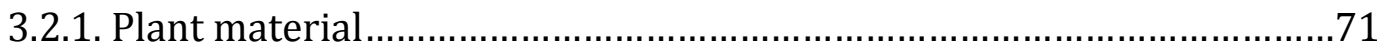

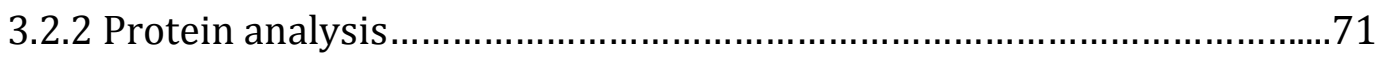

3.2.3. 1D SDS PAGE LC-MS/MS ..................................................................

3.2.4. 2D IEF/SDS PAGE LC-MS/MS..........................................................

3.2.5. OFFGEL Electrophoresis (OGE)LC-MS/MS Data.....................................76

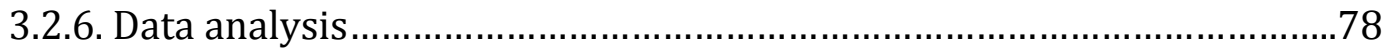

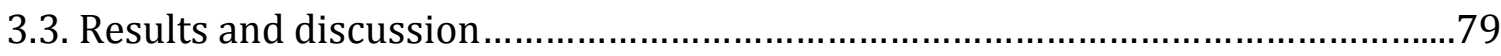

3.3.1. Comparison of 1D SDS PAGE LC-MS/MS, 2D IEF/SDS LC-MS/MS and

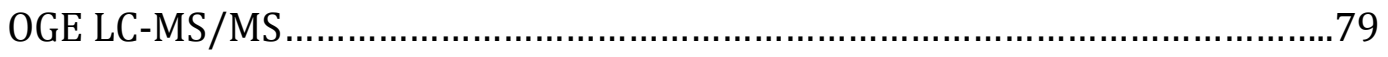

3.3.2. Functional classification of B. napus stigma proteins.............................79

3.3.3. B. napus stigma proteins involved in development................................80

3.3.4. Comparison of the Brassicaceae and Poaceae dry stigma proteomes...86

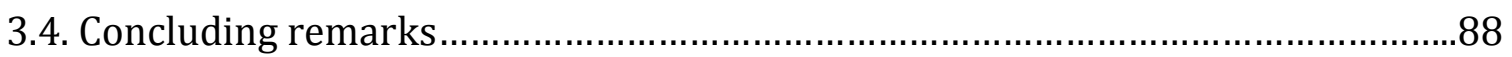

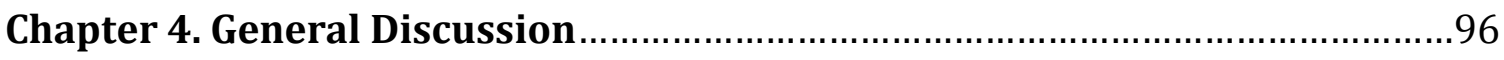

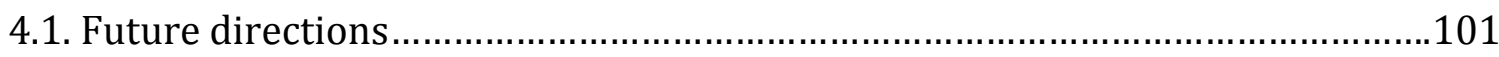

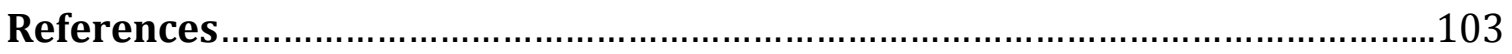




\section{List of Figures}

Figure 1-1 Methods of producing the various types of triticale..................................

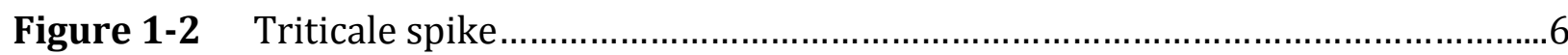

Figure 1-3 Schematic diagram of the triticale floret.................................................

Figure 1-4 Schematic diagram of the B. napus flower.............................................. 10

Figure 1-5 Schematic representation of a Poaceae (A) and Brassicaceae (B) pistil.........13

Figure 2-1 1D SDS-PAGE of triticale mature stigma proteins....................................59

Figure 2-2 2D IEF/SDS PAG gel of triticale mature stigma proteins .............................60

Figure 2-3 Overlap among the proteins identified by the different methods of analysis

Figure 2-4 Multiplex 2D analysis of triticale mature stigma proteins

.62

Figure 2-5 Functional distribution of triticale mature stigma proteins identified using different methods of analysis and their combined total.

Figure 2-6 Comparison of the functional distribution of triticale mature stigma and wheat leaf proteins .64

Figure 2-7 Functional distribution of triticale stigma proteins with a signal peptide......65

Figure 2-8 Functional distribution of triticale mature stigma.....................................66

Figure 2-9 Comparison of the functional distribution of the 2184 proteins and most abundantly expressed genes in the triticale mature stigma..........................67

Figure 2-10 Comparison of triticale mature stigma protein and mRNA abundance..........68 
Figure 3-1 2D IEF/SDS PAGE gel of B. napus mature stigma proteins............................89

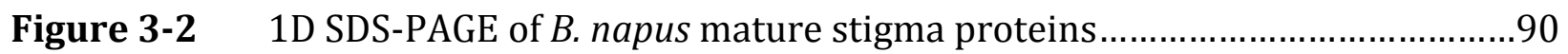

Figure 3-3 Venn diagram of the B. napus stigma proteins identified by the different

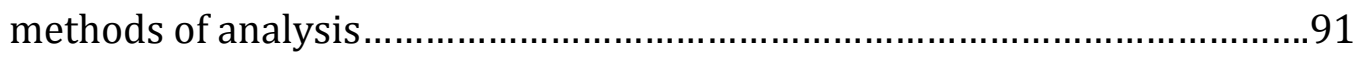

Figure 3-4 Comparison of the 2D maps of the B. napus (A) and triticale (B) mature

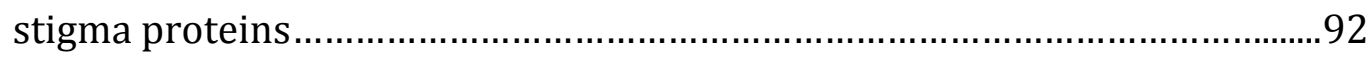

Figure 3-5 Comparison of the functional distribution of B. napus and triticale mature

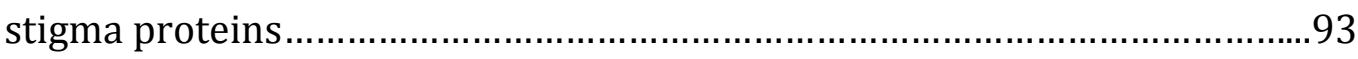

Figure 3-6 Comparison of the functional distribution of B. napus and triticale mature stigma proteins with a signal peptide ...................................................94

Figure 3-7 Differences between B. napus and triticale mature stigma proteins................95

\section{List of Tables}

Table 2-1 List of proteins identified in the triticale mature stigma..............................

Table 3-1 List of proteins identified in the B. napus mature stigma.............................. 


\section{List of Abbreviations}

1D

2D

2DE-MS

ABCG32

ABF3

AGO

AIM1

ALE

AN3

ANL2

AP2

APG6

ARF

ARF

AX

AXR

BEN

BIG one dimensional (SDS-PAGE)

two dimensional (IEF/SDS-PAGE)

two dimensional electrophoresis-mass spectrometry

ATP binding cassette G32

ABA binding factor3

argonaute

abnormal inflorescence meristem 1

asymmetric leaves enhancer

angustifolia3

anthocyaninless2

apetala2

albino or pale green 6

auxin response factor

ADP-ribosylation factor

anion-exchange chromatography

auxin resistant

BFA-visualized endocytotic trafficking defective

brefeldin a-inhibited guanine nucleotide-exchange 


\begin{tabular}{ll} 
BN-PAGE & blue-native page \\
CAM7 & calmodulin7 \\
CAND1 & cullin-assiciated-nedd8-dissociated1 \\
CBB & coomassie brilliant blue \\
CDC & cell division control \\
CDI & cadmium 2+induced \\
CDKF; 1 & cyclin-dependent kinaseF; 1 \\
CDPK & calcium-dependent protein kinase \\
CER8 & eceriferum8 \\
CESA3 & cellulose synthase A3 \\
CHMP & charged multivesicular body \\
CID & collision induced dissociation \\
CK2 & casein kinase2 \\
COP9 & constitutive morphogenesis9 \\
CPN60 & chaperonin60 \\
CRC & crabs claw \\
CXI & collulose synthase-interactive \\
\hline
\end{tabular}




\begin{tabular}{|c|c|}
\hline DCR & defective in cuticular ridges \\
\hline DET 3 & de-etiolated 3 \\
\hline DH & doubled haploid \\
\hline DIGE & differential in gel electrophoresis \\
\hline DIM 1 & diminuto1 \\
\hline DL & drooping leaf \\
\hline DRP & dynamin-related protein \\
\hline EDA & embryo sac development arrest \\
\hline EMB & embryo defective \\
\hline EOL & exinic outer layer \\
\hline ESI-MS/MS & electrospray ionization mass spectrometry/mass spectrometry \\
\hline ESTs & expressed sequence tags \\
\hline EY & embryo yellow \\
\hline FAS & fasciclin-like domain \\
\hline FDH & fiddlehead \\
\hline FDR & false discovery rate \\
\hline FER & feronia \\
\hline FL & flowering locus \\
\hline FLA & fasciclin-like arabinogalactan \\
\hline FORL1 & floral organ regulator-like1 \\
\hline
\end{tabular}


FTICR

FUS

GAP

GDI

GEM

GFA

GL2

GSI

HDA

HERK

HIR

HSC

HSP

HVE

IEC

IEF

ILA

ITRAQ

KIS

KNAT3 fourier transform ion cyclotron

fusca

GTPase activating protein

GDP dissociation inhibitor

glabra2 expression modulator

gametophytic factor

glabra2

gametophytic self-incompatibility

histone deacetylase

hercules

hypersensitive-induced reaction

heat shock cognate

heat shock protein

hemivenata

ion-exchange chromatography

isoelectric focusing

ilityhia

isobaric tags for relative and absolute quantitation

kiesel

knotted-like Arabidopsis thaliana3 


\begin{tabular}{|c|c|}
\hline КОВ 1 & kobito1 \\
\hline KTN 1 & katanin 1 \\
\hline LACS1 & long-chain acyl-CoA synthetase 1 \\
\hline LC & liquid chromatography \\
\hline LOX & lipoxygenase \\
\hline LTP & lipid transfer protein \\
\hline$m / z$ & mass to charge ratio \\
\hline $\mathbf{M} / \Delta \mathbf{M}$ & mass resolution \\
\hline MALDI-TOF & matrix assisted laser desorption/ionization-time of fligh \\
\hline MAP 65-1 & microtubule-associated protein $65-1$ \\
\hline MBD11 & methyl-CPG-binding domain protein1 \\
\hline MEE & maternal effect embryo \\
\hline MIRO 1 & miro-related gtpase 1 \\
\hline MMA & mass measurement accuracy \\
\hline MS & mass spectrometry \\
\hline MSI1 & subunit suppressor of IRA1 \\
\hline MTN & methylthioadenosine nucleosidase \\
\hline MudPIT & multidimensional proteomic identification technology \\
\hline NRX1 & nucleoredoxin1 \\
\hline OGE & OFFGEL electrophoresis \\
\hline
\end{tabular}




\begin{tabular}{|c|c|}
\hline OLI & oligocellula \\
\hline PAGE & polyacrylamide gel electrophoresis \\
\hline PCP & pollen coat protein \\
\hline PDE & pigment defective embryo \\
\hline PDI & protein disulfide isomerase \\
\hline PEP & pepper \\
\hline PER & phosphate deficiency root \\
\hline PFL & pointed first leaf \\
\hline PGY & piggyback \\
\hline PLD & phospholipase D \\
\hline PME & pectin methylesterase \\
\hline PP2AA2 & protein phosphatase $2 \mathrm{~A}$ regulatory subunit $\mathrm{A} 2$ \\
\hline PPIase & peptidyl prolyl isomerase \\
\hline $\mathbf{P R}$ & pathogenesis-related \\
\hline PRA & prenylated rab acceptor \\
\hline PTI1 & protein kinase interactor1 \\
\hline $\mathbf{Q}$ & quadrupole \\
\hline RACK1A & receptor for activated c kinase $1 \mathrm{a}$ \\
\hline RanGAP1 & ran GTPase-activating protein1 \\
\hline RCN & roots curl in naphthylphthalamic acid \\
\hline
\end{tabular}




\begin{tabular}{|c|c|}
\hline REB & root epidermal bulger \\
\hline RGP & reversibly glycosylated polypeptide \\
\hline RHM1 & rhamnose synthase 1 \\
\hline RNA-seq & RNA-sequencing \\
\hline ROL1 & repressor of lrx1 \\
\hline ROS & reactive oxygen species \\
\hline $\mathbf{R P}$ & ribosomal proteins \\
\hline RP HPLC & reverse phase high pressure liquid chromatography \\
\hline RSW5 & radially swollen 5 \\
\hline RT & room temperature \\
\hline SAPK7 & stress-activated protein kinase7 \\
\hline SAR1 & secretion-associated ras1 \\
\hline SC & self-compatibility \\
\hline SCR & $S$-locus cysteine-rich protein \\
\hline $\operatorname{sCX}$ & strong cation-exchange chromatography \\
\hline SE & serrate \\
\hline SE & stigmatic exudate \\
\hline SHI & short internodes \\
\hline SI & self-incompatibility \\
\hline SILAC & stable isotopic labeling with amino acids in call culture \\
\hline
\end{tabular}


SLG

SLP

SLR1

SLR1-BP

SNRK

SRK

SSI

STV

STY

SVL 1

TCP1

TFs

THF1

TOF

TOR

TOR 2

TPL

TS 1, 2

UAM

UBP14
$S$-locus glycoprotein

schlepperless

$S$-locus receptor- related 1

SLR1-binding protein

SNF1-related protein kinase

$S$-locus receptor kinase

sporophytic SI

short valve

stylish

shaven3-like 1

T-complex protein 1

transcription factors

thylakoid formation1

time-of-flight

target of rapamycin

tortifolia 2

topless

tasselseed1, 2

UDP-arabinopyranose mutase

ubiquitin-specific protease 14

xvii 
UGE4

USP

UVR8

ZBF
UDP-glucose 4-epimerase

universal stress protein

UVB-resistance8

Z-box binding factor

xviii 


\section{Chapter1}

\section{General Introduction}

Flowering plants (Angiosperms) are the most diverse group in the plant kingdom and play crucial roles in agriculture. Traditionally, angiosperms are classified into two major classes; Magnoliopsida (dicots) and Liliopsida (monocots) (Cronquist, 1988). One of the most significant differences between dicots and monocots is their floral structure (Johri, 1984). Since flowers play a crucial role in sexual reproduction in angiosperms, it is important to know the specific characteristics of the flower across taxa. Many monocots and dicots possess perfect flowers (monoclinous) that contain both the male (stamen) and female (pistil) organs. Unlike the stamens, little is known about the molecular diversity or similarity in the pistil tissues of different species (Hiroi et al., 2013). The stigma, the upper part of the pistil, plays important roles as a physical and chemical interface between the male and female gametophyte. It is likely that certain molecules are dedicated to stigma function in diverse families of angiosperms. Since proteins are the major molecular effectors of the cell, knowledge of protein identity and abundance in the stigma using proteomics approaches should contribute to a better understanding of its development and function.

In this proteomics study, triticale and Brassica napus will serve as monocot and dicot examples of plants with a dry stigma, respectively. Understanding the reproductive system of these crops will support the development of strategies for yield maintenance under abiotic stress and for pollination control in view of their potential use as bioindustrial platforms. Since reproduction and seed production in major crops rely on the 
success of pollination and fertilization, fertility management can have a direct impact on crop performance, as exemplified by hybrid seed production.

\subsection{Triticale}

Triticale is a cereal crop that was developed by man rather than through natural evolution. Triticale was initially developed by crossing durum wheat (Triticum durum, $2 n=28=A A B B$ ) or common wheat (Triticum aestivum, $2 n=42=A A B B D D$ ) as a female parent, with rye (Secale cereale, $2 n=14=R R$ ) as the male parent (Wilson, 1876). Early triticale was highly sterile and produced completely dysfunctional pollen grains. A breakthrough in the production of fertile hybrids came with the development of a method to double the haploid complement of plant chromosomes using colchicine, a chemical isolated from the autumn crocus (Blakelee and Avery, 1937).

Based on their ploidy level, two major classes of triticale have been developed: hexaploid and octaploid. The hexaploid type $(2 n=42)$ is the most advanced in its development and is recognized by its scientific name $\mathrm{X}$ Triticosecale Wittmack. It combines the $\mathrm{A}$ and $\mathrm{B}$ genome of tetraploid wheat with the $\mathrm{R}$ genome of diploid rye. The octaploid form of triticale $(2 n=56)$ is derived from the three genomes of hexaploid wheat $(A, B$, and D) and the R genome of rye. The hexaploid and octaploid forms of triticale are crosscompatible and hybridization of the two has been used extensively in triticale breeding programs (Figure 1-1). The majority of triticale grown worldwide today consists of hexaploid types (Larter and Gustafson, 1980). 
Triticale was initially developed to combine the positive traits of both parent types: vigour, winter hardiness and adaptability to stress of rye with the higher quality gluten and baking properties of wheat. Triticale has many favourable agronomic qualities. It is more productive than other cereals under abiotic stress conditions, less susceptible to many diseases affecting wheat, competitive with other cereals in term of grain yield, and tolerant to extreme soil conditions (acidic or arid). Triticale is widely used as feed grain or forage, while its utilization for human consumption is still limited. Since triticale has a high yield potential as well as high starch content together with a low content of soluble polysaccharides and proteins, it is considered to be an ideal candidate for bioethanol production (Boros, 2006).

Triticale, like its parents and other cereal crops (rice, maize, barley, oat, and sorghum), belongs to the grass family (Poaceae) and is classified as a long-day flowering plant. The triticale spike is more similar to that of wheat than rye and is composed of a series of spikelets (the flower cluster unit in the grasses) that are alternately arranged on each side of a central axis the rachis (Fig 1-2). Each spikelet is subtended by a pair of modified leaves (glumes) and consists of four to eight florets, usually only three to four of which are fertile. The reproductive parts of each floret are protected by another pair of modified leaves, the palea (innermost) and lemma. The triticale flower is made up of three stamens and an ovary with a bifurcated plumose stigma (Fig 1-3). Each flower is cleistogamous, although it tends to open slightly one or two days after flowering. In general, triticale is self-pollinating (similar to wheat) and not cross-pollinating (like rye) (Larter and Gustafson, 1980). It has been reported that about 5\% outcrossing can occur in advanced strains of triticale (Yeung and Larter, 1972). Pollination is usually initiated when 
the base of the spike has emerged 6 to $10 \mathrm{~cm}$ from the leaf sheath. The first florets that go through anthesis are located in the central portion of the spike. After pollination, anthers are usually soon extruded from the florets. Stigma receptivity and pollen viability in triticale are both relatively short and highly dependent on temperature (Harrington, 1970; Larter, 1977) 
Triticum

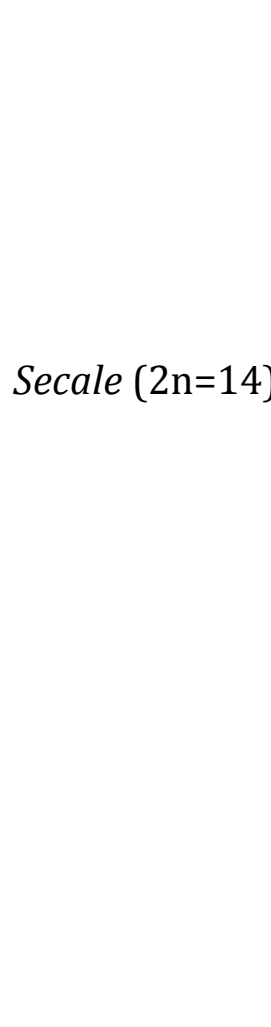

intercrossing $\leftarrow$

$\downarrow$

$\downarrow$

Triticale

\section{AA BB RR}

Primary hexaploid

$(2 n=42)$
AA BB

Tetraploid

$(2 n=28)$

X

RR

$\downarrow$

ABR

(sterile)

|| doubled ||

X

RR

$\downarrow$
AA BB DD

Hexaploid

$(2 n=42)$

ABDR

(sterile)

AA BB DD RR $\rightarrow$ intercrossing

fertile

fertile

$2 n=56$

$2 n=42$

| -------X-------- |

$\downarrow$

$\downarrow$

AA BB DD RR

Secondary hexaploid

Primary octaploid

$(2 n=42)$

$(2 n=56)$

Figure 1-1. Methods of producing the various types of triticale. Modified from Larter and Gustafson (1980). 


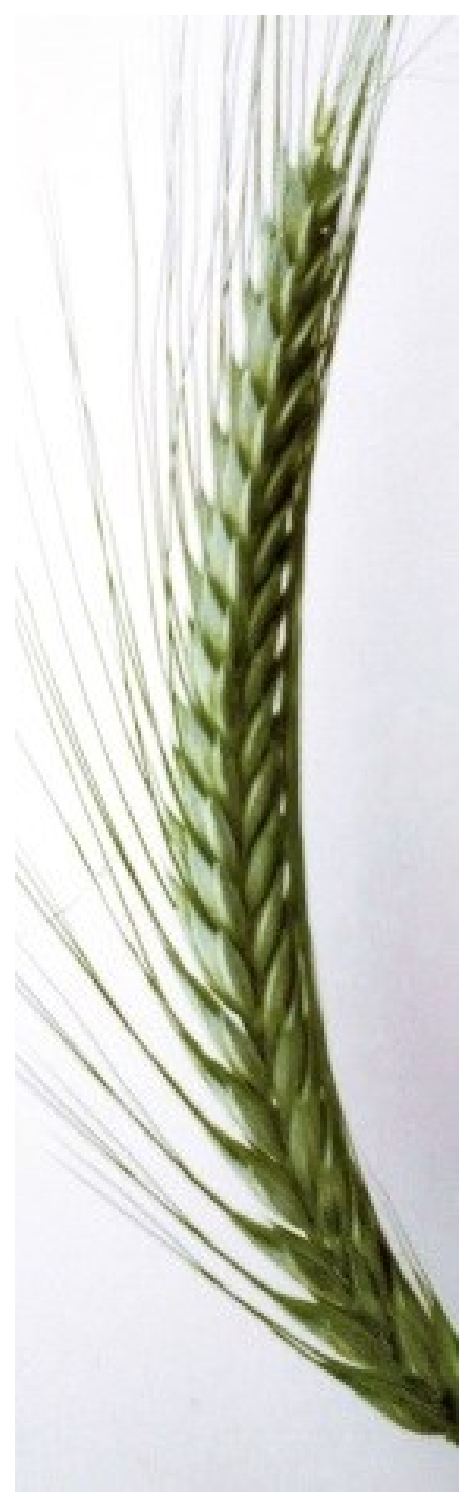

Figure 1-2. Triticale spike (Nazila Nazemof, 2014). 


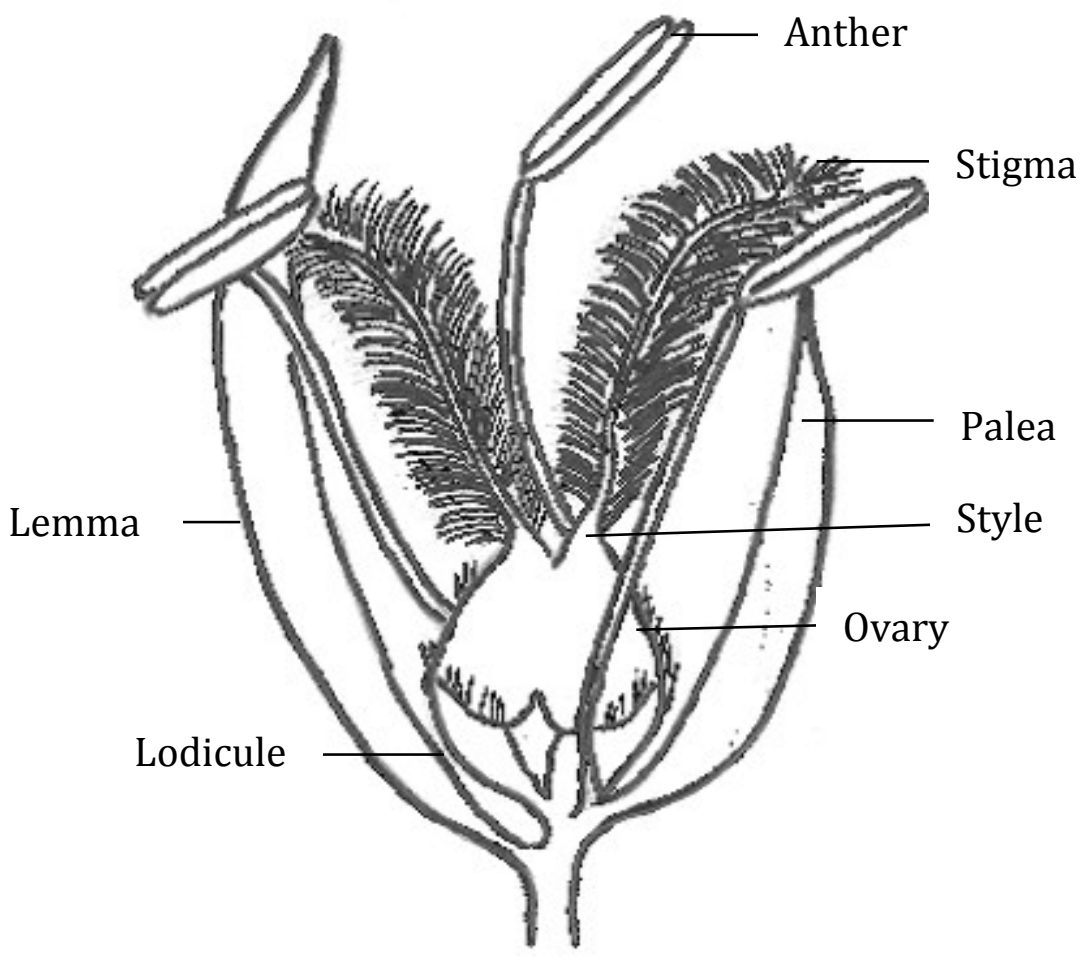

Figure 1-3. Schematic diagram of the triticale floret (Nazila Nazemof, 2014). 


\subsection{Brassica napus}

Brassica napus L. commonly known as rapeseed or Canola belongs to the Brassicaceae (Cruciferae) family. B. napus is an allopolyploid species (AACC, $\mathrm{n}=19$ ) which was derived from natural hybridization between the two diploid species B. oleracea (CC, $\mathrm{n}=9)$ and B. rapa $(\mathrm{AA}, \mathrm{n}=10)$. B. napus is the third most important oilseed crop in the world (FAOSTAT 2011). The early rapeseed varieties had poor quality, containing high levels of erucic acid in the oil and glucosinolates in the meal. Currently, the levels of seed erucic acid and glucosinolates have been greatly reduced making the oil suitable for human consumption and the meal an excellent protein source for animal feed (Friedt and Luhs, 1998)

B. napus flowers are monoclinous, having four sepals, four petals, four long stamens, and two shorter stamens (Figure 1-4). The ovary is a superior type with partial placentation and bicarpelar. There are nectaries located in the center of the flower, two between the ovary and the short stamens and between the long stamens and petals. At maturity, the longer stamens extend passed the stigma and disperse pollen onto its surface. The smaller anthers do not reach the stigma and are likely responsible for cross pollination (Free, 1993; Mussury and Fernandes, 2000). Although B. napus is generally self-pollinated, the B. napus flower releases a light scent which may attract pollinators and it has been reported that about 5-30\% cross-pollination can occur (Treu and Emberlin, 2000).

The production of doubled haploid (DH) B. napus using isolated microspores is one of the most important advances in Brassica germplasm development (Lichter, 1982). Microspore culture consists of culturing male gametophytic cells and inducing them to 
produce haploid embryos instead of mature pollen grains. This technique is a useful tool to produce double homozygous lines for breeding and in obtaining lines showing desired agronomic traits (Morrison and Evans, 1988; Maluszynski et al., 1995). 


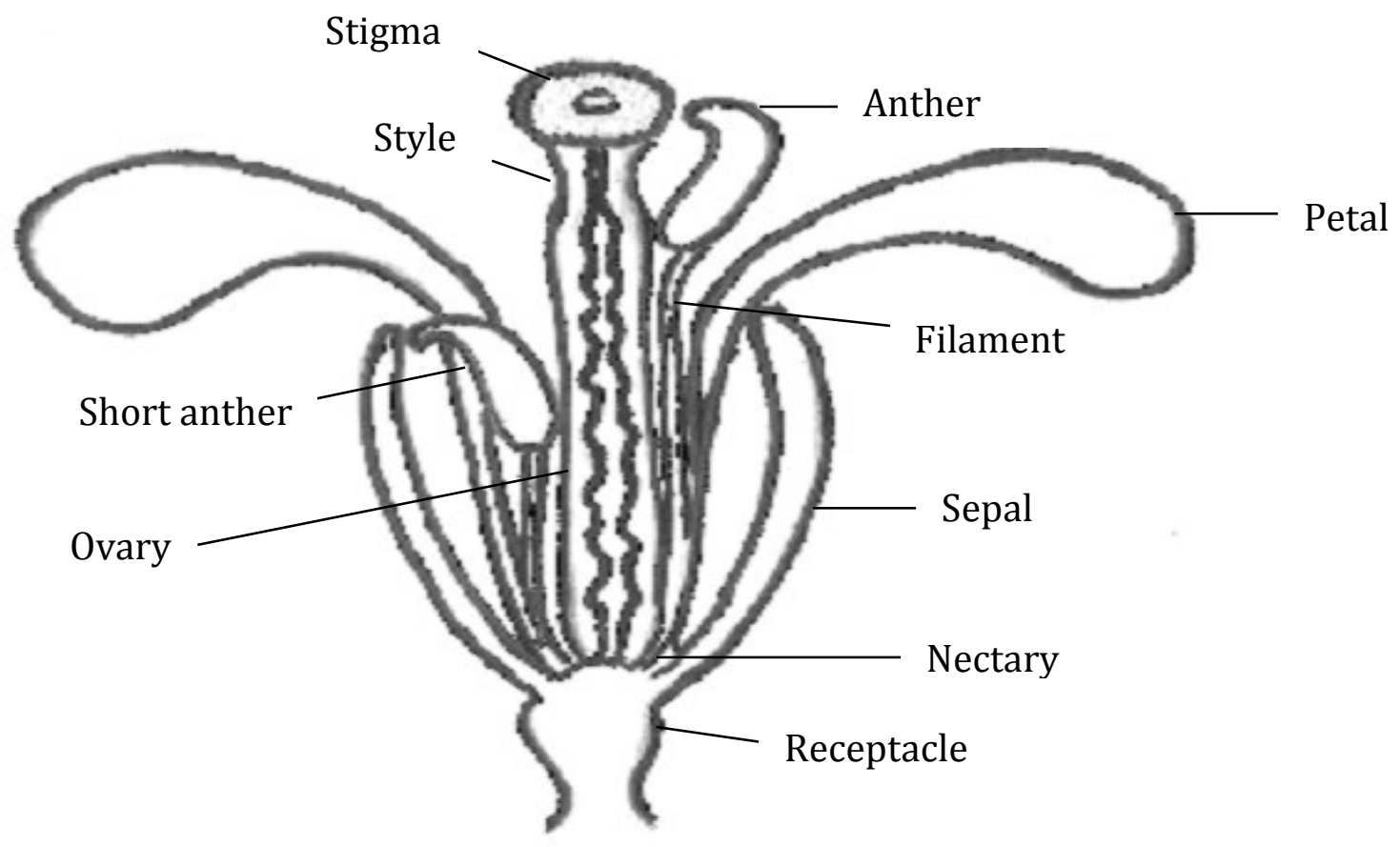

Figure 1-4. Schematic diagram of the B. napus flower (Nazila Nazemof, 2014). 


\subsection{Plant reproductive systems}

Reproduction is the process by which plants multiply themselves. Plants have unique reproductive systems and are generally classified into two groups based on modes of reproduction: sexual reproduction and asexual or vegetative reproduction. Sexually reproducing plants (such as Brassicaceae and Poaceae species) produce seeds. A seed is produced after sexual union (fertilization) involving the fusion of sex cells or gametes. Gametes are products of meiosis where the chromosome number of diploid progenitor cells is reduced to the haploid number. Asexual or vegetative reproduction requires the use of a vegetative part of the plant for propagation.

\subsection{Sexual plant reproduction}

\subsubsection{Female reproductive organs}

The female reproductive organ of the flower is the pistil which typically has three parts: the stigma, style and ovary. The stigma is the receptive surface of the pistil that captures the pollen and facilitates pollen hydration and germination (Hiscock and Allen, 2008). The stigma is one of the most short-lived tissues of a flower and remains receptive to pollen at most for a few days. The stigma can be structurally and functionally very diverse among species and has been classified into two major groups: wet and dry (HeslopHarrison and Shivanna, 1977). The wet stigma secretes a fluid (exudate) containing mostly lipids and/or carbohydrates, and proteins. The dry stigma epidermal cell is covered by a

hydrated proteinaceous layer or pellicle, but no secretion fluid. The dry stigma species can be divided into two groups based on the morphology of the receptive cells: plumose and papillate (Russell and Dumas, 1992). Plumose stigmas are representative of the Poaceae 
and have a two-branched feathery structure adapted to capture wind dispersed pollen (Figure 1-5, A). The epidermal cells of plumose stigmas are covered with a discontinuous cuticle (Heslop-Harrison and Shivanna, 1977). Papillate stigmas are generally characteristic of the Brassicaceae (Figure1-5, B) and their papillae are covered by a continuous cuticle (Hiscock and Allen, 2008)

The style connects the stigma to the ovary and harbours the transmitting tract which supports and guides pollen tube growth. The ovary is the enlarged bottom part of the pistil which contains the female gametophyte. It comprises one (Poaceae) or more (Brassicaceae) ovules (Figure 1-5, A, B). Each ovule contains two concentric outer layers of integument, the nucellus, and the embryo sac (Esau, 1965). 


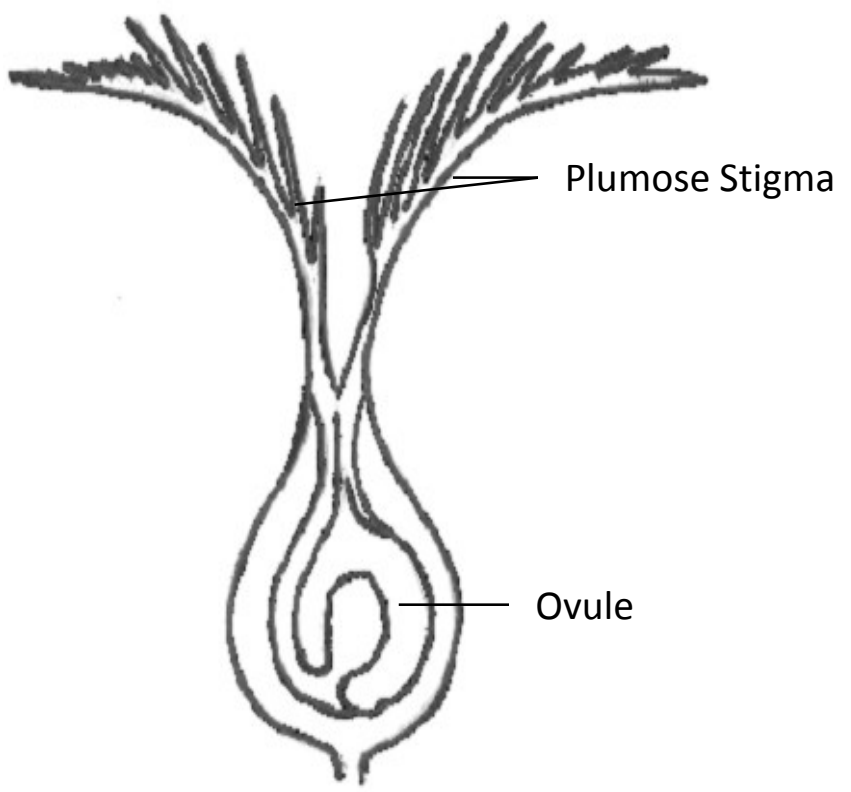

(A)

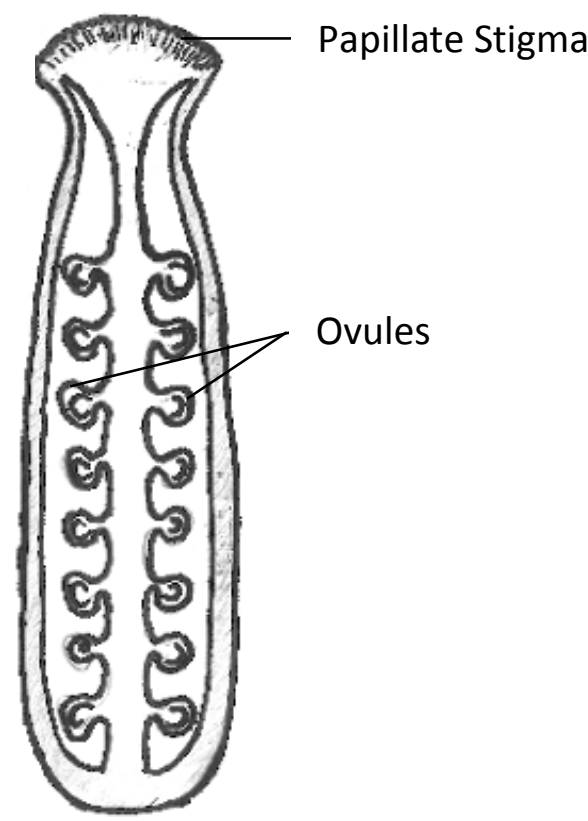

(B)

Figure 1-5. Schematic representation of a Poaceae (A) and Brassicaceae (B) pistil. Modified from (Vishnyakova and Willemse, 1994; Chapman and Goring 2010). 


\subsubsection{Male reproductive organs}

The male reproductive organ of the flower is the stamen which is composed of the filament and the anther. The filament is a long delicate structure that supports the anthers where pollen is produced. In species of both the Poaceae and Brassicaceae, pollen mother cells produce haploid uninucleate microspores after two meiotic divisions. The microspores then undergo a first mitosis yielding the vegetative and generative cells of the bicellular pollen followed by a second mitosis dividing the generative cell into two sperm cells to yield a mature tricellular pollen grain. Mature pollen grains are shed from the anthers at anthesis and in contrast to the Poaceae, the pollen grains in the Brassicaceae are fairly large (32-33 $\mu \mathrm{m})$, heavy, and sticky (Treu and Emberlin, 2000). During pollination, pollen grains are transferred from the anther to the stigma of a flower by a pollination vector. Common pollination vectors are wind, insects, birds, and mammals. Flowers have certain characters that suit the various pollination mechanisms (Pandey, 1997). For example, wind-pollinated flowers (anemophilous) such as in the Poaceae are usually tiny and not showy or aromatic. In contrast, insect-pollinated flowers (entomophilous) such as in Brassicaceae often discharge fragrances and are brightly coloured. Once the pollen grain lands on the stigma, it adheres, hydrates and germinates. The pollen tube grows through the stigma down the style to the ovule and discharges the sperm cells into the embryo sac. One of the sperm cells unites with the egg cell and the other with the central cell leading to fertilization and seed development.

Pollination mechanisms in angiosperms can be grouped into two mating systems: self-pollinated or cross-pollinated. Self-pollination implies self-compatibility (SC) which 
refers to a condition in which a plant accepts pollen primarily from the anthers of the same flower. Cross-pollination can be promoted by a self-incompatibility (SI) system which only accepts pollen from different sources (Hiscock and Allen, 2008). Flowering plants exhibit varying degrees of cross-pollination ranging from lack of to complete cross-pollination. SI is recognized as the best system to prevent selfing and is genetically controlled by one or more loci. Each locus contains at least two separate genes. The function of each gene relies on a series of complex cellular interactions between the pollen and stigma. Two common types of SI systems comprise the sporophytic SI (SSI) and the gametophytic SI (GSI). Brassicaceae species display SSI where the outcome of pollination is determined by the diploid genome of the pollen parent (Dixit and Nasrallah, 2001). SI in the Brassicaceae is controlled by a single polymorphic locus, the $S$-locus (Bateman, 1955). In this SI system, the $S$-locus receptor kinase (SRK) gene encodes a Ser/Thr receptor kinase which localizes to the stigmatic plasma membrane and interacts with the pollen coat cysteine-rich protein (SP11/SCR) encoded by the second gene at the $S$ locus to induce the SI reaction (Takayama et al., 2001). Self-pollen rejection in sporophytic species results in inhibition of pollen hydration or a rapid arrest of the pollen tube growth at the stigma surface. Poaceae species exhibit GSI and in this system the outcome of pollination is determined by the pollen's haploid genome (Wheeler et al., 2001) and is controlled by two unlinked loci $S$ and $Z$ (Langridge and Bauman, 2008). Unlike other gametophytic species (such as in the Solanaceae), the pollen tube growth in the Poaceae is not blocked in the style during incompatible combinations, but at the stigma surface which is more typical of the sporophytic SI system (Heslop-Harrison, 1978). Little is known of the actual genes involved in Poaceae GSI. 


\subsection{Pollen-Stigma interactions in species with dry stigmas}

Pollen-stigma interactions are critical to the reproductive process and failure or inadequacy of these interactions will have a negative impact on crop production (Ma, 2005). In general, pollen-stigma interactions can be divided into four stages: pollen adhesion, hydration, germination, and tube growth. Despite their importance, much remains unknown about the detailed molecular mechanisms underlying these interactions.

Once pollen grains land on the stigma surface, numerous interactions take place at the interface between the pollen and stigmatic papillar cells. The speed of pollen recognition events at the time of pollination varies in different species. In the Brassicaceae, the recognition event is probably completed in less than three minutes (Heslop-Harrison et al., 1975), whereas in the Poaceae, recognition can be completed in less than ninety seconds (Heslop-Harrison, 1978).

The initial adhesion of the pollen on stigmatic papillae requires proteins and lipids from both surfaces (Roberts et al., 1980). On the stigma side, a thin pellicle covering the cuticle is the first site of molecular contact between the stigma surface and the pollen coat (Mattsson et al., 1974; Heslop-Harrison, 1978; Dumas et al., 1984). The pellicle appears to be an essential component for compatible pollen-stigma interactions as removal of the pellicle with proteases prevents pollen tube entry into the stigma (Heslop-Harrison et al., 1975; Heslop-Harrison, 1977; Hiscock and Dickinson, 1993). However, little is known about the protein composition of the pellicle. Esterases and glycoproteins are the major components found in the Brassica and rye stigma pellicles (Heslop-Harrison, 1978). On the pollen side, the exinic outer layer (EOL), a thin layer surrounding the pollen exine wall, is 
the first layer that makes contact with the pellicle. A pellicle-EOL fusion complex mediates the initial pollen adhesion. A pollen adhesion study using the Arabidopsis ECERIFERUM (CER) mutant cer 6-2, which lacks a pollen coat, can still adhere to the stigma. This observation indicated adhesive properties existent in the sporopollenin exine wall (Zinkl et al., 1999). In the Brassicaceae, the pollen adhesion is also dependent on two unlinked but related genes S-locus-related-1 (SLR1) and S-locus glycoprotein (SLG). Both SLR1 and SLG are expressed in stigmatic papillar cells (Stein et al., 1991) and bind to the SLR1-binding protein (SLR1-BP) and PCPs-A1 pollen coat proteins, respectively (Doughty et al., 1993). This interaction plays an important role in strengthening adhesive bonds between pollen and the stigma after the initial pollen adhesion (Swanson et al., 2004; Hiscock and Allen, 2008). A rapid increase of the surface esterase activity in stigmatic papilla at the point of contact with the EOL in rye provided further evidence for pollen adhesion on the stigma. The interaction between pellicle- EOL surfaces is required for activation of the cutinase that digests the cuticle and allows pollen tube penetration (Heslop- Harrison and HeslopHarrison, 1982).

After pollen adhesion, a number of reactions are activated in the stigma. In compatible pollinations, water flows from the stigma into the pollen grain. Pollen grain hydration is regulated by protein synthesis (Sarker et al., 1988). In the Brassicaceae, activation of protein synthesis during pollen hydration is accompanied by protein phosphorylation (Hiscock et al., 1995). Following hydration, the pollen grain germinates and a pollen tube emerges. Cutinase activity digests the stigmatic cuticle and allows entry of the pollen tube into the stigma papilla cell wall on its way to the style (Hiscock et al., 1994, 2002). 


\subsection{The stigma transcriptome}

Transcriptomic studies of the stigma have been reported recently, although not as extensively as with pollen. To date, several gene expression profiling experiments have been conducted on the dry stigma of Poaceae and Brassicaceae species using different techniques.

Within the Poaceae, for example, a mature rice stigma transcriptome study revealed 548 genes preferentially expressed in the stigma papillar cell by using whole-genome array and cDNA microarray analyses and many of these genes were involved in cell wall and signal transduction related activities (Li et al., 2007). Xu et al. (2012) profiled 1,427 genes expressed predominantly or specifically in maize silk using RNA-seq. In their study, a comparative analysis of the stigma-specific/preferential gene datasets of Arabidopsis, rice, and maize suggested that different dry stigmas share similar mechanisms in the early stages of pollen-stigma interaction, that maize shares more conserved functional mechanisms with rice than with Arabidopsis, and that genes involved in amino acid and lipid transport might be responsible for the distinct functions of reproductive processes in maize silk. In a recent study, Tran et al. (2013) identified 634 triticale stigma-enriched and 117 stigma-specific probe sets using the Affymetrix Wheat GeneChip®. A significant number of stigma-specific genes were similar to those identified in rice and Arabidopsis stigmas, and the major functional categories of the triticale stigma-specific genes related to regulation of transcription, lipid metabolism, transport, and the defense response.

Among the Brassicaceae, Tung et al. (2005) identified 115 genes expressed exclusively in the $A$. thaliana stigma when compared to the remaining pistil tissue using the 
Arabidopsis ATH1 GeneChip®. Using the same chip, Swanson et al. (2005) revealed a profile of 317 candidate stigma-enriched genes in Arabidopsis. Both analyses generated similar functional distributions with the major categories being cell signalling and lipid metabolism. Recently, papilla cell-specific gene expression profiles in Brassicaceae species (A. thaliana, A. halleri and B. rapa) were obtained by laser microdissection RNA-seq analysis (Osaka et al., 2013). As a result, 17240, 19260 and 14099 genes were found to be expressed in stigmatic papillar cells of $A$. thaliana, A. halleri and B. rapa, respectively. The major functional categories of these genes included metabolism, transcription, stress/defense, cell wall, signal transduction and ion transport.

\subsection{The stigma proteome}

The stigma as a specialized part of the female reproductive structure is likely to contain a high diversity of proteins that are especially dedicated to the critical processes of pollen adhesion, recognition, acceptance/rejection, germination and tube growth (Hiscock and Allen, 2008). It is also likely that some proteins will be employed for the same roles in pollen-stigma interactions in diverse angiosperm species. Studies dedicated specifically to the study of the stigma proteome are very limited across taxa.

Recently, a proteomic analysis of the stigmatic exudate (SE) of lily (Lilium longiflorum) and olive (Olea europaea) using 1D MS/MS identified 51 and 57 proteins, respectively (Rejón et al., 2013). Major functional categories of the stigma exudate proteins included carbohydrate metabolism, protein fate, cell wall organization, cell signalling and response to biotic and abiotic stresses. The most abundant identified proteins included endo- $\beta$-mannosidase, cysteine and aspartic proteases, chemocyanin, fasciclin-like proteins, 
and antioxidant enzymes. In the olive SE, some of the major identified proteins included heat shock proteins (HSPs), pectin acetylesterase, annexin, actin, calnexin, 14-3-3 proteins and several membrane ATPases. The SE of both species contained GDSL-like lipases, pectin methylesterases (PMEs) proteins and 1, 3- $\beta$-glucanase. About $70 \%$ of lily and $35 \%$ of olive proteins were predicted to contain a signal peptide.

Comparative isobaric tag for relative and absolute quantitation (iTRAQ) proteomic analyses of the unpollinated stigma/style from Solanum pennellii at two different developmental stages was conducted to assess molecular changes during pistil development associated with the acquiring of SI (Chalivendra et al., 2013). Among the identified proteins, 131 were found to be more abundant in the mature stigma than the earlier stage of development. The majority of these proteins were associated with lipid metabolism and transport. Other major proteins present in the mature stigma included arabinogalactan proteins, defensin, thaumatin, chitinase, HT-A protein and S-RNases. SignalP analysis of the top 100 expressed proteins in the mature stigma revealed that 38\% were predicted to be secreted.

A proteomic analysis using 2D MALDI-TOF-MS/MS to compare plants with wet and dry stigmas was recently reported (Sang et al., 2012). The authors identified 67 and 47 proteins expressed preferentially in maize silk and tobacco stigmas, respectively. They also identified 132 proteins from the tobacco stigma exudate. The stigma specifically or preferentially expressed proteins in maize or tobacco shared a similar functional distribution with the most abundant categories including defense/stress response, carbohydrate and protein metabolism, cell wall remodelling, signal transduction and photosynthesis. Moreover, comparisons between transcriptomic and proteomic data 
revealed that post-transcriptional and post-translational regulation occur in both maize and tobacco stigmas.

Lastly, a differential proteomic analysis of Brassica napus stigmas using 2D- DIGE followed by MALDI-TOF MS/MS identified 19 unique proteins that are down-regulated following activation of SI (Samuel et al., 2011). These proteins were found mainly in three biological processes: metabolic processes, response to stimulus and response to stress. The major identified proteins included aconitase, actin, annexin, ATCIMS, biotin carboxylase, enolase, fructose-biosphosphate aldolase, RUBISCO-large subunit, and tubulin alpha-2/alpha-4 chain.

In summary, most proteomics studies of the stigma to date have focused on identifying the proteins preferentially expressed in this tissue as they are likely to reflect a specialized function. Although such studies are very useful, they address only a minute fraction of the proteins expressed in the stigma and there is a need to provide a broader perspective of the stigma proteome and its functions.

\subsection{Plant proteomics analysis}

Proteomics is the large-scale analysis of proteins in a cell, tissue, or whole organism at a particular time and under certain conditions. Proteomics techniques compliment transcriptome-based technologies because proteomics deals directly with the functional molecules rather than profiling the expression of the encoding mRNAs. The field of proteomics addresses all biological functions in the cell and characterizes protein expression, modification, and localization. Plant proteomics became widespread recently due to improvements in mass spectrometry and analytical software (Wilkins et al., 1996). 
Proteomics approaches can be classified into gel-based or gel-free as well as label-free or label-based methods (Abdallah et al., 2012).

\subsubsection{Gel-based proteomics}

Gel-based proteomics techniques are mostly applied for two purposes: separation of proteins followed by mass spectrometry and quantitative analysis of protein mixtures. These techniques include primarily One-Dimensional Gel Electrophoresis (1D), TwoDimensional Gel Electrophoresis (2D), Two-Dimensional Difference Gel Electrophoresis (2D-DIGE), and Blue-Native PAGE (BN-PAGE) (Abdallah et al., 2012). In 1D, complex protein mixtures are separated based on their molecular masses over the range of approximately 7-300KDa. It is highly reproducible, simple, fast, and a powerful initial tool. The major advantages of this technique are the use of SDS as a strong ionic detergent that ensures protein solubility and increases the chance of identifying a wide range of proteins (Kim et al., 2003). In 2D, proteins are separated in the first dimension based on their net charge using isoelectric focusing (IEF) and then in the second dimension based on their molecular weight (MW). 2D is robust, has an excellent resolving power and has been in use for more than 40 years. This technique provides information about the relative abundance, MW, and isoelectric point ( $\mathrm{p} I$ ) of proteins (O'Farrell et al., 1975). In 2D-DIGE, two separate protein samples are labeled with different fluorescent dyes such as $\mathrm{Cy} 2, \mathrm{Cy} 3$, or Cy5 and resolved using 2D. The 2D-DIGE has a significant advantage over 2D because the samples to be compared are run together on the same gel which overcomes the protein ratio errors often resulting from low gel to gel reproducibility. This technique has been mostly applied for quantitative differential analyses (Ünlü et al., 1997). In BN-PAGE, intact protein 
complexes can be separated under native conditions based on their molecular weight and the gel lane of interest can be cut out and separated through a second dimension (SDSPAGE). BN-PAGE is often applied to membrane proteomics studies to improve proteome coverage of gel-based approaches (Eubel et al., 2005).

\subsubsection{Gel-free proteomics}

Gel-free proteomics techniques provide powerful tools for the large scale study of protein expression. Since proteins are normally difficult to apply directly to a mass spectrometer to obtain sequence information (due to the relatively low efficiency of ionization and fragmentation), peptides are first produced by sequence-specific cleavage with enzymes such as trypsin. Two basic principal of gel-free techniques are to separate peptides based on various properties (e.g. charge, hydrophobicity/hydrophilicity and affinity interactions) and to reduce sample complexity for mass spectrometry analysis. There are numerous techniques available for peptide separation such as Ion-Exchange Chromatography (IEC), OFFGEL Electrophoresis (OGE), Reversed-Phase Chromatography (RP), and High Performance Liquid Chromatography (HPLC) (Manadas et al., 2010). In IEC, peptides are separated according to electric charge. In cation-exchange chromatography (CX) negatively charged functional groups attract positively charged peptides at acidic $\mathrm{pH}$, while in anion-exchange chromatography (AX) positively charged functional groups have affinity for negatively charged peptides at basic $\mathrm{pH}$. Strong cation-exchange chromatography (SCX) contains a strong ion exchanger that can ionize at a broad pH range. For peptide separation using SCX columns, the peptide mixture is loaded under acidic condition so that the positively charged peptides bind to the column (Fournier et al., 2007). 
In OGE, peptide separation is carried out in a two-phase system with an upper liquid phase, containing a buffer with carrier ampholytes which is divided into 12 or 24 sections, and a lower phase which is the IPG strip. After sample loading and application of a voltage gradient, peptides migrate through the IPG strip until they reach their $\mathrm{p} I$ in a given section and can be recovered for further analysis. OGE has high loading capacity and resolution power. Unlike other peptide separation methods, OGE provides additional physiochemical information such as peptide $\mathrm{p} I$ which is highly valuable for MS analysis (Hörth et al., 2006). $\mathrm{RP}$ is the most common liquid chromatography-method applied in proteomics which allows separation of neutral peptides based on their hydrophobicity. The separation is based on ion-pairing between the polar mobile phase and hydrophobic (non-polar) stationary phase. RP is an excellent match to IEC and HPLC for multidimensional proteomic identification technology (MudPIT) (Manadas et al., 2010). HPLC is a widespread technique in proteomics which has superior resolving power for peptides separation. This technique relies on pumps to pass a pressurized liquid solvent containing peptides through a column filled with a solid absorbent material. Through the column, peptides interact slightly differently to the adsorbent material causing different flow rates and leading to the separation of the peptides as they flow out of the column (Kupiec, 2004). The flow rates from HPLC are compatible with mass spectrometers (electrospray ionization).

\subsubsection{Label- based or label- free Proteomics}

Label-based and label-free approaches are applied for relative quantification proteomics studies. Relative protein quantification methods allow relative protein 
abundances to be compared in samples and the proteome functions to be characterized (Schulze and Usadel, 2010). The labeling methods can be classified into two main groups: chemical isotope tags (e.g. Isobaric Tags for Relative and Absolute Quantification (iTRAQ) (Ross et al., 2004) or metabolic labelling (e.g. Stable Isotopic Labeling with Amino Acids in Call Culture (SILAC) (Mann, 2006). The first approach is based on the fact that both labelled and unlabelled peptides exhibit the same chromatographic and ionisation properties but can be distinguished from each other by a mass-shift signature. Metabolic labelling introduces the label into the whole cell through the growth medium which allows protein labelling at the time of protein synthesis. Chemical labeling on the other hand, tags proteins or peptides after protein extraction or even after proteolytic digestion. Since labelling-based quantitative analysis requires expensive labelling reagents and high amount of starting samples, label-free methods represent attractive alternatives (Neilson et al., 2011). In this technique, proteins are generally quantified based on two measurements. First, the measurements of ion intensity changes such as peptide peak areas or peak height in chromatography (e.g. Relative Quantification of Peak Intensity of LC/MS) (Silva et al., 2005). Secondly based on the spectral counting of identified proteins after tandem mass spectrometry analysis (e.g. Relative Quantification by Spectral Count) (Lundgren et al., 2010).

\subsubsection{Tandem mass spectrometry (MS/MS)}

Tandem mass spectrometry (MS/MS) approaches are fundamental techniques in proteome research and usually follow after peptide separation by HPLC (LC-MS/MS). MS/MS involves an ion source that brings the molecules into an ionized form in gas phase, 
a mass analyzer that measures the mass to charge ratio $(\mathrm{m} / \mathrm{z})$ of the molecules, and a detector that measures the number of ions at each $m / z$ value( Aebersold and Mann, 2003). Electrospray Ionization (ESI) (Fen et al., 1989) and Matrix-Assisted Laser Desorption/Ionization (MALDI) (Karas et al., 1988) are the two common techniques applied to ionize the proteins or peptides for mass spectrometry analysis. In ESI-MS/MS, molecules in solution are ionized in gas phase. A fine spray of droplets is generated in an electric field at ambient pressure. Usually the positive and multiple charged ions are pumped into the MS. ESI MS/MS is used for the analysis of complex samples. In MALDIMS/MS, the peptides are co-crystallized with an energy absorbing chemical matrix as dry samples on a plate that is bombarded by UV or IR laser, resulting in singly charged ions. MALDI-MS/MS is normally used to analyse relatively simple peptide mixtures. The negative aspects of MALDI include different matrices yield different results and protein or peptide mixtures can show suppression effects (Bienvenut et al., 2002)

The mass Analyser is the central part of MS/MS which take ionized peptides, separate them based on $m / z$ ratios and deriver them to the detector. The peptide ion in the mass analyser can be manipulated by electric or magnetic field. The key elements of this instrument are sensitivity, resolution, speed, mass accuracy, and generation of ion mass spectra from peptide fragments. Four basic types of mass analysers used in proteomics research include ion trap, time-of-flight (TOF), quadrupole (Q), and Fourier transform ion cyclotron resonance (FTICR) analysers. In ion trap, the ions are first captured or trapped for a certain time and then subjected to MS/MS analysis. In this instrument, ions with specific $m / z$ ratios can be selected in the trap and induced for fragmentation through Collision Induced dissociation (CID). The peptide fragments are then measured for $m / z$ 
ratios. In TOF analysers, ions are separated according to their flight time down a field -free tube. The time of ions flight is directly related to their $m / z$ values. MALDI is usually coupled to TOF analysers. In Q/TOF instruments, ions of particular $m / z$ ratio are selected in the quadrupole mass filter, fragmented in the collision cell and analyzed by a TOF. Q/TOF instruments can be used interchangeably with a MALDI and an ESI ion source. TOF/TOF instruments incorporate a collision cell between two TOF sections, fragment in the collision cell, and fragments are separated in the second TOF section. TOF/TOF instruments are usually used with MALDI ion source. FTICR analysers operate by trapping ions in a cell with a static magnetic field. This type of analyser is the most powerful currently available in terms of mass resolution $(\mathrm{M} / \Delta \mathrm{M})$ and mass measurement accuracy (MMA). FTICR analysers can be combined with both MALDI and ESI ion sources (Guerrera and Kleiner, 2005; Domon and Aebersold, 2006).

\subsubsection{Bioinformatics}

Peptide identification from MS/MS data is a major task in proteomics. The accuracy and sensitivity directly impacts the reliability of protein identification from peptide hits. Many software tools have been developed for peptide identification. These tools can be broadly divided into two categories: de novo sequencing and database searching. De novo sequencing derives the peptide sequence directly from the MS/MS spectrum, whereas database searching compares experimental with theoretical tandem mass spectra of each peptide derived from a protein database (e.g. Uniprot (www.uniprot.org) or Swiss-Prot (www.ebi.ac.uk/swissprot)) and scoring the correlation quality. The most common de novo sequencing software packages include PEAKS (www.bioinfor.com) (Ma et al., 2003), 
PepNovo_(Frank and Pevzner, 2005), and Lutefisk (Taylor and Johnson, 1997) and most common database search software packages include Mascot (www.matrixscience.com) (Perkins et al., 1999), X! Tandem_(www.thegpm.org/tandem)(Craig and Beavis, 2004), SEQUEST (Eng et al., 1994), and OMSSA (Geer et al., 2008). Currently, database searching is the most popular method for peptide identification. Mascot (commercial engine) and X!Tandem (open-source engine) are representative of the most suitable search engines in proteomics studies. Both of these engines provide theoretically or experimentally derived statistical threshold to help evaluate the significance of peptide identification. The major difference between these two search engines is defined by their preliminary scoring algorithm (Brosch et al., 2008).

After an initial database search analysis, results are statistically interpreted by converting search engine scores into probabilities of peptide identification using the Peptide Prophet algorithm (Keller et al., 2002). To validate identified peptides, bioinformatics tools are required (e.g. Protein Pilot ${ }^{\mathrm{TM}}$ (www.absciex.com), Trans-Proteomic Pipeline (TPP) (www.proteomecenter.org) and Scaffold (www.proteomesoftware.com) (Searle, 2010). Recently, Scaffold is one of the most popular bioinformatics tool in proteomics analysis. Once accurate peptide probabilities are determined, Scaffold uses the Protein Prophet algorithm to combine peptides into protein identifications based on a distribution of the number of peptides assigned to each protein. Since peptide sequences can often be assigned to several possible proteins, Protein Prophet attempts to assure that proteins are identified from peptide evidence parsimoniously. Scaffold uses an algorithm to assign peptides groups, which can be assigned into multiple proteins, to the most confident identified proteins. Proteins are ranked by the sum of the probabilities of 
assigned peptide groups (SumProb). SumProb is used in place of protein probability to estimate protein confidence. If multiple proteins are assigned the same peptide groups, they are collapsed into single protein group. Moreover, if the two proteins differ by only a few low confidence peptides, they also collapsed. Proteins that are not assigned unique peptide group evidence are discarded. The protein probability in Scaffold report uses the Protein Prophet Probability model (Searle, 2010).

\subsection{Objective}

This study aims to make a contribution towards the characterization of the global proteome of the very different dry stigmas from representative species of the Poaceae and the Brassicaceae families. It is anticipated that both distinct and conserved proteins will be revealed. 


\section{Chapter 2}

\section{Proteomic Profiling Reveals Insights into Triticeae Stigma Development and Function}

\subsection{Introduction}

Triticale, a cross between wheat (Triticum sp.) and rye (Secale sp.), is the first manmade cereal crop. It is more productive than other cereals under poor soil and environmental conditions, less susceptible to many diseases affecting wheat and competitive with other cereals in terms of grain yield (Chapman et al., 2005). Triticale is also considered a reduced input crop as it requires less fertilizer, water and pesticides. Moreover, triticale has a number of potential advantages as a feedstock for bioethanol production (Pejin et al., 2012). Lastly, triticale represents an interesting opportunity to study the implications of allopolyploidization (Ma and Gustafson, 2008).

In flowering plants, pollination is a critical step in sexual reproduction leading to seed production. In triticale, as in other members of the Triticeae, the process begins with the adhesion of the pollen grain to the stigma (the receptive portion of the pistil), the pollen grain then rehydrates, germinates and the newly formed pollen tube penetrates the stigma, grows down the transmitting tissue of the style and ultimately reaches the ovule allowing fertilization to take place (Lausser and Dresselhaus, 2010). The stigma plays a critical role in the capture, recognition and discrimination of the pollen grain, and in supporting pollen germination and tube growth. Generally, it is a relatively short-lived plant structure and has been broadly divided into two major types, wet and dry stigmas (Heslop-Harrison and 
Shivanna, 1977). In species with a dry stigma, such as in the Brassicaceae and Poaceae, the stigma is composed of specialized papillar cells covered with a waxy cuticle overlaid with a distinct proteinaceous pellicle layer which interacts directly with the pollen (Zinkl et al., 1999; Ciampolini et al., 2001). In species with a wet stigma, such as in the Solanaceae and Liliaceae, the epidermis is covered with a viscous surface secretion containing proteins, lipids, polysaccharides, and pigments, and the stigma has three distinct zones: an epidermis with papillae, a sub-epidermal secretory zone and a zone of parenchyma ground tissue (Kandasamy and Kristen, 1987). Compared to the wet stigmas, pollen capture, adhesion and hydration on the dry stigma is a more highly regulated process (Wolters-Arts et al., 1998).

In spite of its crucial role, very little is known regarding the proteome underlying stigma development and function. High throughput transcriptome profiling devoted specifically to the stigma has been reported for a few Brassicaceae species (Swanson et al., 2005; Tung et al., 2005; Osaka et al., 2013; Sankaranarayanan et al., 2013a), rice (Li et al., 2007), maize (Davidson et al., 2011; Xu et al., 2012; Xu et al., 2013), and triticale (Tran et al., 2013). Only a few studies have investigated the stigma proteome and usually focused on a subset. In a comparison between species with wet or dry stigmas using 2DE-MS, stigma-specific/-preferential proteins were identified for maize silk (67 proteins) and tobacco stigmas (47 proteins) (Sang et al., 2012). These authors also identified 132 proteins present within the tobacco stigma exudate, whereas a separate study revealed 51 and 57 exudate proteins from lily and olive (Rejón et al., 2013). Lastly, 19 proteins were found by DIGE-MS to be down-regulated in Brassica stigmas following self-incompatible pollination thus bringing new insights into this process (Samuel et al., 2011). 
This study represents the largest contribution towards a comprehensive survey of the stigma proteome of any species by identifying 2184 triticale mature stigma proteins utilizing different gel-based approaches and MS. The possible role of these proteins in Triticeae stigma development, pollen-stigma interactions, as well as stress tolerance is discussed.

\subsection{Materials and methods}

\subsubsection{Plant material}

The hexaploid triticale spring cultivar (x Triticosecale AC Alta) was grown in $15 \mathrm{~cm}$ diameter plastic pots in a growth chamber at $20^{\circ} \mathrm{C}$ (day) and $18^{\circ} \mathrm{C}$ (night) under a photoperiod of $16 \mathrm{~h}$ light. Plants were held at a constant humidity of $70 \%$ and watered twice daily and fertilized bi-weekly with 20-20-20 (NPK). In this study, the stigma refers to both the stigma and the style as these structures are merged in triticale. Mature triticale stigmas were harvested just prior to anthesis (at this stage the stigma is most receptive to pollen and there is no pollen contamination), immediately frozen in liquid nitrogen and kept at $-80^{\circ} \mathrm{C}$. Bread wheat cultivar Thatcher (Triticum aestivum L.) was grown similarly until the first two true leaves emerged.

\subsubsection{Protein extraction}

Total stigma proteins were extracted using either SDS-PAGE or IEF loading buffer essentially as described previously (Molloy et al. 1998; Damerval et al., 1986; Laemmli, 1970). Frozen stigmas were ground to a fine powder on dry ice and the frozen powder was immediately suspended in 1X SDS-PAGE loading buffer (10\% glycerol, 2\% SDS, $100 \mathrm{mM}$ 
DTT, $1 \%$ bromophenol blue and $60 \mathrm{mM}$ Tris- $\mathrm{HCl}, \mathrm{pH} 6.8$ ) and sonicated $3 \mathrm{X}$ for $10 \mathrm{~s}$ using an Ultrasonic Homogenizer 4710 series (Cole-Parmer, Montréal, Canada). After centrifugation at $27200 \mathrm{~g}$ for $10 \mathrm{~min}$ at $18^{\circ} \mathrm{C}$, the supernatant was transferred to another tube and heated for 5 min at $95^{\circ} \mathrm{C}$ prior to $1 \mathrm{D}$ SDS-PAGE. For the IEF loading buffer extraction, the frozen powder was immediately suspended in sample buffer (8 M Urea, 2 M thiourea, 4\% CHAPS, 0.1\% ampholytes ( $\mathrm{p} I$ range 3-10), $50 \mathrm{mM}$ DTT, $0.0005 \%$ bromophenol blue) and incubated at room temperature (RT) on a rotator overnight. The sample was then sonicated 3 X $10 \mathrm{~s}$ and centrifuged at $48000 \mathrm{~g}$ for $15 \mathrm{~min}$ at $4{ }^{\circ} \mathrm{C}$. Total protein concentrations were determined with the Bio-Rad protein assay kit (Bio-Rad, Mississauga, Canada) according to the manufacturer's instructions.

Wheat leaf proteins were extracted as described previously (Rampitsch et al., 2013) by grinding a $2 \mathrm{~g}$ aliquot in liquid nitrogen, mixing with $25 \mathrm{ml}$ of $50 \mathrm{mM}$ Tris- $\mathrm{HCl} \mathrm{pH} \mathrm{8.3,} 2$ $\%$ (v/v) 2-mercaptoethanol, $20 \mathrm{mM} \mathrm{MgCl}_{2}, 1 \mathrm{mM} \mathrm{PMSF}$ and grinding further. The sample was centrifuged at $10000 \mathrm{~g}$ for $10 \mathrm{~min}$ at $4^{\circ} \mathrm{C}$ and the supernatant frozen overnight at $-80^{\circ} \mathrm{C}$. To deplete ribulose bisphosphate carboxylase (Rubisco is the most abundant protein in leaves and its presence reduces the number of proteins that can be identified by MS), the sample was thawed at RT for $2 \mathrm{~h}$ and then heated to $42^{\circ} \mathrm{C}$ with gentle rotation for $15 \mathrm{~min}$. This was followed by centrifugation as above at RT. Proteins in the supernatant were precipitated with 9 volumes of ice cold acetone containing $0.7 \%(\mathrm{w} / \mathrm{v})$ DTT and the pellet was dissolved in $1 \mathrm{M}$ urea, $50 \mathrm{mM}$ Tris- $\mathrm{HCl} \mathrm{pH}$ 8.3, 0.7\% (w/v) DTT, sonicated, and clarified by centrifugation as above. 


\subsubsection{D SDS PAGE LC-MS/MS}

Stigma proteins $(45 \mu \mathrm{g})$ extracted with SDS-PAGE loading buffer were submitted to the McGill University Genome Québec Innovation Centre (http://gqinnovationcenter.com) where the protein sample was loaded on a $2.4 \mathrm{~cm}$ 1D SDS-PAGE gel with a 7 to $15 \%$ acrylamide gradient. The gel was stained with CBB G (Figure 2-1) and the entire lane was excised into15 bands which were further sub-divided into 6-7 pieces using a Protein Picking Workstation ProXCISION (PerkinElmer, Shelton, USA). Gel pieces were subjected to reduction, cysteine-alkylation and in-gel tryptic digestion in an automated MassPREP Workstation (Micromass, Manchester, UK) as previously described (Wasiak et al., 2002). Briefly, gel pieces were prewashed (100 $\mu$ HPLC grade water for $10 \mathrm{~min})$, destained $(50 \mu \mathrm{l}$ of $100 \mathrm{mM}$ ammonium bicarbonate and $50 \mu \mathrm{l}$ of $100 \%$ acetonitrile for $5 \mathrm{~min}$ ), reduced, and alkylated $(50 \mu \mathrm{l}$ of $10 \mathrm{mM}$ dithiothreitol for $3 \mathrm{~min}, 50 \mu \mathrm{l}$ of $55 \mathrm{mM}$ iodoacetamide for $20 \mathrm{~min}$, and $100 \mu \mathrm{l}$ of $100 \%$ acetonitrile for $5 \mathrm{~min})$. Gel pieces were dehydrated $(50 \mu \mathrm{l}$ of $100 \%$ acetonitrile for $5 \mathrm{~min})$, digested with $25 \mu \mathrm{l}$ of trypsin $(6 \mathrm{ng} / \mu \mathrm{l}$ in $50 \mathrm{mM}$ ammonium bicarbonate, Promega sequence grade modified trypsin, cat number V511A), and incubated for $30 \mathrm{~min}$ at RT followed by $4 \mathrm{~h} 30 \mathrm{~min}$ at $37^{\circ} \mathrm{C}$. The peptides were extracted $(30 \mu \mathrm{l}$ of an aqueous mixture containing $1 \%$ formic acid and $2 \%$ acetonitrile for $30 \mathrm{~min}$ at RT).

For LC MS/MS analysis, the peptides from each band were subjected to MS analysis. The 96-well sample tray was kept in Micro Well-plate Sampler (Agilent 1100 Series). Prior

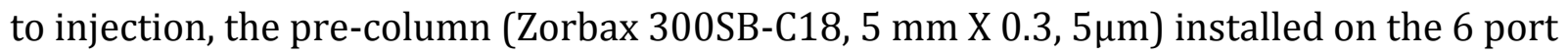
Rheodyne valve of the Column Compartment Module, was conditioned with water containing acetonitrile (3\%) and formic acid (0.1) supplied by an Isocratic pump (Agilent 
1100 series) set at a flow rate of $15 \mu \mathrm{l} / \mathrm{min}$. A volume of $20 \mu \mathrm{l}$ of the tryptic digest solution was injected on the precolumn at $15 \mu \mathrm{l} / \mathrm{min}$ and the sample was washed for $5 \mathrm{~min}$ while the flow through was evacuated to waste. The valve was actuated and the peptides trapped on the pre-column were eluted to the $75 \mu$ li.d PicoFrit column (New Objective, Woburn, Ma) (filled with $10 \mathrm{~cm}$ of BioBasic C18 packing, $5 \mu \mathrm{m}, 300 \mathrm{~A}$ ) by the acetonitrile gradient supplied by the Agilent series 1100 Nanopump at $200 \mathrm{nl} / \mathrm{min}$. Solvent A was water (formic acid $0.1 \%)$ and solvent $B$ was acetonitrile: water: formic acid (97:3:0.1). The linear gradient was started after the washing step. At time 0 , solvent B was $10.5 \%$. It was set to reach $42 \% \mathrm{~B}$ at $45 \mathrm{~min}, 73.5 \% \mathrm{~B}$ at $53 \mathrm{~min}$ and $100 \% \mathrm{~B}$ for $2 \mathrm{~min}$ and brought back to $10.5 \%$ from $60 \mathrm{~min}$ to $72 \mathrm{~min}$.

The mass spectrometer was a Q-Tof micro ${ }^{\mathrm{TM}}$ from Waters Micromass equipped with a Nanosource modified with a nanospray adapter (New Objective, Woburn, MA) to hold the PicoFrit column spraying tip near the sampling cone. The capillarity voltage was adjusted to get the best spraying plume at $35 \% \mathrm{~B}$. The MS survey scan was set to $1 \mathrm{~s}(0.1 \mathrm{~s}$ interscan) and recorded from 350 to $1600 \mathrm{~m} / \mathrm{z}$. In a given MS survey scan all doubly and triply charged ions with intensity higher than 25 counts were considered candidates to undergo MS/MS. From these, the strongest one was selected. MS/MS acquisition stopped as soon as the total ion current reached 2800 counts/scan or after a maximum time of $4 \mathrm{~s}$. The MS/MS scan was acquired from 50 to $1990 \mathrm{~m} / \mathrm{z}$, scan time was $1.35 \mathrm{~s}$ and interscan was $0.15 \mathrm{~s}$. The next precursor ion was selected from the following MS survey scan. The doubly and triply charged selected ions were fragmented with the following preprogrammed collision energies: (i) for doubly charged ion, the collision energies are 25 $\mathrm{eV}$ for the range 400 to $653 \mathrm{~m} / \mathrm{z}, 26 \mathrm{eV}$ for the range 400 to $653 \mathrm{~m} / \mathrm{z}, 26 \mathrm{eV}$ for the range 
653 to $740 \mathrm{~m} / \mathrm{z}, 28 \mathrm{eV}$ for the range 740 to $820 \mathrm{~m} / \mathrm{z}, 32 \mathrm{eV}$ for the range 820 to $1,200 \mathrm{~m} / \mathrm{z}$, and $55 \mathrm{eV}$ for the range 1,200 to $1,600 \mathrm{~m} / \mathrm{z}$. (ii) for triply charged ions, the collision energies are $14 \mathrm{eV}$ for the range 435 to $547 \mathrm{~m} / \mathrm{z}, 19 \mathrm{eV}$ for the range 547 to $605 \mathrm{~m} / \mathrm{z}, 24 \mathrm{eV}$ for the range 605 to $950 \mathrm{~m} / \mathrm{z}$, and $35 \mathrm{eV}$ for $\mathrm{m} / \mathrm{z}$ higher than $950 \mathrm{~m} / \mathrm{z}$.

Mass spectrometric data was acquired by employing the Data Directed Analysis (DDA) feature available on Mass Lynx (Micromass) operating software with a 1,2,4 duty cycle $1 \mathrm{~s}$ in MS mode 2 peptides selected for fragmentation, maximum of 4 second in MS/MS acquisition mode). Analysis was done in two steps. For the first step, acquisition was done by letting MassLynx choose the most intense precursor from the MS Survey scan. From the data for each injected sample, a list of precursor ions with their chromatographic retention times was then prepared and used as exclusion ions with their chromatographic retention times prepared and used as an exclusion list for a second analysis. Each sample was injected again and DDA was performed using the information provided by the exclusion list. This process enabled the mass spectrometer to collect data from precursors that were not acquired during the first analysis because they were not the most intense precursor of the scan. The DDA setting was as above except for the exclusion option for which the following feature were activated. The precursor $m / z$ was excluded within \pm $1900 \mathrm{mDa}$ of the entries on the exclusion list. Furthermore, the $\mathrm{m} / \mathrm{z}$ was also chromatographically excluded for a time window of $\pm 75 \mathrm{~s}$ of the retention time registered during the first analysis. MS/MS raw data were transferred from the Q-Tof micro $^{\mathrm{TM}}$ computer to a 50 terabytes server and automatically manipulated for generation of peak lists by employing Distiller version 2.3.2.0 
(http://www.matrixscience.com/disttiler.htmls) software with pick parameter set at 5 as for Signal Noise Ratio (SNR) and at 0.4 for Correlation Threshold (CT).

\subsubsection{D IEF/SDS PAGE LC-MS/MS}

For 2D gels, stigma proteins extracted with IEF loading buffer $(200 \mu \mathrm{g})$ were first separated on a $17 \mathrm{~cm} \mathrm{pH} \mathrm{3-10} \mathrm{gradient} \mathrm{using} \mathrm{the} \mathrm{PROTEAN} \mathrm{IEF} \mathrm{system} \mathrm{(Bio-Rad)} \mathrm{according}$ to the manufacturer's instructions. After IEF, strips were first equilibrated for $20 \mathrm{~min}$ in 6 M urea, 2\% DTT, $375 \mathrm{mM}$ Tris- $\mathrm{HCl} \mathrm{pH} 8.8$ and then for another $20 \mathrm{~min}$ in the same solution containing $135 \mathrm{mM}$ iodoacetamide instead of 2\% DTT. SDS-PAGE was performed in a $12 \%$ acrylamide gel using the PROTEAN II XI Cell system (Bio-Rad) at a constant voltage of $77 \mathrm{~V}$. The gels were stained with CBB R-250 and gel images were captured with a scanner Astra 2400 SLT (UMAX, Dallas, USA) or Gel Doc XR+ (Bio-Rad). Three 2D gel replicates gave consistent results (Figure 2-2). A total of 170 individual protein spots were excised manually from CBB stained gels and submitted to the Québec Genomics Center (http://proteomique.crchul.ulaval.ca/en/index.html) for MS. Briefly, the excised proteins were automatically de-stained, dehydrated, reduced with $10 \mathrm{mM}$ DTT, alkylated with 55 mM iodoacetamide, and digested with $105 \mathrm{mM}$ of modified porcine trypsin (Sequencing grade, Promega, Madison, WI) at $58^{\circ} \mathrm{C}$ for $1 \mathrm{~h}$ using a MassPrep liquid handling robot (Waters Corporation). Digestion products were extracted using 1\% formic acid, 2\% acetonitrile followed by $1 \%$ formic acid, $50 \%$ acetonitrile and the recovered extracts were pooled, lyophilized and then resuspended into $7 \mu \mathrm{l}$ of $0.1 \%$ formic acid. A peptide sample volume of $2 \mu \mathrm{l}$ was separated by online RP nanoscale capillary liquid chromatography (nanoLC) using a PicoFrit column (New Objective, Woburn, MA) packed with Jupiter 
(Phenomenex, Torrance, USA) $5 \mu, 300 \mathrm{~A} \mathrm{C18,} 10 \mathrm{~cm} \times 0.075 \mathrm{~mm}$ internal diameter. Peptides were eluted with a linear gradient from $2-50 \%$ solvent B (acetonitrile, 0.1 formic acid) for $30 \mathrm{~min}$ at 200nL/min (obtained by flow-splitting) and analyzed by ESI MS/MS. The experiments were performed with a Thermo Surveyor MS pump connected to a LTQ Linear Ion Trap Mass Spectrometer equipped with a nanoelectrospray ion source (ThermoFisher Scientific, San Jose, USA). Mass spectra were acquired using a data dependent acquisition mode using the Xcalibur software version 2.0. Each full scan mass spectrum ( 400 to $2000 \mathrm{~m} / \mathrm{z}$ ) was followed by collision induced dissociation of the seven most intense ions. The dynamic exclusion (30 s exclusion) function was enabled and the relative collisional fragmentation energy was set at 35\%.

\subsubsection{OFFGEL Electrophoresis (OGE) LC-MS/MS}

Triticale stigma proteins $(50 \mu \mathrm{g})$ extracted with IEF loading buffer were sent to Bioproximity Proteomics Services (http://www.bioproximity.com). Briefly the protein sample was processed using the filter-assisted sample preparation (FASP) method (Wiśniewski et al., 2009). The sample was brought to $6 \mathrm{M}$ urea, 100nM Tris- $\mathrm{HCl}, \mathrm{pH} 7.6,3$ mM DTT, transferred to a $30 \mathrm{k}$ Amicon MWCO device (Millipore), and centrifuged at 13000 $\mathrm{g}$ for $30 \mathrm{~min}$. The remaining sample was buffer exchanged with $6 \mathrm{M}$ urea, $100 \mathrm{mM}$ Tris- $\mathrm{HCl}$, $\mathrm{pH}$ 7.6, alkylated with $30 \mathrm{mM}$ iodoacetamide, digested at a 1:40 trypsin to substrate ratio, and incubated overnight at $37^{\circ} \mathrm{C}$. Digested peptides were desalted using C18 stop- and-go extraction (STAGE) tips (Rappsilber et al., 2007), conditioned with $60 \%$ acetonitrile, $0.5 \%$ acetic acid followed by $5 \%$ acetonitrile, $0.5 \%$ acetic acid, and desalted with $0.5 \%$ acetic acid. Peptides were eluted with $60 \%$ acetonitrile, $0.5 \%$ acetic acid and lyophilized in a 
SpeedVac (Thermo Savant) for $2 \mathrm{~h}$. Peptides were then fractionated for $24 \mathrm{~h}$ by OFFGEL isoelectric focusing using an Agilent OFFGEL device (Agilent Technologies Inc.) with a 24 cm pH 3-10 IPG strip in conjunction with a 24-well tray according to the manufacturer's instructions. Each fraction was desalted as above and analyzed by LC-MS/MS. LC was performed using an Easy Nano-LC II HPLC (ThermoFisher Scientific). Mobile phase A was 94.5\% MilliQ water, 5\% acetonitrile, and 0.5\% acetic acid. The 120 min LC gradient ran from $5 \%$ A to $35 \%$ B for 90 min. The samples were first loaded to a $2 \mathrm{~cm} \times 100$ um I.D. trap column and then to $13 \mathrm{~cm} \times 100 \mu \mathrm{m}$ I.D. analytical columns. Both columns were packed with 3.5 um C18 resin (Zorbax SB-Agilent Technologies Inc.). The LC was interfaced to a LTQ Velos Dual-Pressure Linear Ion Trap mass spectrometer (ThermoFisher Scientific) via nano-electrospray ionization (Voltage $1.8 \mathrm{kV}$ ). The mass spectrometer was programmed to acquire, by data-dependent acquisition, tandem mass spectra from the top 15 ions in the full scan from 400-1400 $\mathrm{m} / \mathrm{z}$. Dynamic exclusion was set to $30 \mathrm{~s}$.

\subsubsection{LC-MS/MS of wheat leaf proteins}

After quantification, $500 \mu \mathrm{g}$ sample were reduced with $5 \mathrm{mM}$ DTT for $25 \mathrm{~min}$ at $56^{\circ} \mathrm{C}$, alkylated with $14 \mathrm{mM}$ iodoacetamide (IAA) for $30 \mathrm{~min}$ in the dark, digested with a final concentration of $1 \mathrm{mM} \mathrm{CaCl} 2$ and $5 \mathrm{ng} / \mu \mathrm{l}$ of trypsin at $37^{\circ} \mathrm{C}$. The reaction was terminated with $0.4 \% \mathrm{v} / \mathrm{v}$ TFA after which samples were lyophilized. To prepare the sample for offline separation by RP nanoscale HPLC, each leaf peptide sample replicate was first desalted using a $5 \mathrm{~cm}$ RP column (MOS1-Hypersil: ThermoFisher) connected to an analytical HPLC pump (Ultimate 3000: Dionex, Bremen, Germany) with a linear water-acetonitrile gradient (20mM ammonium formate $\mathrm{pH} 10$ in both eluents $\mathrm{A}$ and $\mathrm{B}, 1 \%$ acetonitrile/min, 150 
$\mu \mathrm{L} / \mathrm{min}$ flow rate). Approximately $100 \mu \mathrm{g}$ of the digest was fractionated in replicates runs, while UV detection at $214 \mathrm{~nm}$ was used to monitor the elution profile, which showed good reproducibility between these replicates. Each was lyophilized and resuspended in $25 \mu \mathrm{L}$ of buffer A ( $2 \%$ acetonitrile and $0.1 \%$ formic acid in water) solution for the second-dimension separation. The eluent was monitored at $220 \mathrm{~nm}$ and a single desalted fraction was collected. The desalted peptides were separated into 60 fractions using a high-pH acetonitrile gradient as described (Dwivedi et al., 2008) and pooled by interlacing fractions $1+21+41 ; 2+22+42$ etc. resulting in 20 fractions. Leaf peptides were separated by RP nanoscale HPLC (LC: Ultimate 3000, ThermoFisher, San Jose, CA, USA) coupled to a linear ion trap mass spectrometer (LTQXL: ThermoFisher). A $10 \mathrm{~cm}$ C18 column (5 $\mu \mathrm{m}$ particle $/ 300^{\circ} \mathrm{A}$ pores) was prepared in-house and used to deliver peptides into the mass spectrometer via nano-spray ionization at $250 \mathrm{~nL} / \mathrm{min}$ using a $2-80 \% \mathrm{v} / \mathrm{v}$ ACN gradient in $1 \% \mathrm{v} / \mathrm{v}$ formic acid, $0.5 \% \mathrm{v} / \mathrm{v}$ acetic acid over $65 \mathrm{~min}$. The mass spectrometer was programmed to acquire a full survey scan $(300-2000 \mathrm{~m} / \mathrm{z})$, to select the five most abundant ions from this and preform, serially, an MS2 scan on each. Former precursor ions were excluded from analysis for 30 s (Rampitsch et al., 2013).

\subsubsection{Data analysis}

All MS/MS spectra were analyzed using Mascot version 2. 3. 0 (http://www.matrixscience.com) and X! Tandem version 2007.01.01.1 (www.thegpm.org/tandem) to search the Universal Protein Resource (UniProt) Viridiplantae database. The search was restricted to a maximum of one missed (trypsin) cleavage, fixed carbamidomethyl alkylation of cysteine, variable oxidation of methionine, as 
well as a 0.5 Da mass unit tolerance for fragment ions and 2.0 Da for parent ions. The maximum FDR was set to $0.3 \%$ for proteins and $5.3 \%$ for peptides. Scaffold version 4.0 .4 (Proteome Software Inc., Portland, OR, USA) was used to validate MS/MS based peptide and protein identifications. Peptide identifications were accepted if they could be established at greater than $95 \%$ probability as specified by the peptide Prophet algorithm (Keller et al., 2002). Protein identifications were accepted if they could be established at greater than 95\% probability and contained at least 2 identified peptides. Proteins displaying shared peptides were grouped in Scaffold to satisfy the laws of parsimony. Proteins with a single peptide match at a greater than 95\% probability (Table $2-1$ ) were validated manually based on the following criteria: the peptide must be identified at least by two search engines (Mascot with significant ion score of 25 and X! Tandem), contain a minimum of $80 \%$ coverage of theoretical $y$ or $b$ ions (at least 3 amino acids in a row in either $\mathrm{y}$ or $\mathrm{b}$ ions series), and show an absence of prominent unassigned peaks greater than 5\% of the maximum intensity (Prenni et al., 2012; Feng et al., 2009). SignalP4.1 (http://www.cbs.dtu.dk/services/SignalP) was utilized to predict the presence of signal peptides. Triticale functional annotations were performed manually using AmiGO 2 (http://amigo.geneontology.org) as a guide as well as evidence from the scientific literature, and with this type of annotation there was no overlap among the different metabolic process categories (Tran et al., 2013). Proteins with no significant matches were classified as 'unknown', whereas proteins matching known proteins or domains, but without an associated biological process were considered 'unclassified'.

To compare triticale mature stigma protein and mRNA data, the 542 protein sequences identified in the 1D SDS PAGE LC-MS/MS analysis were submitted to a tBLASTn 
search against an in-house triticale reference transcriptome assembly and the 239 contigs (a set of overlapping DNA segments that together represent a consensus and contiguous mRNA sequence) whose derived protein sequences showed $\geq 95 \%$ identity were selected for further analysis. These contigs were then aligned to the sequences used to generate the different probe sets of the 55K Affymetrix GeneChip® wheat genome array (represents 55k transcripts for all 42 chromosomes of wheat genome) (affymetrix@microarray.ca) and the 180 contigs showing $\geq 95 \%$ identity were selected for expression comparisons with the matching proteins. The mature triticale stigma gene expression levels for these 180 contigs were derived from the normalized values of a triplicate microarray analysis of the triticale mature stigma shown at the 2-logarithmic scale ( $\left.\log _{2}\right)$ (Tran et al., 2013). Quantification of the corresponding proteins was performed based on spectral counting after 1D SDS PAGE LC MS/MS analysis. The normalized spectral abundance factor (NSAF) was calculated both manually and using Scaffold software as the number of spectral counts (SpC) identifying a protein, divided by the protein's length (L), divided by the sum of SpC/L for all proteins in the experiment (Table 2-1).

\subsection{Results and discussion}

\subsubsection{Comparison of 1D SDS PAGE LC-MS/MS, 2D IEF/SDS PAGE LC-MS/MS and OGE LC-} $M S / M S$

In this study, the proteome of the mature triticale stigma was analyzed using three different electrophoretic approaches. A total of 2555 proteins were identified including 542 proteins using 1D SDS PAGE LC-MS/MS, 303 proteins by OGE LC-MS/MS and 1710 
proteins with 2D IEF/SDS PAGE LC-MS/MS, which represented a total of 2184 unique proteins (Table 2-1). We examined the overlap in the proteins identified using the three different proteomics techniques and only 66 proteins of the 2184 proteins identified in this study were identified by all three approaches and an additional 237 proteins were detected by two of the three methods (Figure 2-3). Half of the proteins found with OGE LC-MS/MS were also identified by 2D IEF/SDS PAGE LC-MS/MS and this may reflect the fact that they share the same protein extraction buffer, although in the 2D IEF/SDS PAGE LC-MS/MS it was the proteins that were separated by IEF, whereas it was tryptic peptides with OGE LCMS/MS. These results clearly indicate that different proteomics approaches can yield distinct proteins from the same tissue and combining different techniques increases the number of identified proteins.

Evidently the 'shotgun' approaches 1D SDS PAGE LC-MS/MS and OGE LC-MS/MS did not uncover as many stigma proteins as 2D IEF/SDS PAGE LC-MS/MS and this is likely a result of a lower number of more highly complex samples. Although labour intensive, 2DIEF/SDS PAGE LC-MS/MS does provide considerable information pertaining to the proteins detected, as well as a protein profile (Figure 2-2) that can be used in comparative analyses such as DIGE. For example, almost one third of the 1710 identified proteins were found in multiple spots with different $\mathrm{pIs}$ and molecular masses (Table 2-1) pointing to the existence of isoforms possibly resulting from post-translational modifications, multimeric forms of the protein, proteolytic processing, and alternative transcripts. This is a higher proportion than reported for Arabidopsis floral buds (Feng et al., 2009) and may indicate a higher degree of post-translational modification within the stigma. The 2D gels were also analyzed for the presence of phosphorylated or glycosylated proteins using commercially 
available stains (Figure 2-4), but MS analysis of intensely fluorescent spots (labeled P and G in Figure 2-2) could not confirm the presence of these post-translational modifications.

\subsubsection{Funtional classification of triticale mature stigma proteins}

Generally, the proteins identified by the different electrophoretic procedures displayed similar overall functional distribution patterns (Figure 2-5), although for reasons that are not evident 1D SDS PAGE LC-MS/MS differed considerably in the categories Metabolic Process, Translation and Transport. More than 75\% of the 2184 triticale mature stigma proteins identified in this study were found in only 5 categories: Metabolic Process (30.5\%), Protein Metabolic Process (17.2\%), Transport (11.9\%), Translation (9.6\%), and Response to Stress (7.3\%). A detailed description of the constituent proteins of each functional category is beyond the scope of this thesis; the discussion will therefore be restricted to some examples relevant to three critical aspects of stigma biology: stigma development, pollen-stigma interactions and stigma responses to biotic and abiotic stress.

\subsubsection{Proteins involved in stigma development}

Very little is known regarding the identity and function of the proteins underlying stigma development in the Triticeae, however, it is possible to infer a potential role for the triticale stigma proteins identified in this study (Table 2-1) based on homology to proteins shown to play a role in development primarily in model species. Transcription factors (TFs) are evident candidates as potential regulators of stigma development and some of the TFs found within the triticale mature stigma included orthologs to TFs known to have a role in gyneocium development including DROOPING LEAF (DL)/CRABS CLAW (CRC) which is involved in determining carpel identity and mid-rib formation (Li et al., 2011), 
GT2 , KNOTTED-LIKE, ARABIDOPSIS THALIANA3 (KNAT3) which, although shown to be involved in embryo sac development in Arabidopsis (Pagnussat et al., 2007), was also found in the triticale stigma as a transcript (Tran et al., 2013), and SHORT INTERNODES (SHI)/STYLISH (STY) which regulates auxin-mediated stigma and style development by interacting with YUCCA4 (YUC4) (Larsson et al., 2013). Auxin has been proposed to play a role in stigma and style development and function (Ståldal and Sundberg, 2009), and microarray analysis has shown that auxin-signalling components are over-represented in the rice stigma (Li et al., 2007) and that several auxin response factors (ARFs) show enriched expression in the triticale stigma (Tran et al., 2013). A role for auxin in triticale stigma development is further supported by the presence of orthologs to the Arabidopsis proteins HEMIVENATA (HVE) a CULLIN-ASSOCIATED-NEDD8-DISSOCIATED1 (CAND1) protein that negatively regulates ubiquitin-mediated auxin signalling and plays a role in leaf venation and cell division (Pérez-Pérez et al., 2011), AUXIN RESISTANT1 (AXR1) a RUB/NEDD8-activating enzyme E1 regulatory subunit which plays a role in auxin signalling and in development (Nakasone et al., 2012), as well as the ABC transporter ABCB15 shown to transport auxin (Kaneda et al., 2011).

A variety of additional proteins were identified that may also function in triticale stigma development and these comprised several CELL DIVISION CONTROL (CDC) 48-like proteins which are transitional endoplasmic reticulum ATPases involved in protein turnover shown in Arabidopsis to affect cell division, expansion and differentiation, as well as pollen tube growth (Park et al., 2008). Other triticale stigma proteins with homologs shown to have developmental roles included FLORAL ORGAN REGULATOR-LIKE1 (FORL1) and FORL2 which are related to OsFOR1 that regulates floral organ number in rice (Jang et 
al., 2003), TASSELSEED2 (TS2) which when absent leads to the feminization of maize tassels (Delong et al., 1993), POINTED FIRST LEAF (PFL) which represents ribosomal proteins that can affect growth and development (Ito et al., 2000), a RAN GTPase-activating protein (RanGAP1) with a conserved function in cell division and important to female gametophyte development in Arabidopsis (Rodrigo-Peiris et al., 2011), ABNORMAL INFLORESCENCE MERISTEM1 (AIM1) a fatty acid $\beta$-oxidation multifunctional protein (Richmond and Bleecker, 1999), and PEPPER (PEP) a protein containing KH RNA-binding domains that regulates gynoecium development including that of the stigma (Ripoll et al., 2006).

A number of proteins highlight the importance of epigenetic mechanisms in triticale stigma development such as orthologs to the Arabidopsis METHYL-CPG-BINDING DOMAIN PROTEIN11 (MBD11) which when downregulated causes developmental defects including abnormal flower positions, delayed flowering and reduced fertility (Berg et al., 2003), MULTI-SUBUNIT SUPPRESSOR OF IRA1 (MSI1) involved in gene silencing during female gametogenesis and early seed development (Hennig and Derkacheva, 2009), as well as GLABRA2 EXPRESSION MODULATOR (GEM) which, via histone modification, inhibits the expression of the transcription factor GLABRA2 (GL2) implicated in epidermal cell division and cell fate (Qing and Aoyama, 2012) and which may play a role in Triticeae stigma papillae formation. Lastly, the conservation of mechanisms underlying monocot floral patterning is indicated by the presence of an ortholog to the Arabidopsis HISTONE DEACETYLASE19 (HDA19) shown to be part of a repressor complex with APETAL2 (AP2) and TOPLESS (TPL) regulating floral organ identity genes (Krogan et al., 2012). 
A role for protein phosphorylation in stigma development is supported by the presence of Arabidopsis orthologs CYCLIN-DEPENDENT KINASE F;1 (CDKF;1) a major regulator of cell proliferation and expansion (Takatsuka et al., 2009), three different SNF1related protein kinase (SNRK) regulatory subunits which can interact with NAC domain TFs to positively regulate development (Kleinow et al., 2009), CASEIN KINASE2 (CK2) implicated in multiple developmental pathways (Mulekar and Huq, 2014), and 2A PHOSPHATASE ASSOCIATED PROTEIN OF 46KD (TAP46) with roles in development via the TARGET OF RAPAMYCIN (TOR) and ABI5 regulatory pathways (Hu et al., 2014). At present, the great majority of the many protein phosphatases identified in this study could not be assigned a putative role.

The Triticeae stigma is a non-green tissue enclosed within the floret and hence it will be interesting to investigate the role of a number Arabidopsis orthologs associated with photomorphogenesis including different subunits of the CONSTITUTIVE MORPHOGENESIS9 (COP9) SIGNALOSOME (CSN) which although involved in photomorphogenesis also regulates many different cellullar processes by regulating the activity of CULLIN-RING E3 ubiquitin ligases (Stratmann and Gusmaroli, 2011), TF Z-BOX BINDING FACTOR3 (ZBF3)/CALMODULIN7 (CAM7) that integrates light signals with seedling development (Gangappa et al., 2013), THYLAKOID FORMATION1 (THF1) whose rice ortholog NYC4 was recently shown to play a role in chlorophyll-protein complexes degradation during leaf senescence (Yamatani et al., 2013), as well as SCHLEPPERLESS (SLP)/CHAPERONIN60 (CPN60) and chaperones part of the chloroplast multi-subunit Clp protease such as DE-REGULATED CAO ACCUMULATION1 (DCA1)/ClpC1 and ALBINO OR 
PALE GREEN6 (APG6)/ClpB3 which are all involved in chloroplast development (Apuya et al., 2001; Sjögren et al., 2004; Myouga et al., 2006).

These few examples illustrate (mostly for the first time) the occurrence of proteins involved in the regulation of Triticeae stigma development and other such examples can be found in Table 2-1.

\subsubsection{Proteins involved in pollen-stigma interactions}

The landing of a compatible pollen grain onto the stigma surface marks the beginning of pollen-pistil interactions enabling pollen recognition, adhesion, germination, tube growth and finally fertilization. Little is known of the molecules involved in the recognition process within the grasses (Klaas et al., 2011). The first layers of contact are the protein pellicle and then the cuticle covering the dry stigma, both of which the pollen tube must breach. The triticale mature stigma expressed many proteases (Table 2-1) and some may facilitate penetration of the protein pellicle. A cutinase responsible for the breakdown of the stigma cuticle has not been identified, but a GDSL lipase was recently shown to fit the description (Takahashi et al., 2010) and one of the GDSL lipases expressed in the triticale stigma could have a similar role. A significant number of other triticale stigma proteins within the Lipid Metabolic Process category are likely to be involved in stigma cuticle formation and these include orthologs to the Arabidopsis FIDDLEHEAD (FDH) which has been shown to play a role in pollen-stigma interactions (Lolle and Cheung, 1993), DEFECTIVE IN CUTICULAR RIDGES (DCR) a diacylglycerol acyltransferase involved in cuticle formation, epidermal cell differentiation and the regulation of water flow (Panikashvili et al., 2009), a GDSL lipase shown to function in cutin biosynthesis (Shi et al., 
2011), an ABC transporter similar to the barley EIBI1 and the Arabidopsis ATP BINDING CASSETTEG32 (ABCG32) likely to export cutin precursors from the epidermal cells (Bessire et al., 2011), ECERIFERUM8 (CER8)/LONG-CHAIN ACYL-COA SYNTHETASE1 (LACS1) proteins involved in wax and cutin synthesis (Lü et al., 2009), and ANTHOCYANINLESS2 (ANL2) an HD START TF which plays a role in epidermal cell development as well as anthocyanin and cutin accumulation (Wu et al., 2011). HD-START TFs represented a major category of TFs enriched within the stigma transcriptome (Tran et al., 2013). Finally, several non-specific lipid transfer proteins (LTPs) were found within the stigma proteome, LTPs have been ascribed a number of different roles in development, signaling, biotic and abiotic stresses, as well as cutin biosynthesis (Edstam et al., 2011). As many of the proteins described below, it will be interesting to investigate whether many of these proteins play a role primarily in maturing stigma development/growth, pollen germination/tube growth, or are involved in both activities.

The pollen tube penetrates the stigma cell wall and grows within it thus necessitating proteins for both cell growth and cell wall degradation and synthesis. The triticale stigma proteome exhibited numerous cell wall modifying proteins including for example many glycosyl hydrolases, several expansins, as well as pectin modifying enzymes like pectinesterases and pectate lyase (Table 2-1). Other proteins of interest included lipoxygenases (LOXs) which are known to affect papillae expansion (Caldelari et al., 2011), TASSELSEED1 (TS1) a lipoxygenase necessary for maize pistil primordial abortion possibly via the jasmonic acid pathway (Acosta et al., 2009), dynamin-related proteins (DRPs) which have a role in cytokinesis and cell expansion including cell wall formation (Collings et al., 2008) and were shown to be involved in Arabidopsis stigma papillae expansion (Kang et 
al., 2003), two CELLULOSE SYNTHASE-INTERACTING (CSI) proteins shown in Arabidopsis to bridge cellulose synthase to cortical microtubules a process underlying directional growth (Li et al., 2012a), and multiple versions of UDP-ARABINOPYRANOSE MUTASE (UAM)/REVERSIBLY GLYCOSYLATED POLYPEPTIDE (RGP), UAM generates UDParabinofuranosyl associated with arabinoxylan an important component of grass primary and secondary cell walls (Konishi et al., 2011). In addition, four different fasciclin-like arabinogalactan (FLA) proteins were identified, arabinogalactan proteins are known to be abundant in transmitting tissue and are a major constituent of lily stigma exudate (Rejón et al., 2013), while the fasciclin domain involved in protein-protein interactions was shown to be involved in cell adhesion and could also mediate extracellular interactions (Ellis et al., 2010). Lastly, orthologs to the Arabidopsis FERONIA (FER) and HERCULES (HERK) were identified within the triticale stigma proteome and these receptor-like PKs are important to cell wall metabolism and cell growth (Lindner et al., 2012).

The growth of the pollen tube through the stigma eventually becomes auxotrophic and relies on support from the surrounding tissue and this in turn signifies a requirement for the transport of various nutrients and signals. Accordingly, transport is the third largest functional category of the triticale stigma proteins (Figure 2-8) consistent with the enrichment of transport-related transcripts in the mature stigma (Xu et al., 2012; Tran et al., 2013). A role for vesicle-mediated secretion of stigma resources has been suggested (Samuel et al., 2011) and a high proportion of the transport proteins of the triticale stigma proteome belong to relevant proteins such as annexins, coatomer subunits, and SEC proteins (Table 2-1). GTPase-mediated regulation of membrane trafficking is also reflected by the high number of associated proteins detected in the triticale stigma proteome 
including ADP-RIBOSYLATION FACTORS (ARFs), GDP DISSOCIATION INHIBITORS (GDIs), ARF GTPASE ACTIVATING PROTEINS (ARFGAPs), PRENYLATED RAB ACCEPTORS (PRAs), as well as many GTPases, most of which are either dynamin-related or Rab GTPases, with the most highly represented GTPase being SECRETION-ASSOCIATED RAS1 (SAR1). The role of Rab GTPases in membrane trafficking and signaling has recently been reviewed (Rehman and Di Sansebastiano, 2014) and characterizing the role of this process in cereal pollen-pistil interactions will be a significant future challenge. The next largest group of proteins in the Transport category were ATPases mainly V-type and P-type proton ATPases important to the creation of gradients underlying membrane potential and ion transport during pollen tube growth (Hepler et al., 2013), as well as AAA+ ATPases which are essentially molecular chaperones with a diversity of functions revolving around processes such as protein unfolding or disassembly of protein complexes (Ogura and Wilkinson, 2001).

Stigmas can accumulate high amounts of reactive oxygen species (ROS) (McInnis et al., 2006) and these are known to function as signaling molecules in a wide range of processes in plants including stress responses (Foyer and Noctor, 2013). Furthermore, the role of redox regulation in pollen-stigma interactions is becoming increasingly evident (Dresselhaus and Franklin-Tong, 2013; Traverso et al., 2013). The Metabolic Process category contained a high proportion of triticale stigma proteins associated with redox processes (Table 2-1) with examples including many enzymes involved in glutathione metabolism such as glutathione-S-transferases, peroxidases, reductases, and synthetases, as well as numerous redoxins and enzymes such as superoxide dismutases, ascorbate peroxidases, catalases, peroxidases, malate dehydrogenases, malic enzymes, 6- 
phosphogluconate dehydrogenases, and isocitrate dehydrogenases. The role of these proteins in Triticeae pollen-stigma interactions remains to be elucidated.

The continuous interaction between the pollen grain/tube and the stigma implies a high degree of communication and numerous additional triticale stigma proteins likely to play a significant role in signaling were identified including several 14-3-3 proteins which regulate an ever growing number of processes such as cell growth and responses to hormones, light, and stress via phosphorylation-dependent associations (Denison et al., 2011), as well as proteins linked to calcium signaling such as calmodulins, calreticulins, CaLB domain containing proteins, calcium-dependent protein kinases (CDPKs) and several phospholipase D (PLDs) which have been shown to be involved for example in cytoskeletal dynamics, membrane re-modeling, biotic and abiotic stress responses (Wang et al., 2014). The triticale stigma also expressed RECEPTOR FOR ACTIVATED C KINASE 1A (RACK1A) proteins which are scaffolding proteins that interact with signaling proteins in a variety of signaling pathways associated with development, hormonal and stress responses (Dongping et al., 2013), and several inositol-3-phosphate synthases responsible for the first step of inositol biosynthesis a key substrate in the phosphoinositide signaling pathway affecting processes such as growth and development, as well as stress responses (Boss and Im, 2012). As exemplified above, the interaction between the pollen grain/tube and the stigma operates at multiple levels and the elucidation of the cellular processes involved will be of great interest. 


\subsubsection{Proteins involved in biotic and abiotic stress}

The stigma and style are meant to be breached by and provide nutrients to the growing pollen tube while preventing this from happening with pathogens and this represents a remarkable challenge to the plant. Furthermore, the next generation must also be preserved against abiotic stresses. Accordingly, these tissues often express relatively high numbers of stress-related genes and indeed it has been found that considerable functional overlap exists between reproductive and stress responsive genes (Li et al., 2007). In this study, this is supported by the fact that many of the proteins involved in stigma development and pollen-stigma interactions discussed above such as AIM1, HDA19, FORL, SNRK, CK2, THF1, APG6, COP9, and PLDs, as well as many of the redox proteins, are known to also play a role in the stress response. The triticale mature stigma expressed a number of proteins with homology to PKs known to be involved in the defense and stress responses including ZmCPK11 (Ding et al., 2013), PROTEIN KINASE INTERACTOR1 (PTI1) (Forzani et al., 2011), OsCDPK7 (Saijo et al., 2000), STRESSACTIVATED PROTEIN KINASE7 (SAPK7) (Kobayashi et al., 2004), and AtMPK1 (Hwa and Yang, 2008). The TF AtNF-YC2 which is activated by oxidative stress and is involved in flowering (Hackenberg et al., 2012) was also identified in the triticale stigma proteome.

The major class of stress-associated proteins found in the triticale stigma consisted of heat shock related proteins represented mainly by HEAT SHOCK COGNATE70 (HSC70), HEAT SHOCK PROTEIN70 (HSP70), and HSP90 proteins (Table 2-1). In fact, nearly half of the Protein Metabolic Process category was made up of proteins involved in chaperone activities also including many PROTEIN DISULFIDE ISOMERASES (PDIs), PEPTIDYL 
PROLYL ISOMERASES (PPIases) and CHAPERONIN60 (CPN60)/T-COMPLEX PROTEIN1 (TCP1) family proteins, all of which may play a role in the stress response. The next largest group of the Protein Metabolic Process category was made up of proteins associated with the proteasome which not only mediates many developmental processes, but also plays a major role in plant responses to stress (Lyzenga and Stone, 2012). One possible example is the triticale ortholog to the Arabidopsis TF ABA BINDING FACTOR3 (ABF3), which like many other proteins in this study implicate ABA in stress tolerance and was recently shown to be regulated via proteasome-mediated proteolysis (Chen et al., 2013). Stressrelated proteins which were found repeatedly also included the UNIVERSAL STRESS PROTEIN (USP) family proteins and UVB-RESISTANCE8 (UVR8) proteins (Table 2-1).

Lastly, defense proteins which appeared often within the triticale mature stigma proteome included HYPERSENSITIVE-INDUCED REACTION (HIR) proteins, PATHOGENESIS-RELATED (PR) proteins, thaumatin-like proteins, chitinases, ricin B-like proteins, allene oxide oxidases, as well as HEAT repeat containing ILITYHIA (ILA)-like proteins required for disease resistance in Arabidopsis (Monaghan and Li, 2010) and ARGONAUTE4 (AGO4) proteins involved in RNA-directed DNA methylation shown to be involved in bacterial and viral disease resistance (Seo et al., 2013).

Therefore, this study not only confirms the presence of a high proportion of proteins involved in both biotic and abiotic stress in the stigma, but also the occurrence of a considerable functional overlap in many stress and developmental proteins. 


\subsubsection{Comparison of the stigma and leaf proteome}

In the hope of highlighting functional categories that may be under- or overrepresented within the stigma, the stigma functional distribution of mature stigma proteins (OGE) was compared to that of the wheat leaf proteome obtained in a different project (Figure 2-6). Metabolic Process represented a much larger proportion of the leaf proteome and this reflects the greater number of leaf proteins associated with photosynthesis (Table 2-1). In contrast, the stigma proteome was noticeably enriched in a number of categories including Cell Wall Modification, Cytoskeleton, Defense, Lipid Metabolic Process, Protein Metabolic Process, Signaling and Transport. These results are only in partial agreement with the functional classification of the transcripts enriched in the mature triticale stigma (Tran et al., 2013) and this may be due to the fact that the gene expression enrichment analysis was much more comprehensive and compared all vegetative and reproductive triticale tissues. Considerably more proteomics data from Triticeae tissues will be required for a thorough comparison.

\subsubsection{Stigma proteins with a signal peptide}

Many of the interactions between the stigma and the pollen grain/tube are extracellular and although not all extracellular proteins possess signal peptides (Drakakaki and Dandekar, 2013), the presence of a signal peptide is a reliable indicator of protein secretion (Lum and Min, 2011) and may point to stigma proteins involved in extracellular interactions. We identified 158 proteins predicted to contain a signal peptide representing $7.9 \%$ of the total number of stigma proteins with a start codon (Table 2-1). Since the proportion of all the triticale proteins with a signal peptide is unknown, it is impossible to 
determine whether this percentage represents a possible enrichment in the stigma. However as a comparison, about $14 \%$ of all the maize proteins are predicted to have a signal peptide (Xu et al., 2012), so it seems possible that the low proportion of secreted proteins identified in this study represent specialized proteins that need to be present for the initial interactions with the pollen whereas additional proteins are generated as the pollen tube grows through the stigma. The great majority of the triticale stigma proteins with a signal peptide were found within only 5 functional categories Protein Metabolic Process (36\%), Carbohydrate Metabolic Process (21\%), Cell Wall Modification (18\%), Defense (10\%), and Transport (8\%) (Figure 2-7). The Protein Metabolic Process category consisted primarily of proteins such as heat shock proteins/luminal-binding proteins and protein disulfide isomerases which are likely important in maintaining protein integrity (Table 2-1). It also included several protease inhibitors and proteases, and although proteolytic enzymes can have significant roles in reproduction such as defense, signaling and programmed cell death (Radlowski, 2005), their potential function in the triticale stigma remains unknown. As many of the proteins in the Carbohydrate Metabolic Process class were also found in Cell Wall Modification, the need for their extracellular localization is in line with a role in allowing and supporting pollen tube growth. The proportion of extracellular proteins in the Defense category is higher than the value for the total stigma proteome (Fig 2-8) again indicating a requirement for these proteins at the site of pollen tube penetration. The Transport category included more than half of the LTPs and this could be due for example to requirements for cuticle synthesis and maintenance. 


\subsubsection{Correlation between triticale mature stigma mRNA and protein expression}

Although it is not possible at present to compare the triticale stigma proteome to that of another species, it can be compared with the triticale mature stigma transcriptome (Tran et al., 2013). Based on the assumption that the 2184 proteins identified in the current study are biased towards the most abundant proteins (Feng et al., 2009), their functional distribution was compared to that of the 2184 most abundantly expressed genes identified in the microarray analysis (Figure 2-9). Of the 2184 genes, 238 showed enriched expression in the pistil when compared to all other triticale tissues and 179 of those genes showed enriched expression in the stigma (Table 2-1). While similarities were observed in the number of expressed genes and proteins found in certain functional categories, differences were also evident, for example, the proportion of proteins associated with the categories Cytoskeleton and Metabolic Process was considerably higher than that of the associated genes, whereas the reverse trend was observed for Protein Phosphorylation, Regulation of Transcription, Regulation of Cellular Process and Transport (Figure 2-9). These observations are in general agreement with reports describing metabolic and structural genes as being stable and having a high protein/mRNA ratio, unlike proteins involved in regulatory processes which may require more rapid production and turnover in reaction to a stimulus (Vogel and Marcotte, 2012). Given that the mature stigma has essentially stopped growing and stands in readiness for pollination, it is possible that it accumulates mRNA encoding regulatory and transport genes to be rapidly translated upon pollen adhesion, hydration, germination, and tube growth. 
In order to explore further the relationship between production and degradation of individual mRNAs and proteins, 180 proteins from the 1D SDS PAGE LC-MS/MS analysis that were found to specifically match genes present in the microarray analysis were used to compare corresponding mRNA and protein levels (Table 2-1). There was very little correlation between the level of mRNA and that of the corresponding proteins $\left(\mathrm{R}^{2}=0.267\right)$ within this relatively small dataset (Figure 2-10). Such a low correlation has also been described for the Arabidopsis floral proteome (Feng et al., 2009) and not only emphasizes the importance of both post-transcriptional and post-translational processes, but confirms the importance of investigating both the transcriptome and the proteome.

\subsection{Conclusion}

To our knowledge, this is first investigation of the Triticeae stigma proteome. Numerous proteins likely to play significant roles in stigma development, function and protection of the next generation were revealed and should provide the basis for future research aimed at better understanding cereal pollen-stigma interactions. 


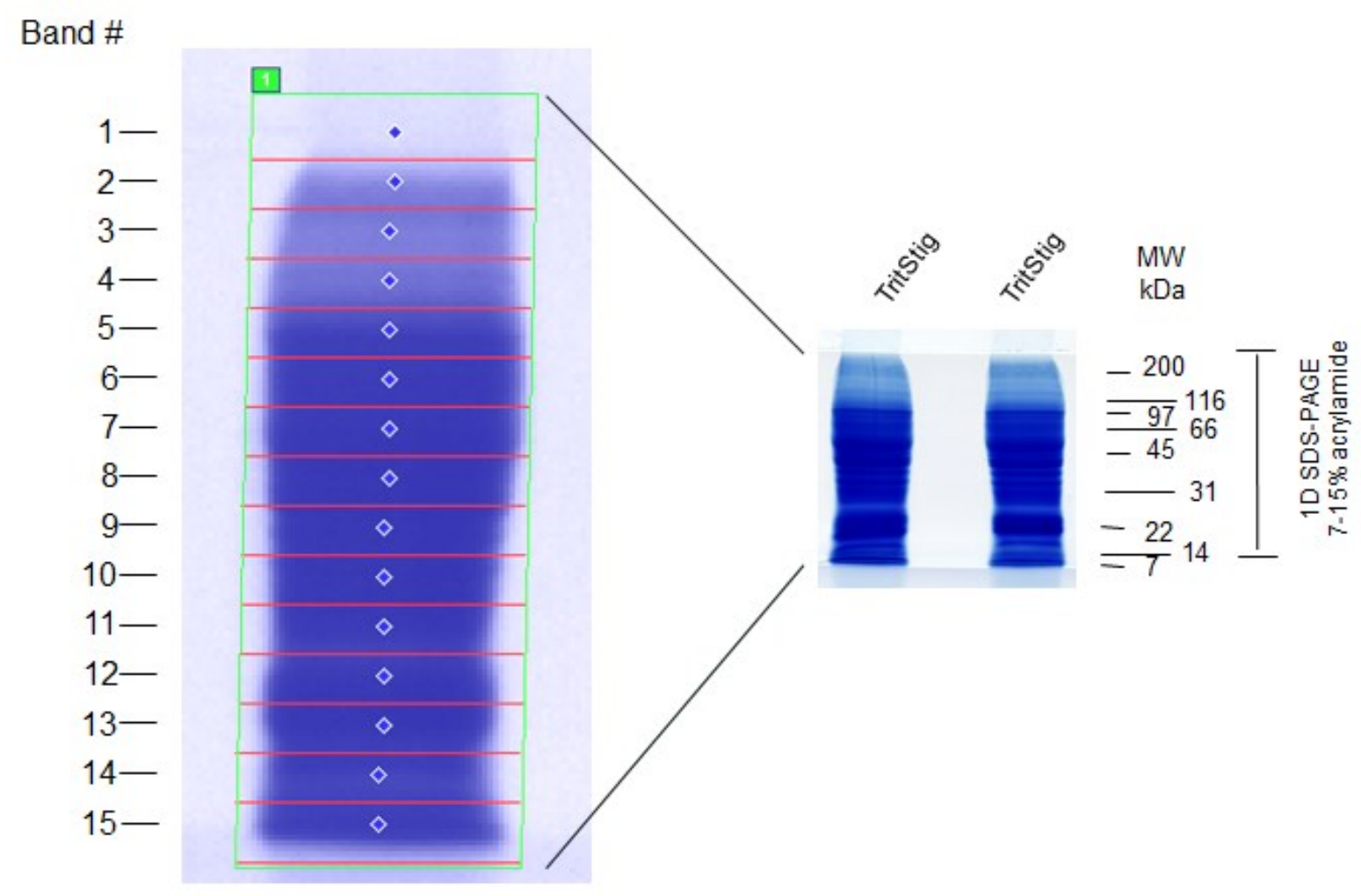

Figure 2-1. 1D SDS-PAGE of triticale mature stigma proteins. The protein sample $(45 \mu \mathrm{g})$ was electrophoresed on a $2.4 \mathrm{~cm}$ 1D SDS-PAGE gel with a 7-15\% acrylamide gradient and stained with CBB G. The 15 gel bands that were excised for MS analysis are numbered on the left. Protein molecular weight (MW) markers are shown on the right. TritStig - mature triticale stigma protein sample. 


\section{$\mathrm{MW}(\mathrm{kDa})$}
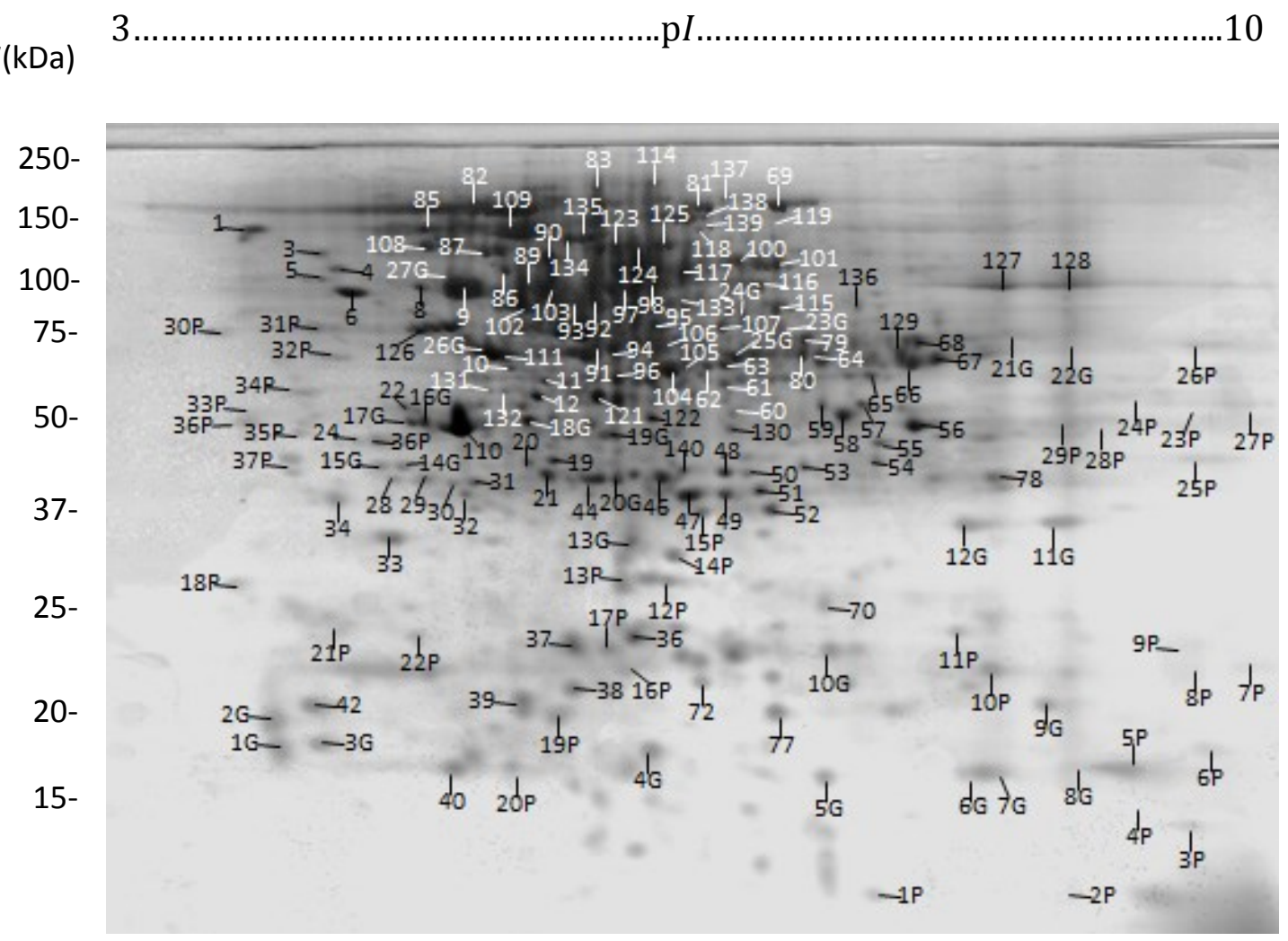

Figure 2-2. 2D IEF/SDS PAGE gel of triticale mature stigma proteins stained with Coomassie Brilliant Blue. Numbers correspond to the spots sent for MS analysis and the corresponding data is listed in Table2-1. A replicate gel was stained with the Pro-Q Diamond phosphoprotein gel stain (Life technologies, Burlington, Canada) to identify phosphorylated proteins and the most fluorescent spots (P) were sent for MS analysis. Another replicate gel was also stained with the Pro-Q Emerald glycoprotein gel stain (Life Technologies) to identify glycosylated proteins and the most fluorescent spots (G) were sent for MS analysis. The molecular weight (MW) markers are indicated in kilodaltons $(\mathrm{KDa})$ and the IEF isoelectric point $(\mathrm{p})$ range is shown at the top of the gel image. These results were obtained in three separate gels from different stigma protein extractions. 


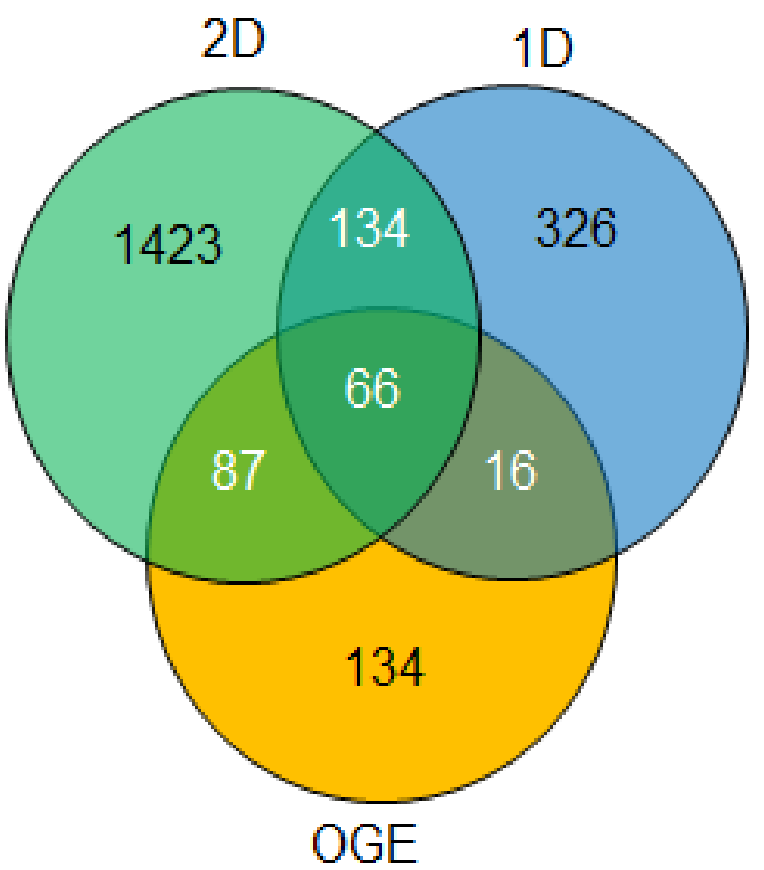

Figure 2-3. Overlap among the proteins identified by the different methods of analysis. 1D: 1D SDS PAGE LC-MS/MS; 2D: 2D IEF/SDS PAGE LC-MS/MS; OGE: OGE LC-MS/MS. 
$\mathrm{MW}(\mathrm{kDa})$

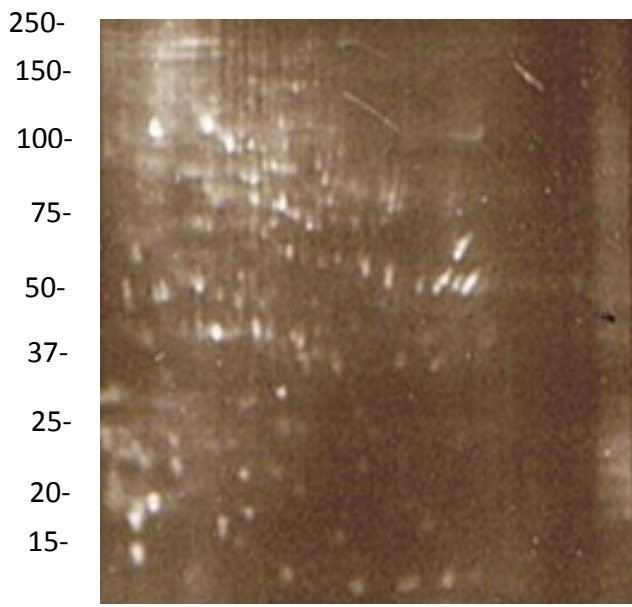

(A)
10

3.

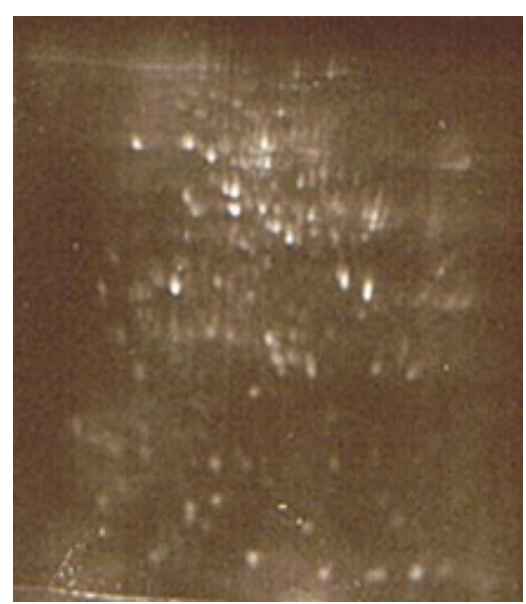

(B)

pl.

.10
3.

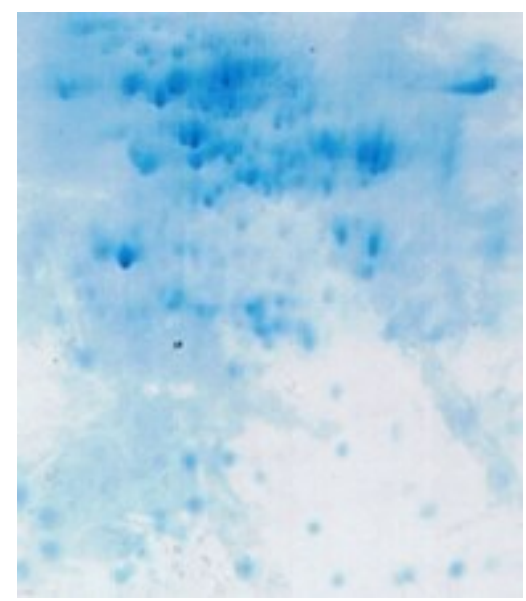

(C)

Figure 2-4. Multiplex 2D analysis of triticale mature stigma proteins. Visualization of (A) the phosphorylated proteins using Pro-Q Diamond dye, (B) the glycosylated proteins using Pro-Q Emerald 300 dye, and (C) the total protein profile using CBB. The relative molecular weight (MW) in kilodaltons (KDa) of the protein markers and the IEF isoelectric point $(\mathrm{p} I)$ range are shown on the left and top of the gel image. 


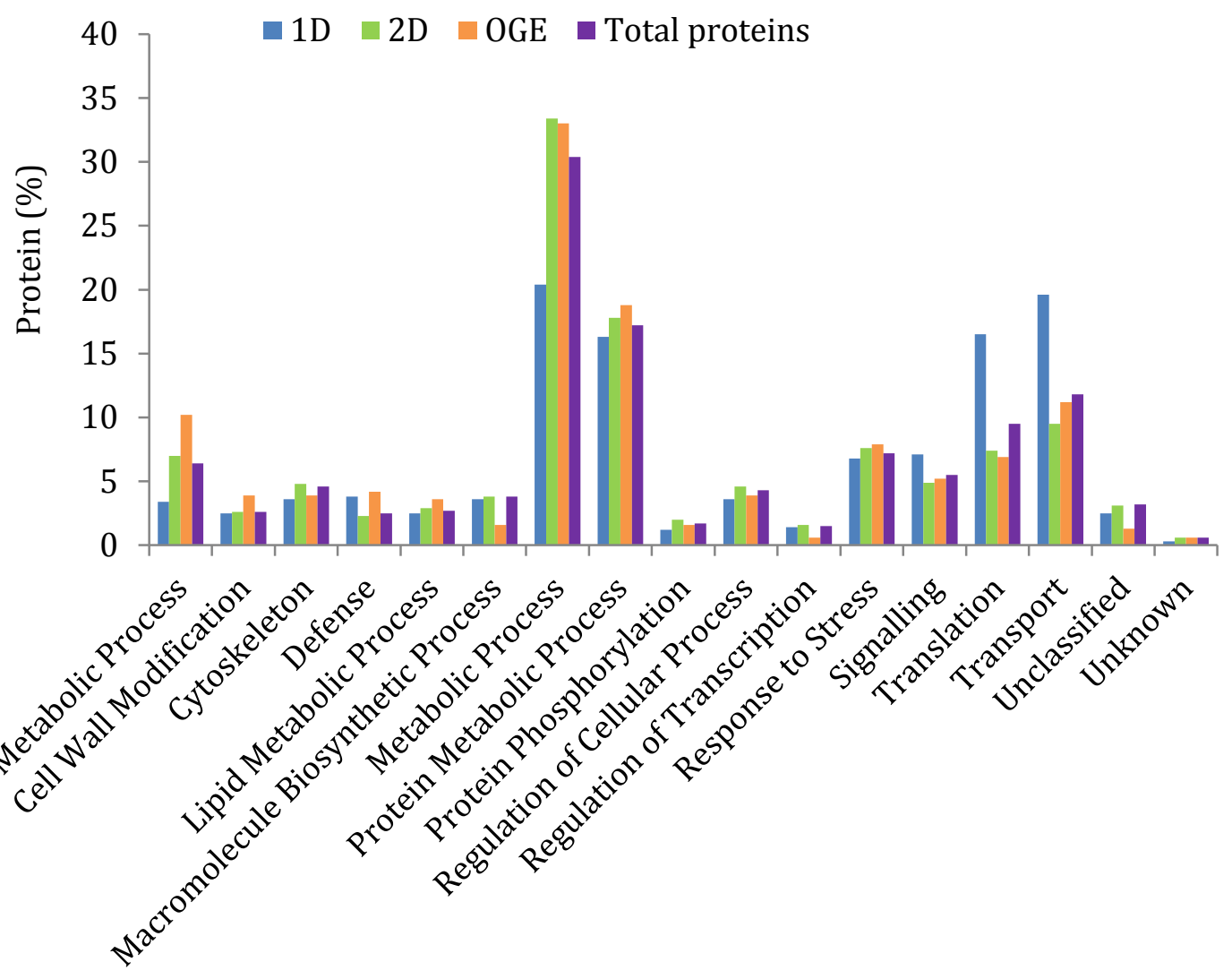

Figure 2-5. Functional distribution of triticale mature stigma proteins identified using different methods of analysis and their combined total. 1D: 1D SDS PAGE LC-MS/MS; 2D: 2D IEF/SDS PAGE LC-MS/MS; OGE: OGE LC-MS/MS. Triticale proteins were annotated manually and an individual protein is not found in more than one Metabolic Process category. 


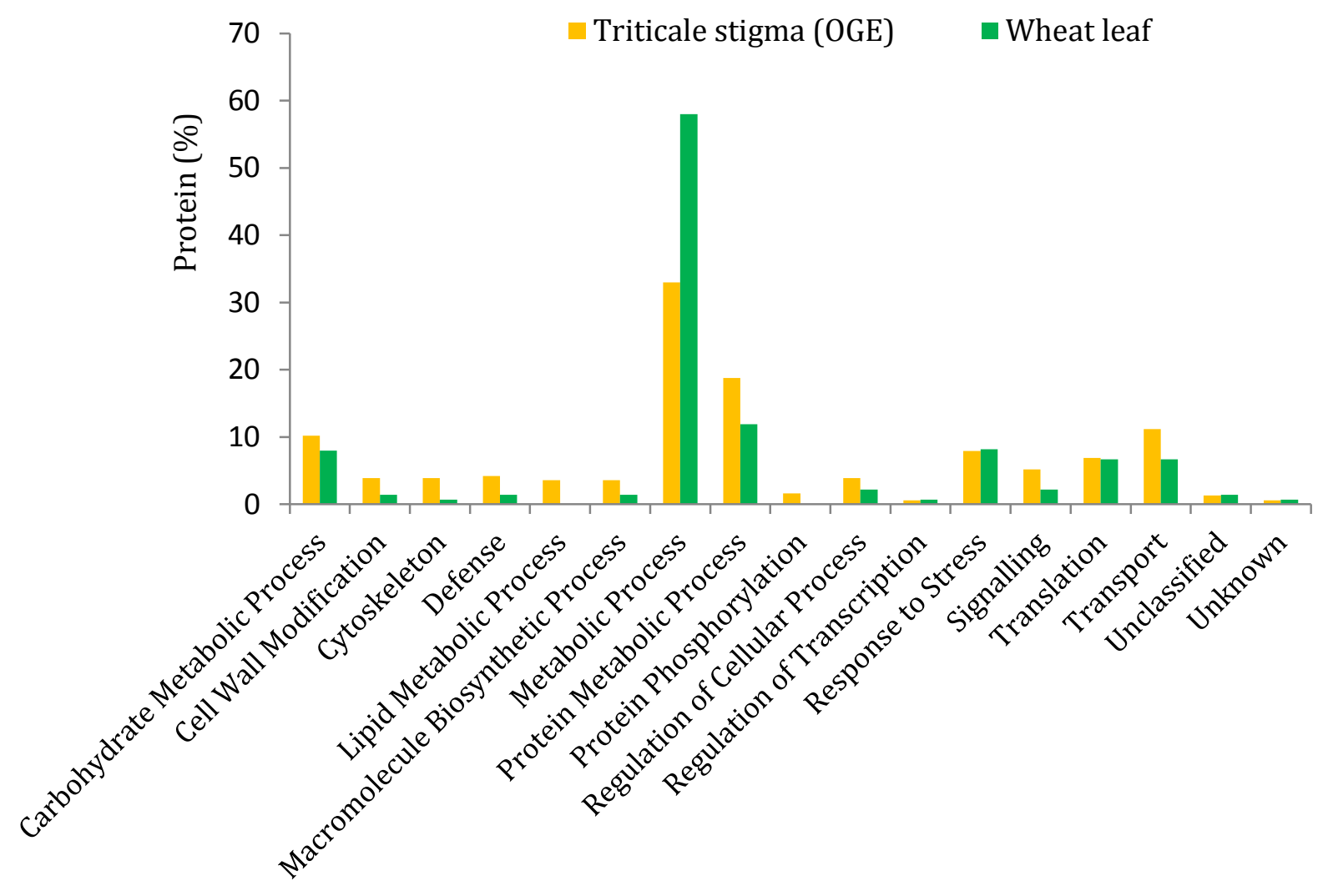

Figure2-6. Comparison of the functional distribution of triticale mature stigma and wheat leaf proteins. OGE: OGE LC-MS/MS. Triticale and wheat proteins were annotated manually and an individual protein is not found in more than one Metabolic Process category. 


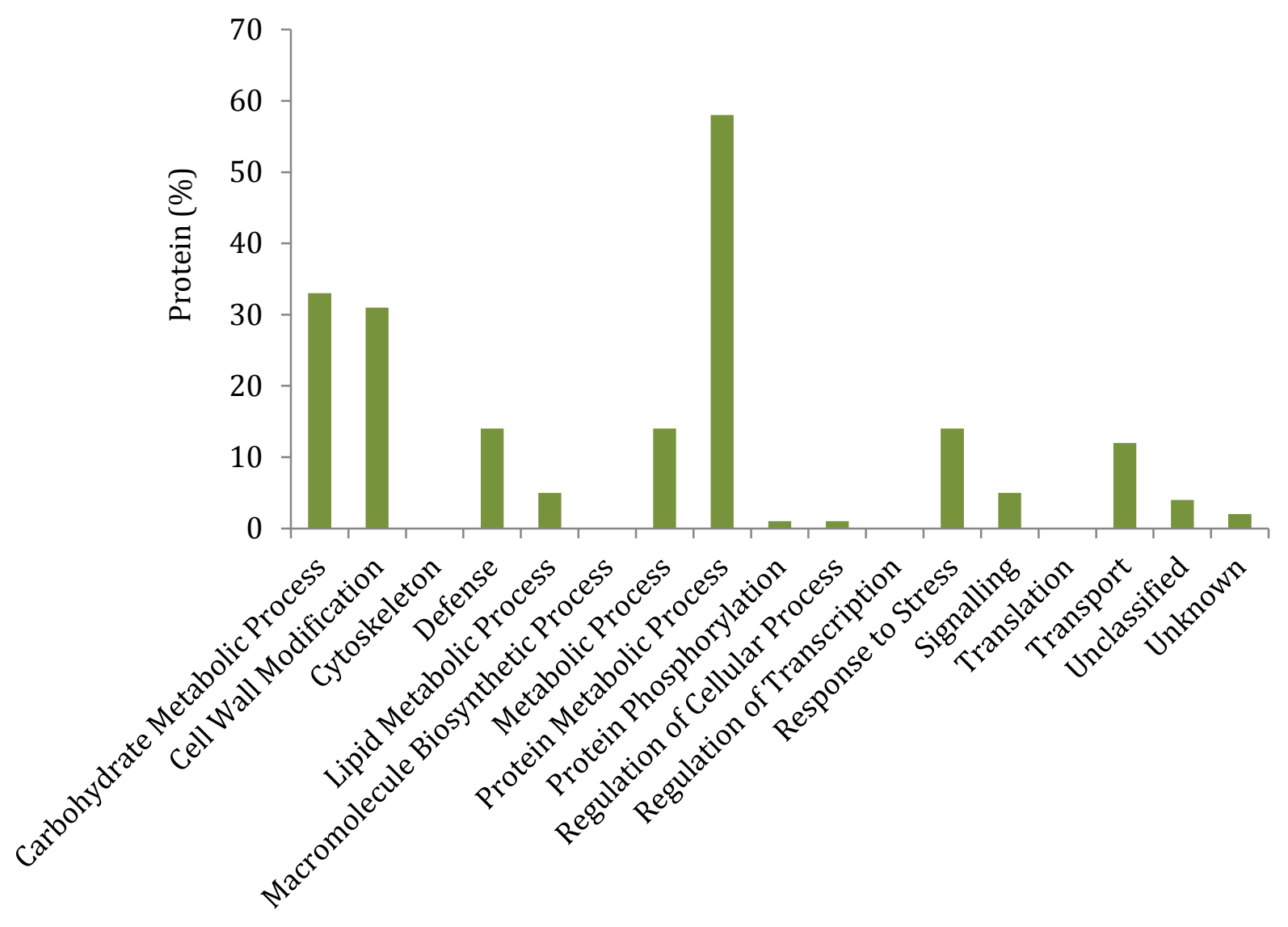

Figure 2-7. Functional distribution of triticale stigma proteins with a signal peptide as determined using SignalP4.1 (http://www.cbs.dtu.dk/services/SignalP). Triticale proteins were annotated manually and an individual protein is not found in more than one Metabolic Process category. 


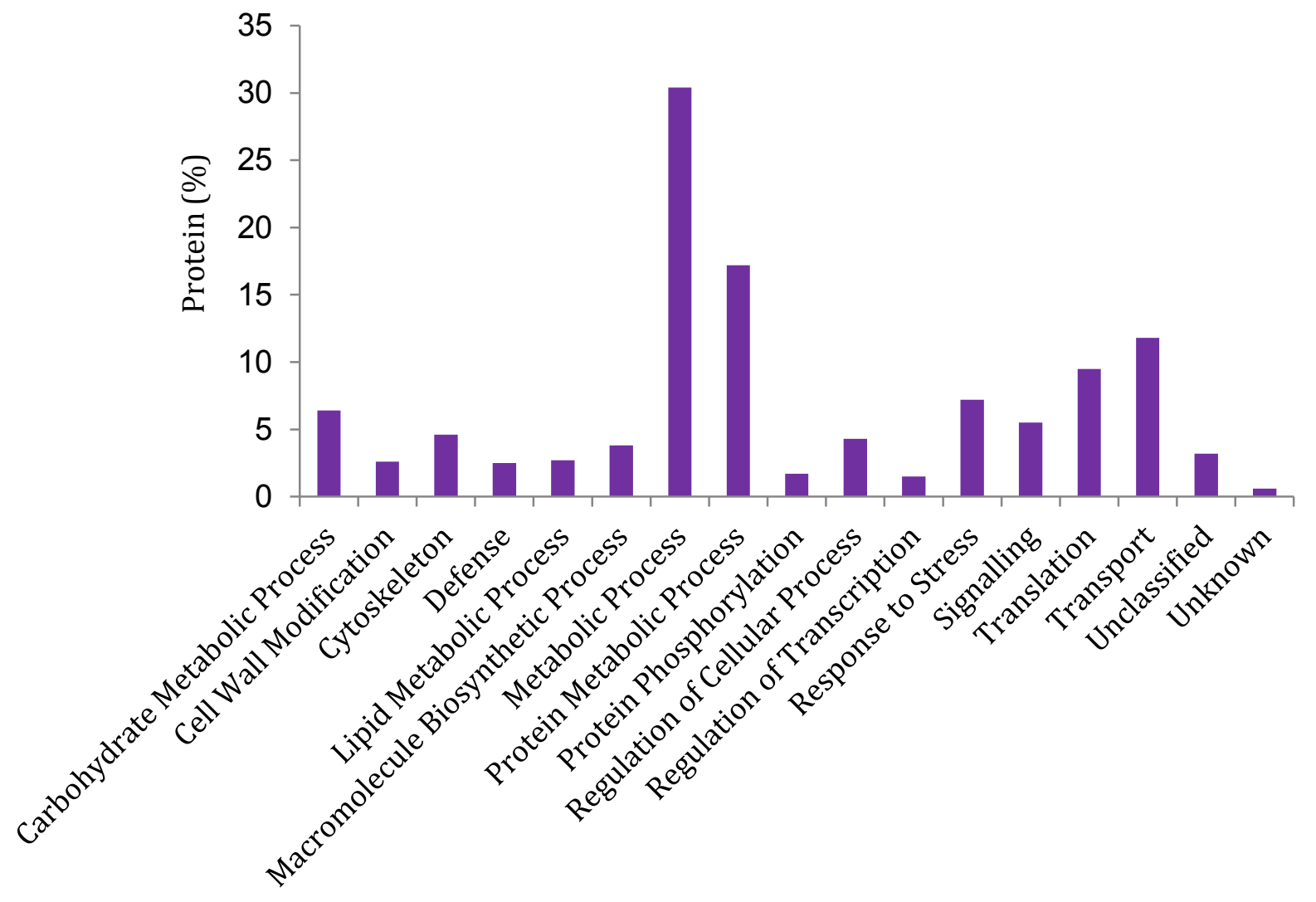

Figure 2-8. Functional distribution of triticale mature stigma proteins. Triticale proteins were annotated manually and an individual protein is not found in more than one Metabolic Process category. 


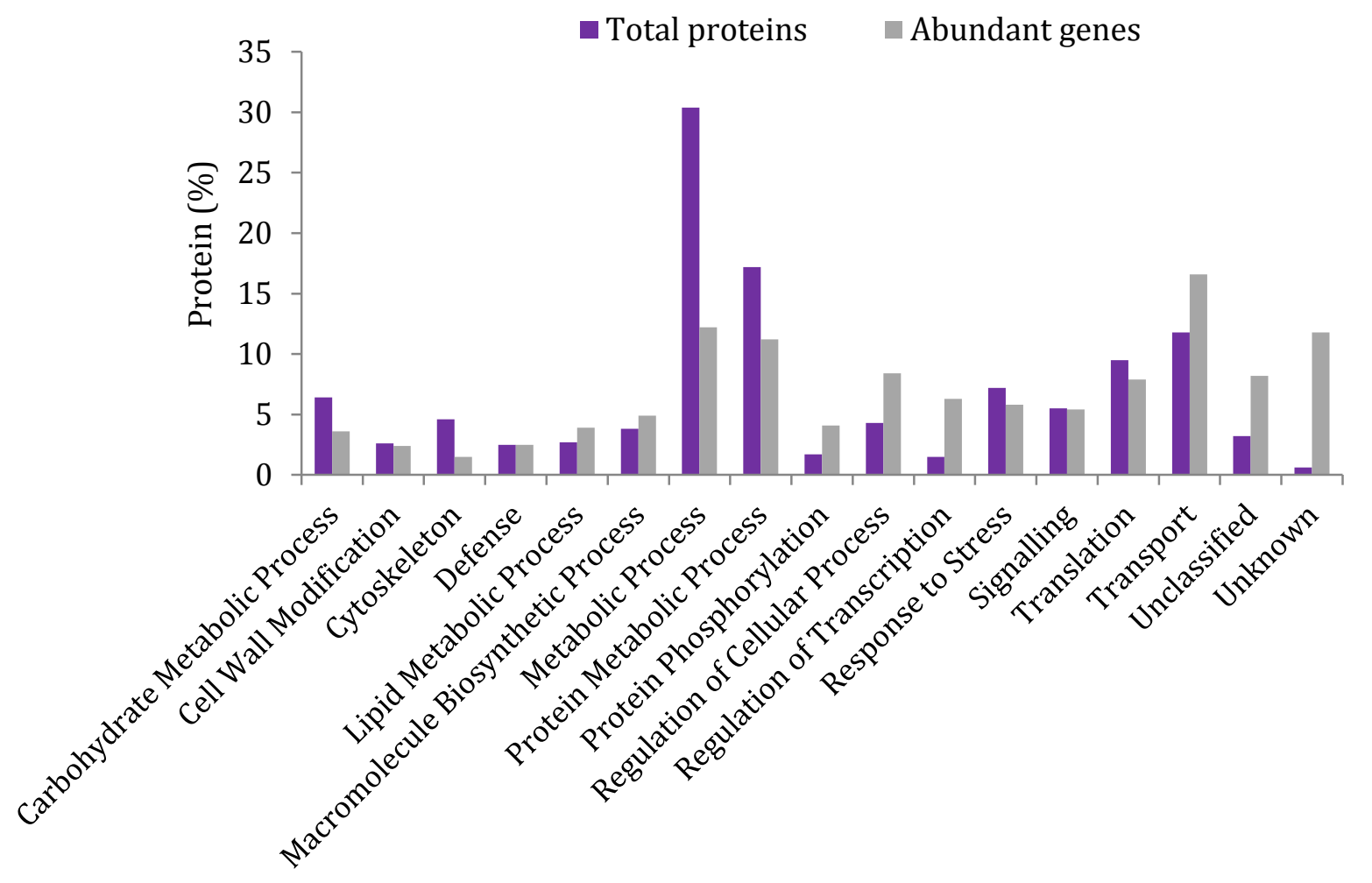

Figure 2-9. Comparison of the functional distribution of the 2184 proteins and most abundantly expressed genes in the triticale mature stigma. Triticale proteins and genes were annotated manually and an individual protein or gene is not found in more than one Metabolic Process category. 


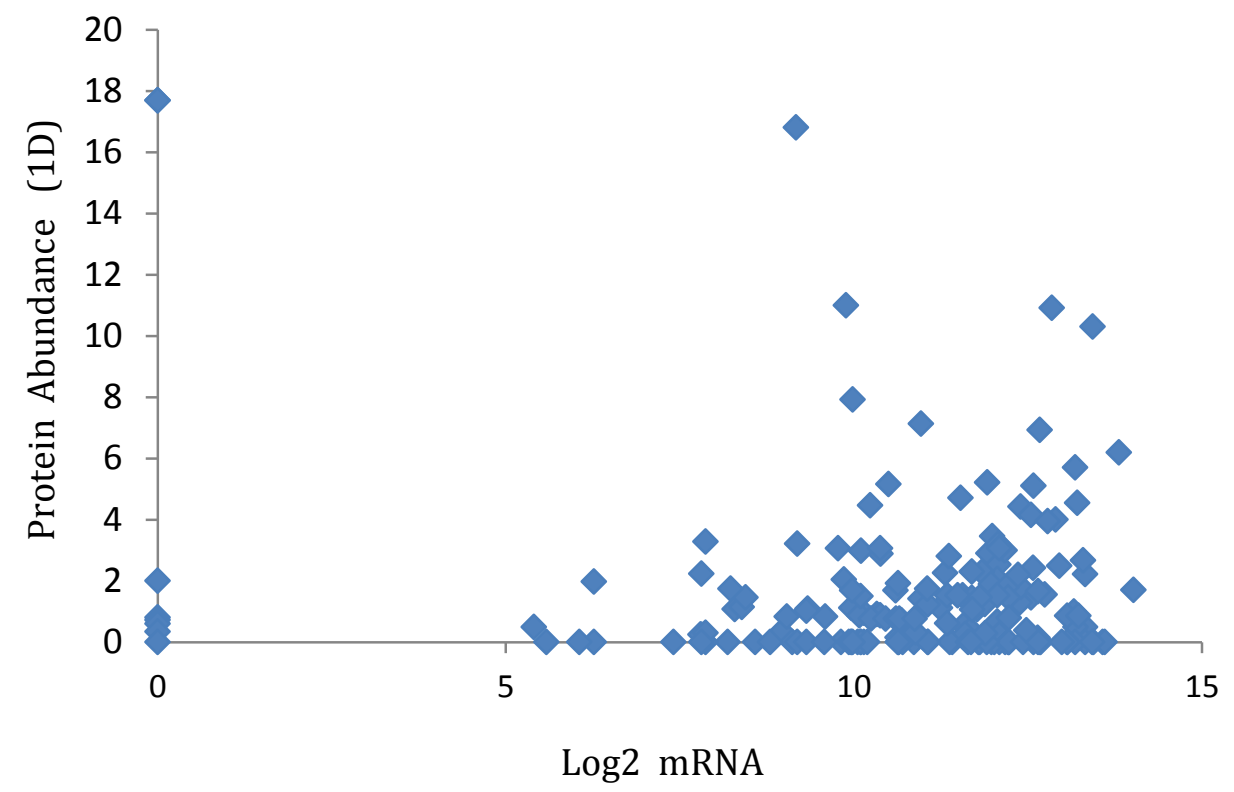

Figure 2-10. Comparison of triticale mature stigma protein and mRNA abundance.

Protein quantification was performed using the normalized data from the 1D SDS PAGE LCMS/MS (1D) analyses. The expression levels represent the $\log _{2}$ of the normalized expression values obtained from microarray analysis for the corresponding proteins. Pearson correlation coefficient $\mathrm{R}^{2}=0.267$ 


\section{Chapter 3}

\section{Analysis of the Brassica napus Stigma Proteome Reveals Numerous Proteins Involved in Cellular and Organ Development}

\subsection{Introduction}

In angiosperms, reproductive development relies on successful pollen-stigma interactions. The stigma, the specialized receptive portion of the female organ, plays key roles in pollen capture, discrimination, hydration, germination, and guidance (Hiscock and Allen, 2008). It can vary both structurally and functionally among species and has been classified into two main types: wet and dry stigmas (Heslop-Harrison and Shivanna, 1977). In species with wet stigmas, such as in the Solanaceae and Liliaceae, a liquid exudate containing mainly lipids and/or carbohydrates and proteins is secreted onto the epidermal surface. In contrast, in dry stigma species, such as in the Brassicaceae and Poaceae, their epidermal cells are covered by a waxy cuticle coated by a proteinaceous pellicle and pollenstigma interactions are more actively regulated. Members of the latter two families illustrate well the extent of morphological variations observed with dry stigmas when comparing the plumose form observed within the Poaceae which is adapted to capture wind dispersed pollen (anemophily) and the unicellular papillate dome-shaped form of the Brassicaceae where the heavier pollen grain is usually carried by insects (entomophily). 
Furthermore, members of the Poaceae species can exhibit gametophytic SI, whereas Brassicaceae SI is sporophytic (Heslop-Harrison and Shivanna, 1977).

The detailed molecular processes underlying the development and function of the dry stigma are still being elucidated with the study of SI in the Papaveraceae and Brassicaceae having made considerable progress (Peer, 2014). Few transcriptional profiling studies specific to the Brassica dry stigma have been reported. Recently, a combination of laser microdissection and RNA-seq of stigma papillar cells from A. thaliana, A. halleri and B. rapa revealed that although differences existed, the three species share a large proportion of genes involved primarily in metabolic processes, transcription regulation, oxidation-reduction processes, translation, phosphorylation, and transport (Osaka et al., 2013). In addition, a Brassica microarray analysis identified 287 differentially expressed stigma genes associated with early responses following compatible or selfincompatible pollinations (Sankaranarayanan et al., 2013a).

Although significant advances have been made in the characterization of the Brassicaceae stigma transcriptome, there remains a large gap in our knowledge of its proteome. Given the poor correlation demonstrated between floral mRNA and protein abundance (Feng et al., 2009; Chapter 2), and the fact that transcriptomic studies provide limited information regarding post-translational modifications, protein localization and protein-protein interactions, the study of the proteome can reveal insights which cannot be predicted from knowledge of the transcriptome. As effectors of development and function, proteins thus provide a more accurate representation of cellular state. A number of studies have focused on the proteins involved in Brassicaceae SI (Sankaranarayanan et al., 2013b), 
but there are no reports attempting to describe the global proteome of the Brassicaceae stigma.

In this report, Brassica napus serves as a representative of the Brassicaceae and the proteome of its dry mature stigma was analyzed using 1D SDS PAGE LC-MS/MS, 2D IEF/SDS PAGE LC-MS/MS and OGE LC-MS/MS. These results are compared directly to those obtained (Chapter 2) in an equivalent study of the dry mature stigma of triticale a representative member of the Poaceae.

\subsection{Materials and methods}

\subsubsection{Plant material}

The double haploid B. napus line, DH12075 (Rakow, G. and Séguin-Swartz, G., Agriculture and AgriFood Canada) was grown in growth cabinets under a 16h/8h day-night cycle at $22^{\circ} \mathrm{C}$. Mature stigmas were manually dissected with a scalpel just before anthesis and individually inspected for the presence of contaminating style tissue or pollen before being flash frozen in liquid nitrogen.

\subsubsection{Protein analysis}

B. napus stigma proteins were extracted using either SDS-PAGE or IEF loading buffers as previously described (Chapter 2). Frozen stigmas were ground to a fine powder on dry ice and the frozen powder was immediately suspended in 1X SDS-PAGE loading buffer (10\% glycerol, 2\% SDS, $100 \mathrm{mM}$ DTT, 1\% bromophenol blue and $60 \mathrm{mM}$ Tris- $\mathrm{HCl}$, pH 6.8) and sonicated $3 \mathrm{X}$ for $10 \mathrm{~s}$ using an Ultrasonic Homogenizer 4710 series (ColeParmer, Montréal, Canada). After centrifugation at $27200 \mathrm{~g}$ for $10 \mathrm{~min}$ at $18^{\circ} \mathrm{C}$, the 
supernatant was transferred to another tube and heated for 5 min at $95^{\circ} \mathrm{C}$ prior to $1 \mathrm{D}$ SDS-

PAGE. For the IEF loading buffer extraction, the frozen powder was immediately suspended in sample buffer (8 M Urea, $2 \mathrm{M}$ thiourea, 2\% CHAPS, 0.1\% ampholytes ( $\mathrm{p} I$ range 3-10), $50 \mathrm{mM}$ DTT, $0.0005 \%$ bromophenol blue) and incubated at room temperature (RT) on a rotator overnight. The sample was then sonicated 3 X $10 \mathrm{~s}$ and centrifuged at 48 $000 \mathrm{~g}$ for $15 \mathrm{~min}$ at $4{ }^{\circ} \mathrm{C}$. Total protein concentrations were determined with the Bio-Rad protein assay kit (Bio-Rad, Mississauga, Canada) according to the manufacturer's instructions.

\subsubsection{D SDS PAGE LC-MS/MS}

B. napus Stigma proteins ( $45 \mu \mathrm{g}$ ) extracted with SDS-PAGE loading buffer were submitted to the McGill University Genome Québec Innovation Centre (http://gqinnovationcenter.com) where the protein sample was loaded on a $2.4 \mathrm{~cm}$ 1D SDS-PAGE gel with a 7 to $15 \%$ acrylamide gradient. The gel was stained with CBB G (Figure 2-1) and the entire lane was excised into15 bands which were further sub-divided into 6-7 pieces using a Protein Picking Workstation ProXCISION (PerkinElmer, Shelton, USA). Gel pieces were subjected to reduction, cysteine-alkylation and in-gel tryptic digestion in an automated MassPREP Workstation (Micromass, Manchester, UK) as previously described (Wasiak et al., 2002). Briefly, gel pieces were prewashed (100 $\mu$ l HPLC grade water for 10 min), destained ( $50 \mu \mathrm{l}$ of $100 \mathrm{mM}$ ammonium bicarbonate and $50 \mu \mathrm{l}$ of $100 \%$ acetonitrile for $5 \mathrm{~min}$ ), reduced, and alkylated ( $50 \mu \mathrm{l}$ of $10 \mathrm{mM}$ dithiothreitol for $3 \mathrm{~min}, 50 \mu \mathrm{l}$ of $55 \mathrm{mM}$ iodoacetamide for $20 \mathrm{~min}$, and $100 \mu \mathrm{l}$ of $100 \%$ acetonitrile for $5 \mathrm{~min}$ ). Gel pieces were dehydrated ( $50 \mu \mathrm{l}$ of $100 \%$ acetonitrile for $5 \mathrm{~min})$, digested with $25 \mu \mathrm{l}$ of trypsin $(6 \mathrm{ng} / \mu \mathrm{l}$ in 
$50 \mathrm{mM}$ ammonium bicarbonate, Promega sequence grade modified trypsin, cat number V511A), and incubated for $30 \mathrm{~min}$ at $\mathrm{RT}$ followed by $4 \mathrm{~h} 30 \mathrm{~min}$ at $37^{\circ} \mathrm{C}$. The peptides were extracted $(30 \mu \mathrm{l}$ of an aqueous mixture containing $1 \%$ formic acid and $2 \%$ acetonitrile for 30 min at RT).

For LC MS/MS analysis, the peptides from each band were subjected to MS analysis. The 96-well sample tray was kept in Micro Well-plate Sampler (Agilent 1100 Series). Prior

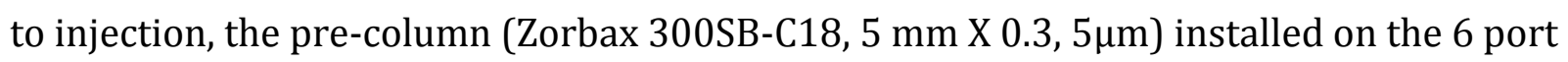
Rheodyne valve of the Column Compartment Module, was conditioned with water containing acetonitrile (3\%) and formic acid (0.1) supplied by an Isocratic pump (Agilent 1100 series) set at a flow rate of $15 \mu \mathrm{l} / \mathrm{min}$. A volume of $20 \mu \mathrm{l}$ of the tryptic digest solution was injected on the precolumn at $15 \mu \mathrm{l} / \mathrm{min}$ and the sample was washed for $5 \mathrm{~min}$ while the flow through was evacuated to waste. The valve was actuated and the peptides trapped on the pre-column were eluted to the $75 \mu$ i.d PicoFrit column (New Objective, Woburn, Ma) (filled with $10 \mathrm{~cm}$ of BioBasic C18 packing, $5 \mu \mathrm{m}, 300 \mathrm{~A}$ ) by the acetonitrile gradient supplied by the Agilent series 1100 Nanopump at $200 \mathrm{nl} / \mathrm{min}$. Solvent A was water (formic acid 0.1\%) and solvent B was acetonitrile: water: formic acid (97:3:0.1). The linear gradient was started after the washing step. At time 0 , solvent B was $10.5 \%$. It was set to reach $42 \% \mathrm{~B}$ at $45 \mathrm{~min}, 73.5 \% \mathrm{~B}$ at $53 \mathrm{~min}$ and $100 \% \mathrm{~B}$ for $2 \mathrm{~min}$ and brought back to $10.5 \%$ from 60 min to $72 \mathrm{~min}$.

The mass spectrometer was a Q-Tof micro ${ }^{\mathrm{TM}}$ from Waters Micromass equipped with a Nanosource modified with a nanospray adapter (New Objective, Woburn, MA) to hold the PicoFrit column spraying tip near the sampling cone. The capillarity voltage was adjusted 
to get the best spraying plume at $35 \% \mathrm{~B}$. The MS survey scan was set to $1 \mathrm{~s}(0.1 \mathrm{~s}$ interscan) and recorded from 350 to $1600 \mathrm{~m} / \mathrm{z}$. In a given MS survey scan all doubly and triply charged ions with intensity higher than 25 counts were considered candidates to undergo MS/MS. From these, the strongest one was selected. MS/MS acquisition stopped as soon as the total ion current reached 2800 counts/scan or after a maximum time of $4 \mathrm{~s}$. The MS/MS scan was acquired from 50 to $1990 \mathrm{~m} / \mathrm{z}$, scan time was $1.35 \mathrm{~s}$ and interscan was $0.15 \mathrm{~s}$. The next precursor ion was selected from the following MS survey scan. The doubly and triply charged selected ions were fragmented with the following preprogrammed collision energies: (i) for doubly charged ion, the collision energies are 25 $\mathrm{eV}$ for the range 400 to $653 \mathrm{~m} / \mathrm{z}, 26 \mathrm{eV}$ for the range 400 to $653 \mathrm{~m} / \mathrm{z}, 26 \mathrm{eV}$ for the range 653 to $740 \mathrm{~m} / \mathrm{z}, 28 \mathrm{eV}$ for the range 740 to $820 \mathrm{~m} / \mathrm{z}, 32 \mathrm{eV}$ for the range 820 to $1,200 \mathrm{~m} / \mathrm{z}$, and $55 \mathrm{eV}$ for the range 1,200 to $1,600 \mathrm{~m} / \mathrm{z}$. (ii) for triply charged ions, the collision energies are $14 \mathrm{eV}$ for the range 435 to $547 \mathrm{~m} / \mathrm{z}, 19 \mathrm{eV}$ for the range 547 to $605 \mathrm{~m} / \mathrm{z}, 24 \mathrm{eV}$ for the range 605 to $950 \mathrm{~m} / \mathrm{z}$, and $35 \mathrm{eV}$ for $\mathrm{m} / \mathrm{z}$ higher than $950 \mathrm{~m} / \mathrm{z}$.

Mass spectrometric data was acquired by employing the Data Directed Analysis (DDA) feature available on Mass Lynx (Micromass) operating software with a 1,2,4 duty cycle $1 \mathrm{~s}$ in MS mode 2 peptides selected for fragmentation, maximum of 4 second in MS/MS acquisition mode). Analysis was done in two steps. For the first step, acquisition was done by letting MassLynx choose the most intense precursor from the MS Survey scan. From the data for each injected sample, a list of precursor ions with their chromatographic retention times was then prepared and used as exclusion ions with their chromatographic retention times prepared and used as an exclusion list for a second analysis. Each sample was injected again and DDA was performed using the information provided by the 
exclusion list. This process enabled the mass spectrometer to collect data from precursors that were not acquired during the first analysis because they were not the most intense precursor of the scan. The DDA setting was as above except for the exclusion option for which the following feature were activated. The precursor $m / z$ was excluded within \pm $1900 \mathrm{mDa}$ of the entries on the exclusion list. Furthermore, the $m / z$ was also chromatographically excluded for a time window of $\pm 75 \mathrm{~s}$ of the retention time registered during the first analysis. MS/MS raw data were transferred from the Q-Tof micro ${ }^{\mathrm{TM}}$ computer to a 50 terabytes server and automatically manipulated for generation of peak lists by employing Distiller version 2.3.2.0 (http://www.matrixscience.com/disttiler.htmls) software with pick parameter set at 5 as for Signal Noise Ratio (SNR) and at 0.4 for Correlation Threshold (CT).

\subsubsection{D IEF/SDS PAGE LC-MS/MS}

For 2D gels, stigma proteins extracted with IEF loading buffer $(100 \mu \mathrm{g})$ were first separated on a $17 \mathrm{~cm} \mathrm{pH} \mathrm{3-10} \mathrm{gradient} \mathrm{using} \mathrm{the} \mathrm{PROTEAN} \mathrm{IEF} \mathrm{system} \mathrm{(Bio-Rad)} \mathrm{according}$ to the manufacturer's instructions. After IEF, strips were first equilibrated for 20 min in 6 M urea, 2\% DTT, $375 \mathrm{mM}$ Tris- $\mathrm{HCl} \mathrm{pH} 8.8$ and then for another $20 \mathrm{~min}$ in the same solution containing $135 \mathrm{mM}$ iodoacetamide instead of 2\% DTT. SDS-PAGE was performed in a $12 \%$ acrylamide gel using the PROTEAN II XI Cell system (Bio-Rad) at a constant voltage of $77 \mathrm{~V}$. The gels were stained with CBB R-250 and gel images were captured with a scanner Astra 2400 SLT (UMAX, Dallas, USA) or Gel Doc XR+ (Bio-Rad). Three 2D gel replicates gave consistent results (Figure 2-2). A total of 170 individual protein spots were excised manually from CBB stained gels and submitted to the Québec Genomics Center 
(http://proteomique.crchul.ulaval.ca/en/index.html) for MS. Briefly, the excised proteins were automatically de-stained, dehydrated, reduced with $10 \mathrm{mM}$ DTT, alkylated with 55 mM iodoacetamide, and digested with $105 \mathrm{mM}$ of modified porcine trypsin (Sequencing grade, Promega, Madison, WI) at $58^{\circ} \mathrm{C}$ for $1 \mathrm{~h}$ using a MassPrep liquid handling robot (Waters Corporation). Digestion products were extracted using 1\% formic acid, 2\% acetonitrile followed by $1 \%$ formic acid, $50 \%$ acetonitrile and the recovered extracts were pooled, lyophilized and then resuspended into $7 \mu \mathrm{l}$ of $0.1 \%$ formic acid. A peptide sample volume of $2 \mu \mathrm{l}$ was separated by online RP nanoscale capillary liquid chromatography (nanoLC) using a PicoFrit column (New Objective, Woburn, MA) packed with Jupiter

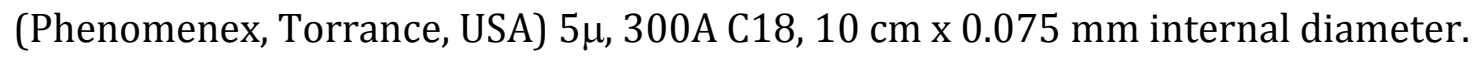
Peptides were eluted with a linear gradient from 2-50\% solvent B (acetonitrile, 0.1 formic acid) for $30 \mathrm{~min}$ at $200 \mathrm{~nL} / \mathrm{min}$ (obtained by flow-splitting) and analyzed by ESI MS/MS. The experiments were performed with a Thermo Surveyor MS pump connected to a LTQ Linear Ion Trap Mass Spectrometer equipped with a nanoelectrospray ion source (ThermoFisher Scientific, San Jose, USA). Mass spectra were acquired using a data dependent acquisition mode using the Xcalibur software version 2.0. Each full scan mass spectrum (400 to $2000 \mathrm{~m} / \mathrm{z}$ ) was followed by collision induced dissociation of the seven most intense ions. The dynamic exclusion (30 s exclusion) function was enabled and the relative collisional fragmentation energy was set at 35\%.

\subsubsection{OFFGEL Electrophoresis (OGE) LC-MS/MS}

B. napus stigma proteins ( $50 \mu \mathrm{g}$ ) extracted with IEF loading buffer were sent to BioProximity Proteomics Services (http://www.bioproximity.com). The protein sample 
was processed using the filter-assisted sample preparation (FASP) method (Wiśniewski et al., 2009). Briefly the sample was brought to $6 \mathrm{M}$ urea, $100 \mathrm{nM}$ Tris- $\mathrm{HCl}, \mathrm{pH} 7.6,3 \mathrm{mM}$ DTT, transferred to a $30 \mathrm{k}$ Amicon MWCO device (Millipore), and centrifuged at $13000 \mathrm{~g}$ for 30 min. The remaining sample was buffer exchanged with $6 \mathrm{M}$ urea, $100 \mathrm{mM}$ Tris- $\mathrm{HCl}, \mathrm{pH} 7.6$, alkylated with $30 \mathrm{mM}$ iodoacetamide, digested at a 1:40 trypsin to substrate ratio, and incubated overnight at $37^{\circ} \mathrm{C}$. Digested peptides were desalted using C18 stop- and- go extraction (STAGE) tips (Rappsilber et al., 2007), conditioned with $60 \%$ acetonitrile, $0.5 \%$ acetic acid followed by 5\% acetonitrile, $0.5 \%$ acetic acid, and desalted with $0.5 \%$ acetic acid. Peptides were eluted with $60 \%$ acetonitrile, $0.5 \%$ acetic acid and lyophilized in a SpeedVac (Thermo Savant) for $2 \mathrm{~h}$. Peptides were then fractionated for $24 \mathrm{~h}$ by OFFGEL isoelectric focusing using an Agilent OFFGEL device (Agilent Technologies Inc.) with a 24 cm pH 3-10 IPG strip in conjunction with a 24-well tray according to the manufacturer's instructions. Each fraction was desalted as above and analyzed by LC-MS/MS. LC was performed using an Easy Nano-LC II HPLC (ThermoFisher Scientific). Mobile phase A was 94.5\% MilliQ water, 5\% acetonitrile, and 0.5\% acetic acid. The 120 min LC gradient ran from 5\% A to 35\% B for $90 \mathrm{~min}$. The samples were first loaded to a $2 \mathrm{~cm}$ x 100 um I.D. trap column and then to $13 \mathrm{~cm} \times 100 \mu \mathrm{m}$ I.D. analytical columns. Both columns were packed with 3.5 um C18 resin (Zorbax SB-Agilent Technologies Inc.). The LC was interfaced to a LTQ Velos Dual-Pressure Linear Ion Trap mass spectrometer (ThermoFisher Scientific) via nano-electrospray ionization (Voltage $1.8 \mathrm{kV}$ ). The mass spectrometer was programmed to acquire, by data-dependent acquisition, tandem mass spectra from the top 15 ions in the full scan from 400-1400 m/z. Dynamic exclusion was set to $30 \mathrm{~s}$. 


\subsubsection{Data analysis}

Peptide mass spectra were analyzed using Mascot version 2.3.0

(http://www.matrixscience.com) and X! Tandem version 2007.01.011

(www.thegpm.org/tandem/) to search the Universal Protein Resource (UniProt)

Viridiplantae database, whereas Scaffold version 4.0.4 (Proteome software Inc., Portland, OR, USA) was used to validate MS/MS based peptide and protein identifications as previously described (Chapter 2). B. napus and triticale annotations were performed with BLAST2GO (WWW.blast2go.com) using the top 20 hits at $1 \mathrm{e}-30$ and the NCBI nonredundant protein sequence (nr) database. Each Biological Process BLAST2GO annotation was assigned to a Biological Process category using the 'Inferred Tree View' option in AmiGO 2 (http://amigo.geneontology.org). Since this classification depended directly on the BLAST2GO results, a protein could be found in multiple Metabolic Process categories (Table 3-1) unlike the manual annotations used in Chapter 2. Proteins with no significant matches were classified as 'unknown', whereas proteins matching known proteins or domains but without an associated biological process were considered 'unclassified'. To identify the proteins involved in glucosinolate metabolism, isoprenoid metabolism, photosynthesis or self-incompatibility, the Arabidopsis loci best matching the entire $B$. napus protein dataset were analyzed using the Princeton GO Term Finder (http://go.princeton.edu/cgi-bin/GOTermFinder) using the Arabidopsis thaliana annotations at $1 \mathrm{e}-10$. 


\subsection{Results and discussion}

\subsubsection{Comparison of 1D SDS PAGE LC-MS/MS, 2D IEF/SDS PAGE LC-MS/MS and OGE LC-} $M S / M S$

In order to investigate the B. napus mature stigma proteome, 1D SDS PAGE LCMS/MS, 2D IEF/SDS PAGE LC-MS/MS and OGE LC-MS/MS analyses were performed and identified 486, 1739, and 434 proteins respectively for a total of 2275 proteins (Table 3-1). Only 51 proteins were identified by all three approaches (Figure 3-3). These results are very similar to an equivalent proteome analysis performed on triticale mature stigmas suggesting that the number of proteins identified is independent of the source species of the dry stigmas. However, comparison of the B. napus stigma 2D protein gel with that obtained for triticale (Figure 3-4) showed clear differences in the spot pattern with most proteins occurring in a narrower $\mathrm{p} I$ range. The vast majority of the $B$. napus stigma proteins identified had a very close match to specific Arabidopsis thaliana proteins (Table 3-1) allowing further insight into their potential roles.

\subsubsection{Functional classification of B. napus stigma proteins}

The B. napus proteins were classified into different functional categories with the major groups being Metabolic Process, Response to Stimulus or Stress, Protein Metabolic Process, Cellular or Developmental Process, and Transport, a pattern very similar to that obtained with triticale (Figure 3-5). These results indicate a significant level of conservation in the broad functional aspects of these two types of dry stigmas probably reflecting their highly conserved role in plant reproduction. It should be mentioned that in order to allow a direct comparison with B. napus results, the triticale proteins were 
classified using a different approach to that used in the previous work (Tran et al. 2013, Chapter 2) which relied on conservative manual annotations. One of the major differences between the two approaches is the higher representation of the B. napus categories Response to Stimulus and Response to Stress likely resulting from the fact that nearly $60 \%$ of the proteins showed 'response to cadmium ion' and 'response to salt stress' respectively, which would not have figured in the conservative annotation. Given that many of the pollen-stigma interactions are extracellular, the proteins were analyzed for the presence of a signal peptide. A total of $170(8.1 \%)$ B. napus stigma proteins were found to possess a signal peptide and their functional distribution is compared to that of triticale in Figure3-6 Similarities with triticale are evident both in the proportion of proteins with a signal peptide which was $7.9 \%$ for triticale (Chapter 2 ) and in functional trends except maybe for Signalling and Cell Wall Modification.

\subsubsection{B. napus stigma proteins involved in development}

In this study, B. napus stigmas were collected just prior to pollination and at this stage the papillar cells have fully expanded and stigma proteins should therefore reflect the final phase of papilla maturation and/or the initial phase of pollen-stigma interactions. There is very little information about the proteins involved in the formation of the Brassicaceae stigma and this study revealed many proteins known to have roles in development although primarily demonstrated in other tissues (Table 3-1). The discussion will mostly focus on examples of B. napus stigma proteins with known corresponding Arabidopsis developmental mutants. 
Given that the B. napus stigma consists essentially of a highly specialized epidermal layer, proteins shown to be implicated in determining cell number, size and morphology may be particularly relevant to Brassicaceae stigma development. A number of proteins were identified whose mutations are known to affect cell number and compensatory expansion including ribosomal proteins RPL5A/OLIGOCELLULA(OLI)5 and RPL5B/OLI7 (Fujikura et al., 2009), 26S proteasome subunits RPT2A, RPN10 and RPN12A (Kurepa et al., 2009), pyrophosphatase ACP1/FUGU5 (Ferjani et al., 2013) and transcriptional coactivator ANGUSTIFOLIA(AN)3/GIF1 shown recently to move from leaf mesophyll to epidermal cells where it influences cell proliferation (Kawade et al., 2013). The cytoskeleton affects cell morphogenesis and proteins affecting microtubules included KATANIN(KTN)1/BOT1/FTR2/FRA2/ERH3/FRC2/LUE1 involved in microtubule disassembly (Burk et al., 2001), TORTIFOLIA(TOR)2 a tubulin mutant showing altered cell torsions (Buschmann et al., 2009), KIESEL(KIS) a tubulin folding cofactor (Steinborn et al., 2002), and MICROTUBULE-ASSOCIATED PROTEIN(MAP)65-1 important to axial cell growth (Lucas et al., 2011). The cell wall is also a major determining factor in cellular phenotype and proteins involved in cell wall modification included cellulose synthase A(CESA)3/RADIALLY SWOLLEN (RSW)5/CEV1/ELI1/IXR1/MRE1 and alpha-1,3 glucosidase/RSW3/PSL5 (Wang et al., 2006), V-ATPase subunit VHA-C/DEETIOLATED(DET)3 (Ferjani et al., 2013), novel plasma membrane protein KOBITO(KOB)1/ELD1/ABI8 (Pagant et al., 2002), DIMINUTO(DIM)1/DWF1/CBB1 a protein involved in brassinosteroid biosynthesis affecting cell elongation (Hossain et al., 2012), as well as FERONIA(FER) a receptor-like protein kinase important to cell wall metabolism and growth (Lindner et al., 2012) also detected in the triticale stigma proteome 
(Chapter 2). The cellulose synthase-interactive protein (CSI)1/POM-POM(POM)2 which functionally links microtubules and cellulose synthase (Bringmann et al., 2012) was also present in the mature stigma.

Many additional B. napus stigma proteins associated with the cytoskeleton and cell wall modification were identified (Table 3-1) and these are likely to participate in papillar cell development and/or facilitate pollen tube penetration and growth through the stigma. In fact, several B. napus stigma proteins have been demonstrated to function in unidimensional cell growth and more specifically root hair elongation and pollen tube growth. Examples of proteins involved in root hair development include SHAVEN3LIKE(SVL)1 a glycerophosporyl diester phosphodiesterase-like protein important to cell wall organization and epidermal cell development (Hayashi et al., 2008), ROOT EPIDERMAL BULGER(REB)1/RHD1 a UDP-glucose 4-epimerase (UGE4) that implicates arabinogalactan proteins and microtubules in root epidermal cell phenotype (AndèmeOnzighi et al., 2002), PHOSPHATE DEFICIENCY ROOT HAIR DEFECTIVE(PER)1/TTN6 a ubiquitin-specific protease (UBP14) affecting root hair elongation and epidermal cell differentiation in a phosphate-dependent manner (Li et al., 2010) and REPRESSOR OF LRX1(ROL1) a UDP-L-rhamnose synthase (RHM1) involved in flavonol glycosylation that suppresses the root hair mutant Irx1 (Ringli et al., 2008). Proteins involved in pollen tube growth included CELL DIVISION CONTROL(CDC)48A an endoplasmic reticulum ATPase participating in protein turnover (Park et al., 2008), NUCLEOREDOXIN(NRX)1 which possibly links pistil signals to pollen tube growth (Qin et al., 2009), MIRO-RELATED GTPASE(MIRO)1 which regulates mitochondrial morphology and trafficking and is critical to pollen tube growth and megagametogenesis (Sørmo et al., 2011), and CADMIUM 
2+INDUCED(CDI) a putative nucleotide-diphospho-sugar transferase essential to pollen germination and tube growth (Li et al., 2012b).

Although the selected proteins described above are meant to exemplify proteins present in the B. napus mature stigma with a potential role in papillar cell and pollen tube development and expansion, numerous other proteins were identified that have been shown to play broader roles in vegetative and reproductive development. For example, proteins associated with mutant embryo phenotypes included 32 EMBRYO DEFECTIVE(EMB), 8 MATERNAL EFFECT EMBRYO ARREST(MEE), 8 PIGMENT DEFECTIVE EMBRYO(PDE), 3 EMBRYO SAC DEVELOPMENT ARREST(EDA), and 1 EMBRYO YELLOW(EYE) (Table S1). The proteins ASYMMETRIC LEAVES ENHANCER(AE)3/MOV34, SERRATE(SE), as well as PIGGYBACK(PGY)1 and PGY3 (Nakata and Okada, 2013) are all involved in abaxial/adaxial patterning. On the other hand, COP9 SIGNALOSOME(CSN)5A/AJH1, FUSCA(FUS)7 and Z-BOX BINDING FACTOR(ZBF)3 have roles in photomorphogenesis (Stratmann and Gusmaroli, 2012; Gangappa et al., 2013), whereas proteins such as FLOWERING LOCUS(FL)T, FLK and FVE have been demonstrated to influence flowering time (Lim et al., 2004).

To illustrate the potential role of phytohormones in stigma development, some proteins involved in auxin function will be described as auxin and its polar transport are known to be important to Arabidopsis gynoecium development (Larsson et al., 2013) and a function in triticale stigma development was recently supported by both microarray and proteome analysis (Tran et al., 2013; Chapter 2). The B. napus mature stigma exhibited several proteins involved in the asymmetrical localization at the plasma membrane of PIN- 
FORMED(PIN) auxin efflux carriers and in intercellular polar auxin transport such as BFAVISUALIZED ENDOCYTOTIC TRAFFICKING DEFECTIVE(BEN)1/BIG5/MIN7, BEN2/VPS45, BREFELDIN A-INHIBITED GUANINE NUCLEOTIDE-EXCHANGE PROTEIN(BIG)/UMB1/TIR3/CRM1, BIG3/EDA10, and CHARGED MULTIVESICULAR BODY PROTEIN(CHMP)1A (Löfke et al., 2013; Kania et al., 2014). As in triticale, both HEMIVENATA(HVE)/CAND1/ETA2 and AUXIN RESISTANT(AXR)1 which participate in auxin signaling and in development via CULLIN1 post-translational modification (Candela et al., 2007) were found in B. napus indicating a conserved role in these very different stigmas. Other proteins involved in auxin function can be found in Table S1 and some will be discussed below. It should also be mentioned that $\mathrm{ABA}$, jasmonic acid and salicylic acid were also well represented among the GO terms associated with the B. napus stigma proteins (Table 3-1).

The B. napus stigma clearly expresses numerous proteins with varied roles in development, but some also have known roles in gynoecium development. Examples of proteins with demonstrated roles in female gametophyte development include protein disulfide isomerase (PDI)11/PDIL2-1/MEE30/UNE5 involved in embryo sac maturation and pollen tube guidance (Wang et al., 2008), RNA splicing factor GAMETOPHYTIC FACTOR(GFA)1/CLOTHO that affects megagametogenesis and pollen tube growth (Coury et al., 2007), and the cysteinyl tRNA synthetase SYCO-1/FIONA necessary for central cell nuclei fusion (Kagi et al., 2010). Examples of proteins with roles in carpel development include HISTONE DEACETYLASE (HDA)19 shown to be part of a repressor complex with APETAL2 (AP2) and TOPLESS that restricts AGAMOUS expression and carpel identity specification (Krogan et al., 2012), ARGONAUTE(AGO)1 which associates with miR165/166 
and miR172 possibly repressing AP2 and plays a role in floral determinacy and carpel development (Ji et al., 2011), SHORT VALVE(STV)1/RPL24 which has been proposed to affect the apical-basal development of the gynoecium by permitting translation re-initiation of the ARF genes ETTIN and MONOPTEROS (Nishimura et al., 2005), and SNF1-RELATED PROTEIN KINASE(SNRK) subunit AKIN10 involved in carpel fusion (Tsai and Gazzarrini, 2012).

Some of the proteins also had demonstrated roles in stigma development such as RPL27A involved in carpel development and whose mutation causes ectopic stigmas (Szakonyi and Byrne, 2011), METHYLTHIOADENOSINE NUCLEOSIDASE(MTN)1 with $m$ tn11/mtn2-1 mutants having duplicated stigmas (Waduwara-Jayabahu et al., 2012), AUXIN RESPONSE FACTOR(ARF)8/FWF a transcription factor whose mutation causes parthenocarpy and that is involved in carpel development and can display shorter stigmatic papillae (Vivian-Smith et al., 2001), PROTEIN PHOSPHATASE 2A REGULATORY SUBUNIT A2(PP2AA2) which when mutated in the presence of another regulatory A subunit mutant, ROOTS CURL IN NAPHTHYLPHTHALAMIC ACID(RCN)1 yields shorter stigma papillae which may be unreceptive to pollen (Zhou et al., 2004), and AN3/GIF1 mentioned above, which along with GFI2 and GFI3, functions in the maintenance meristematic competence of the carpel margin meristem and affects gynoecium development and the timing of stigmatic papillae production (Lee et al., 2014).

The B. napus stigma evidently expresses numerous proteins whose mutation causes a wide variety of developmental defects and yet only a few examples have been reported to display a phenotype in the stigma. This may be the result of functional redundancy in a 
critical reproductive structure, as well as undetected or unreported minor phenotypes. Given that the proteomics approaches used in this study are likely biased towards abundant proteins, it is also possible that some of the mutants did not completely abolish the presence of the proteins in the stigma. The present work should greatly facilitate the identification and further analysis of developmental proteins with potential roles in stigma formation.

\subsubsection{Comparison of the Brassicaceae and Poaceae dry stigma proteomes}

There were numerous differences in the stigma proteins identified within the $B$. napus and triticale, however it will not be possible to ascertain whether these represent true distinctions until their proteomes are fully characterized. Nevertheless, some trends were evident and likely reflect genuine differences in the biology of these stigmas (Figure 3-7). For example, the B. napus stigma expressed nearly 50 different proteins associated with glucosinolate metabolism. Glucosinolates are sulfur-rich secondary metabolites typical of the Brassicales and they likely serve to protect the stigma from insects and pathogens (Sønderby et al., 2010). Some triticale proteins had G0 terms associated with glucosinolate metabolism and these are also known to participate in other metabolic activities.

Proteins involved in isoprenoid metabolism also seemed to be considerably enriched in the B. napus stigma. Many of these proteins are associated with carotenoid biosynthesis and are likely to contribute to the yellow colour acquired by the B. napus stigma as it matures, as opposed to the triticale stigma which essentially lacks pigmentation. With the exception of saffron (IqbaLMzr et al., 2013), carotenoid 
biosynthesis has received little attention in the stigma. Isoprenoids function as substrates for phytohormones (e.g. ABA, strigolactones) and signalling molecules, as well as in pollinator attraction, photoprotection and defense (Cazzonelli, 2011). For example, the sesquiterpene $(E)$ - $\beta$-caryophyllene produced by $A$. thaliana stigmas was shown to defend against bacterial pathogens which are often abundant on the stigma surface (Huang et al., 2012). Isoprenoids may serve all these functions in the Brassica stigma especially when it becomes exserted. Another difference between the triticale and B. napus stigmas was the presence of many more proteins involved in photosynthesis in the latter. Earlier in development, the B. napus stigma is green and apparently conserves proteins involved in photosynthesis even at maturity when it becomes yellow.

Lastly, stigma proteins associated with the Brassicaceae SI, SRK and SLG, were detected in B. napus and absent from triticale. This confirms the presence of these proteins in B. napus, shown previously by Western blot analysis (Haffani et al., 2004), and suggests that the self-compatible phenotype of the B. napus line used in this study rests with defects of the SCR protein the male SI determinant as is often the case (Okamoto et al., 2007). Although not involved in the SI response, SLR1 protein was also identified only in the $B$. napus stigma where, along with SLG, it is believed to facilitate pollen adhesion (Luu et al., 1999). There were other groups of proteins that were more prevalent in either the $B$. napus (e.g. carbonic anhydrases, long chain acyl-CoA synthetases, multicopper oxidases, putative methyltransferases) or the triticale (e.g. fasciclin-like arabinogalactan proteins, profilins) stigma, but a more in depth analysis of their proteomes will be required to validate these differences. 


\subsection{Concluding remarks}

In summary, this study represents the first global proteomic analysis of a Brassicaceae stigma. Even though emphasis was placed on proteins involved in development, many of the proteins identified are known to function in different aspects of stigma function including pollen-stigma interactions, as well as biotic and abiotic stress

tolerance. Comparison between dry stigmas from the Brassicaceae and Poaceae revealed conserved global functional trends as well as significant differences in protein composition. 
$\mathrm{MW}(\mathrm{kDa})$

3.

$\mathrm{p} I$

.10

250-

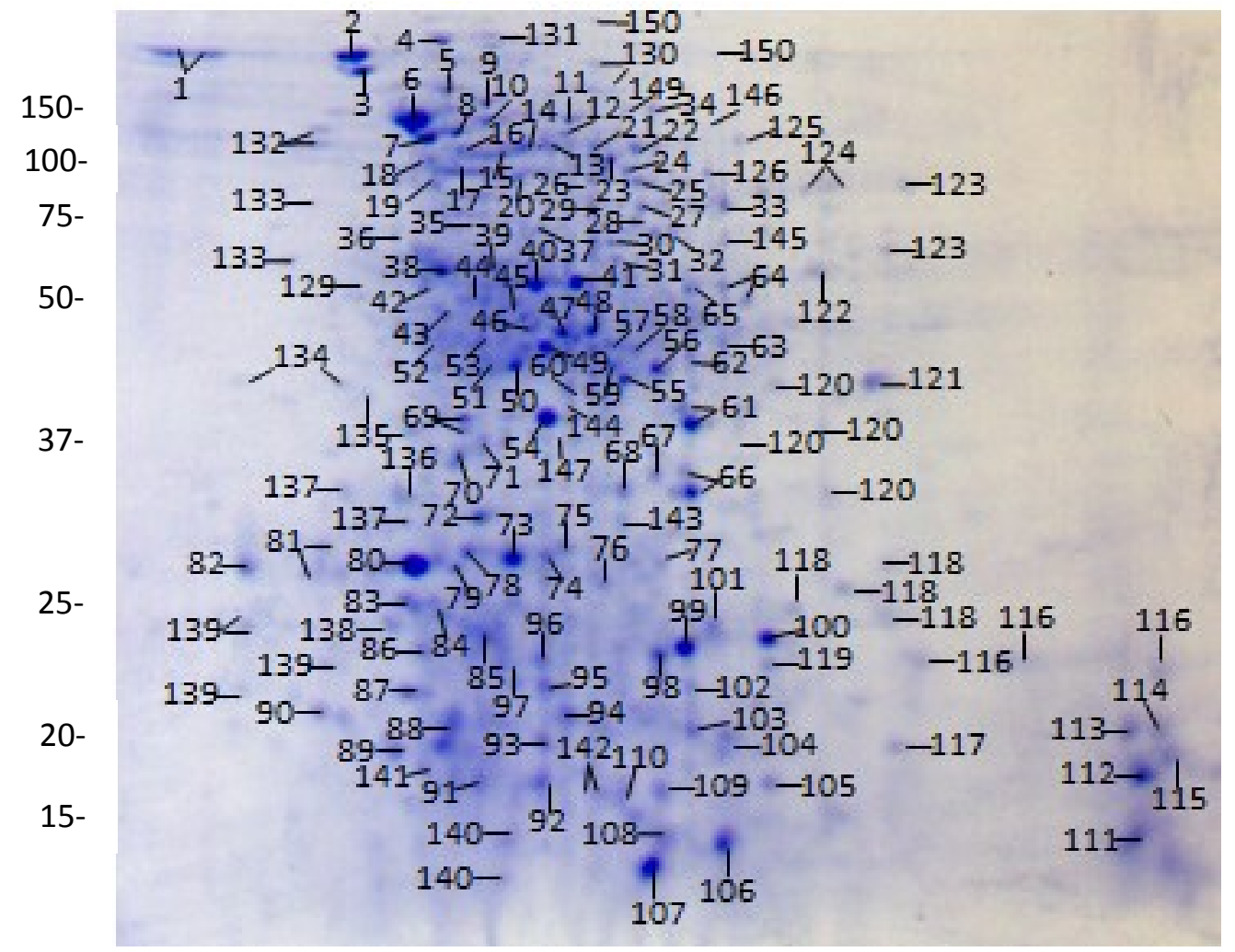

Figure 3-1. 2D IEF/SDS PAGE gel of B. napus mature stigma stained with CBB G. Molecular weight (MW) markers are shown in kilodaltons $(\mathrm{kDa})$ and the IEF isoelectric point (pI) range is shown at the top of the gel image. Three independent electrophoresis runs were performed from different B. napus stigma protein extractions. The derived data from each spot are presented in Table 3-1. 


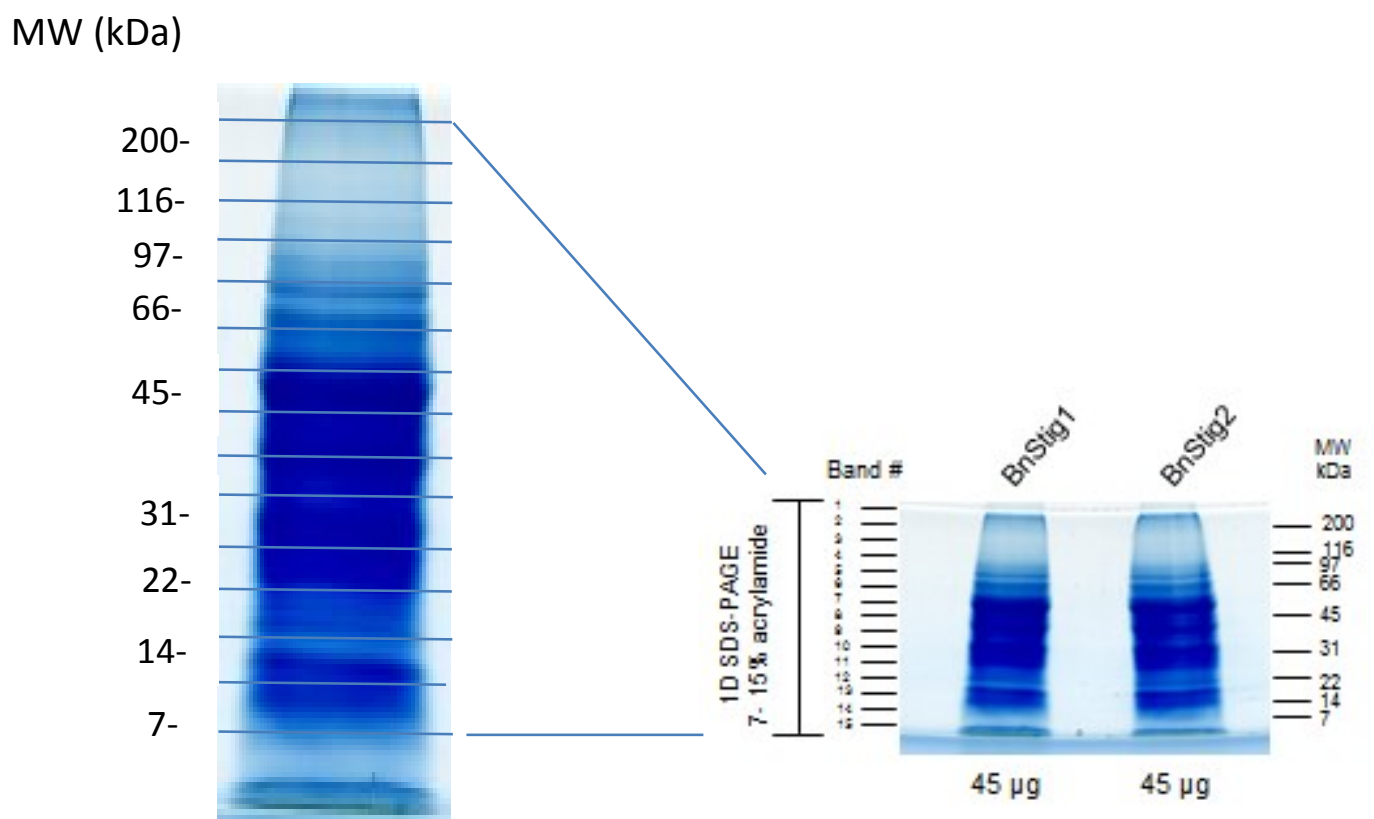

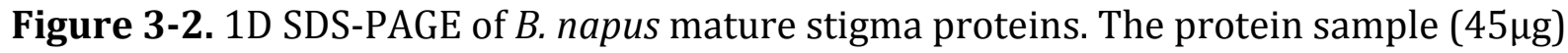
was electrophoresed on a $2.4 \mathrm{~cm}$ 1D SDS-PAGE with 7-15\% acrylamide gradient and stained with CBB G. The 15 gel bands that were excised for MS analysis are shown throughout the gel. Protein molecular weight (MW) markers in kilodaltons (kDa) are shown. BnStig- B. napus mature stigma sample. 


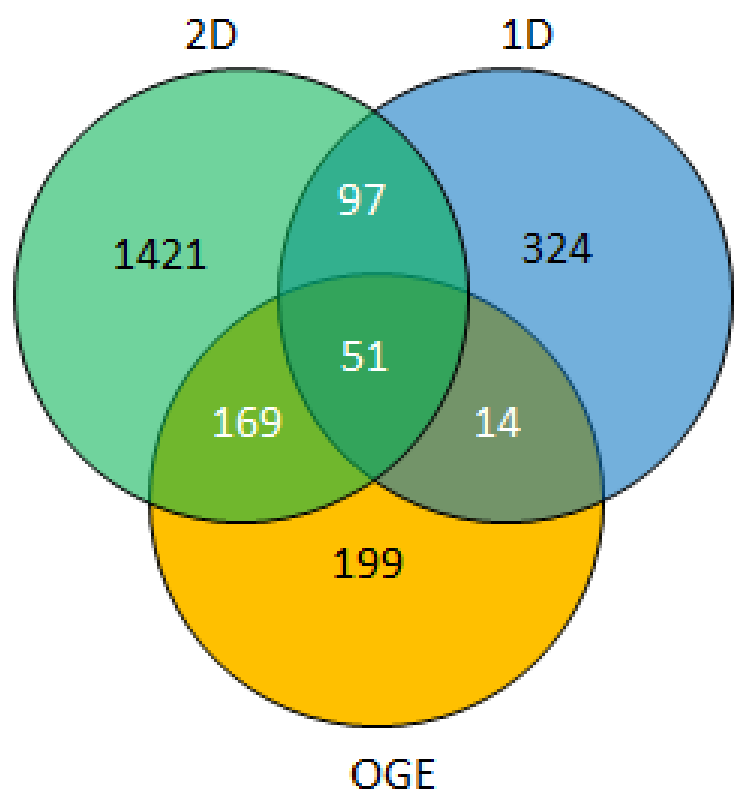

Figure 3-3. Venn diagram of the $B$. napus stigma proteins identified by the different methods of analysis. 2D: 2D IEF/SDS PAGE LC-MS/MS; 1D: 1D SDS PAGE LC-MS/MS; OGE: OGE LC-MS/MS. 
$\mathrm{MW}(\mathrm{kDa})$

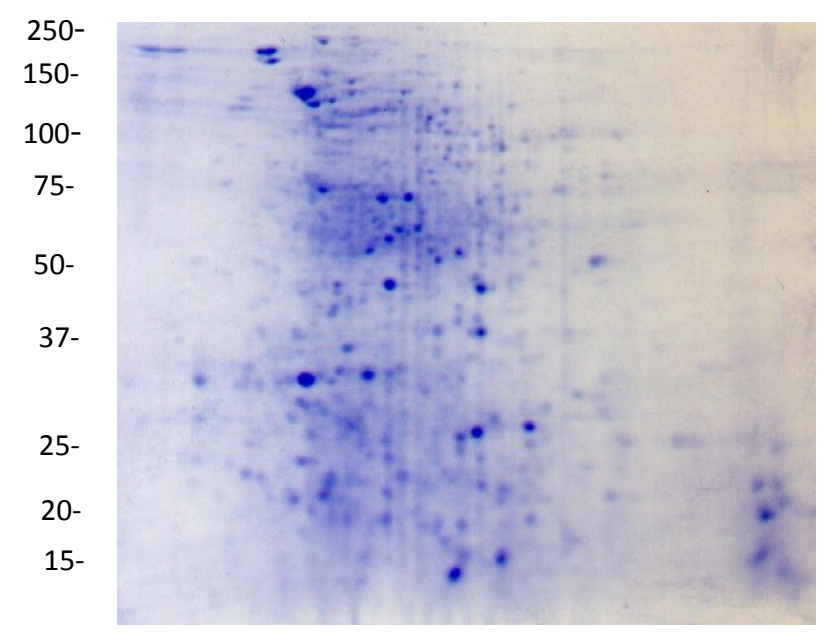

(A)
.10
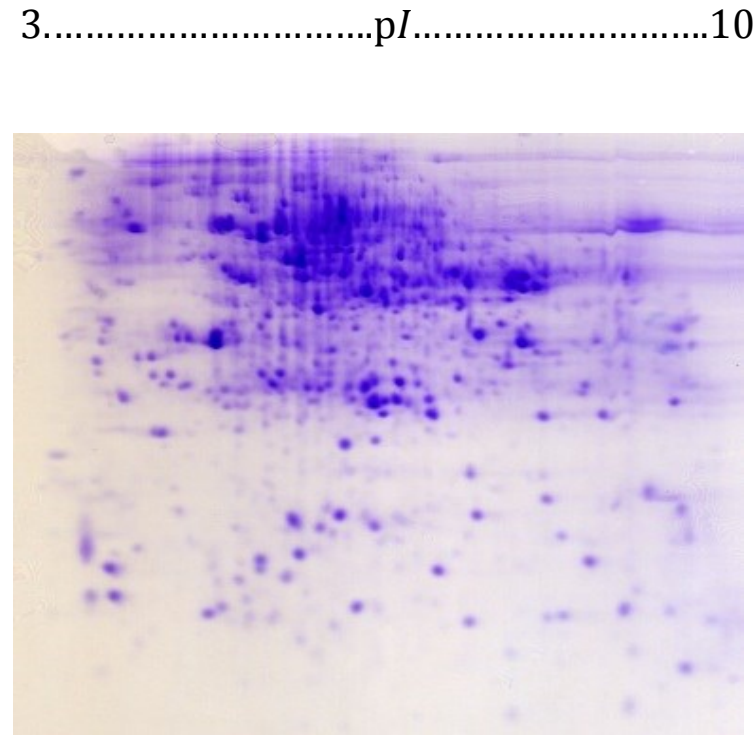

(B)

Figure 3-4. Comparison of the 2D maps of the B. napus (A) and triticale (B) mature stigma proteins. Proteins were separated by 2D IEF/SDS PAGE and stained with CBB G. The molecular weight (MW) markers are shown in kilodaltons (kDa) and the IEF isoelectric point $(\mathrm{p} I)$ range is indicated at the top of the gel image. 


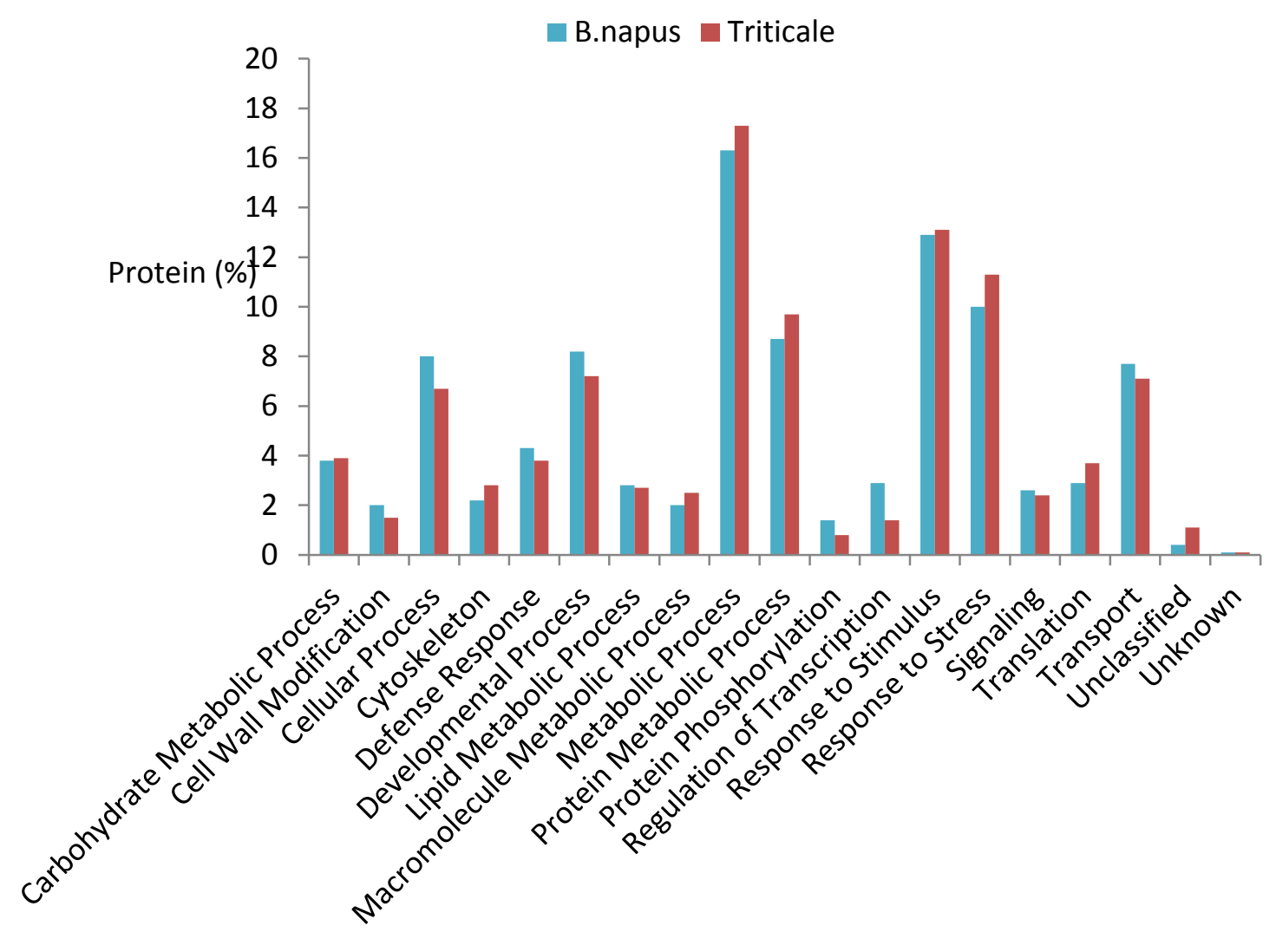

Figure 3-5. Comparison of the functional distribution of B. napus and triticale mature stigma proteins. Annotations were obtained using BLAST2GO of the NCBI nr database using the top 20 hits at 1e-30. Assignment of the protein annotations to the different categories was done using AMIGO 2. 


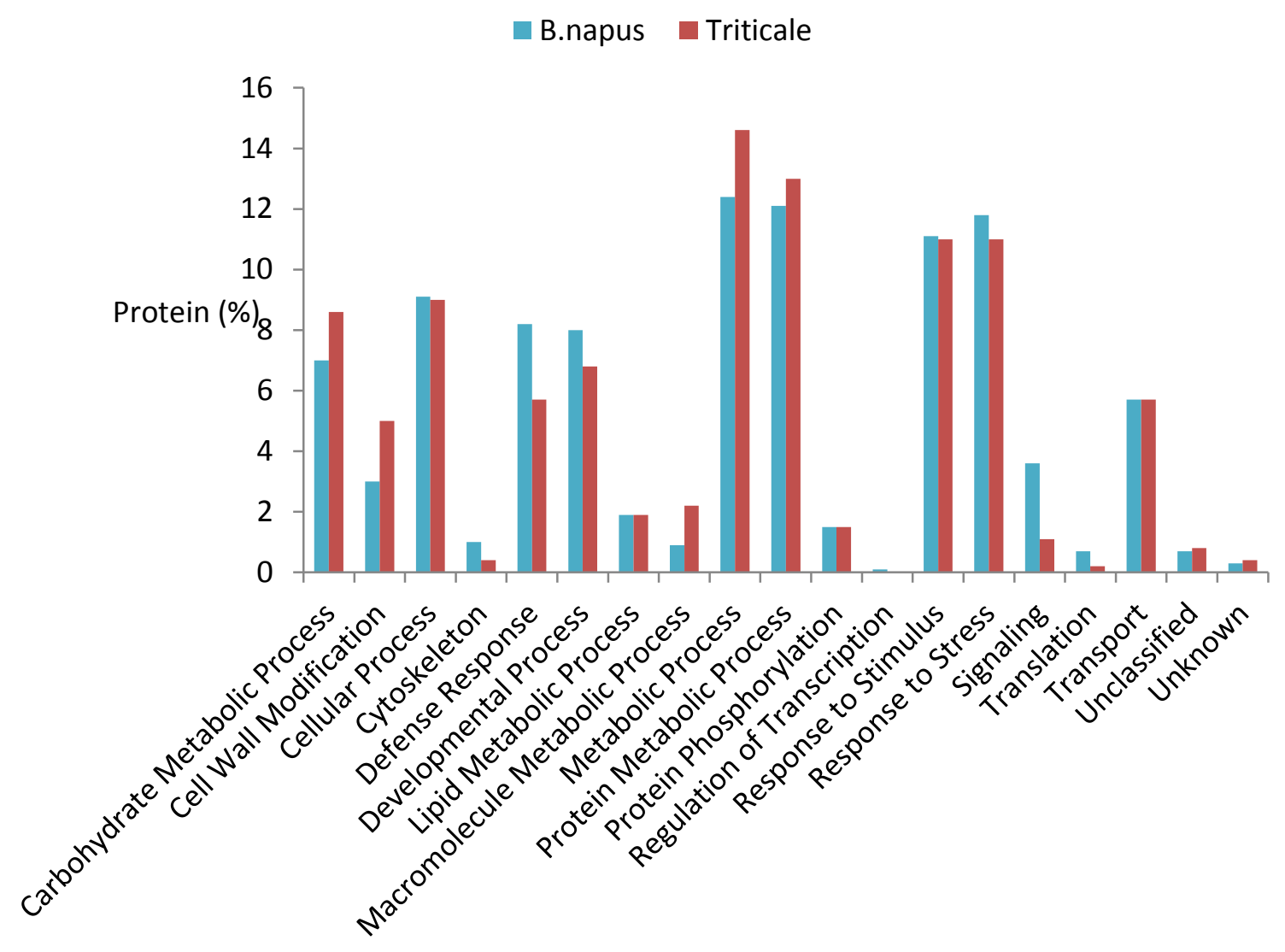

Figure 3-6. Comparison of the functional distribution of B. napus and triticale mature stigma proteins with a signal peptide. Annotations were obtained using BLAST2GO of the NCBI nr database using the top 20 hits at 1e-30. Assignment of the protein annotations to the different categories was done using AMIGO 2. 


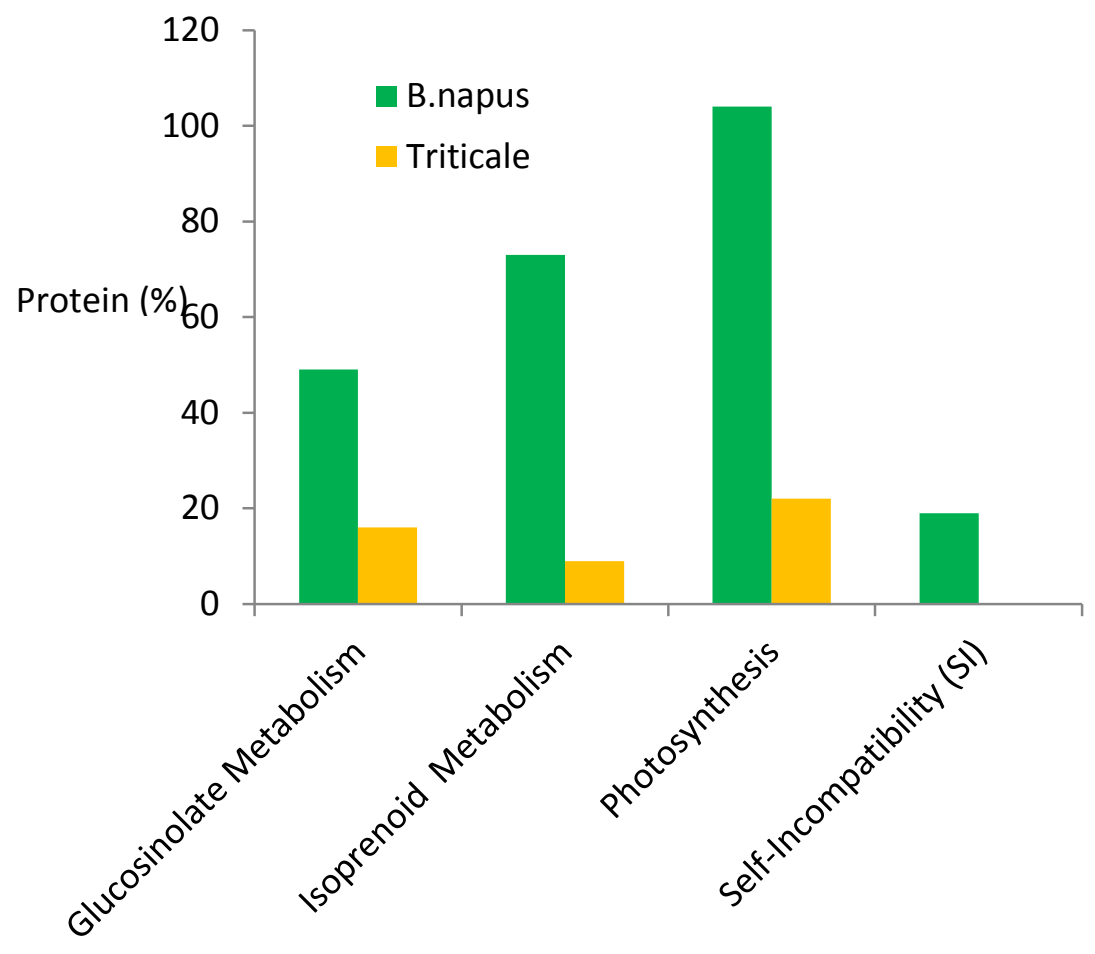

Figure 3-7. Differences between B. napus and triticale mature stigma proteins.

Proteins found in the different categories were identified using the Princeton GO Term Finder with the Arabidopsis thaliana annotations at 1e-10. 


\section{Chapter 4}

\section{General Discussion}

The female reproductive organ of flowering plants, which is located in the center of the flower, has specialized functions for successful pollination and seed development. Although it is a highly complex organ that differs widely in form among species, most of the different angiosperms have a set of common structures: stigma, style, and ovary. Among these structures, the stigma plays a key role in pollen binding and recognition, and participates in the induction of pollen germination. Incomplete or abnormal development of the stigma can cause female sterility or reduced fertility (Li et al., 2012c; Liu et al., 2012). Angiosperm stigmas are structurally very diverse and the surface adapted for pollen grain capture differs broadly. Little is known about the molecules involved in stigma development and pollen-stigma interactions across taxa.

In this thesis, the mature stigma of triticale and B. napus, which are representatives of the Poaceae and Brassicaceae, respectively, were selected for in depth proteomics investigations. The stigma surface of both species is dry, lacks fluid secretion, and is covered with a thin proteinaceous pellicle. Unlike the Brassicaceae, the Poaceae stigma epidermal papillae are covered with a discontinuous cuticle layer (Heslop-Harrison and Shivanna, 1977). The plumose stigma of the Poaceae displays gametophytic SI and is adapted to wind pollination and to enable rapid hydration and germination of the pollen grain (Russell and Dumas, 1992). In contrast, the Brassicaceae have a dome-shaped papillate stigma which is associated with sporophytic SI and insect pollination and 
responds a little more slowly to a pollination event (Shivanna et al., 1989). Although the differences between the morphology of these two dry stigmas are extremely obvious (Figure 1-6), pollen germination and tube growth proceed in much the same manner (Heslop-Harrison and Heslop-Harrison, 1982).

The aim of this thesis was to identify proteins in the triticale and B. napus dry stigmas and compare their functional distribution. Protein extraction procedures were optimized and different proteomics techniques, namely, 1D SDS PAGE LC-MS/MS, 2D IEF/SDS PAGE LC-MS/MS, and OGE LC-MS/MS were applied to maximize the number of identified proteins. All MS peptides spectra were searched against the UniProt Viridiplantae database using two search engines, MASCOT and X! Tandem, while the Scaffold proteomics software was used to validate identified peptides and proteins. In chapter 2, 2184 triticale mature stigma proteins were reported and their functional roles were discussed in three main areas: stigma development, pollen-stigma interactions and stigma protection against biotic and abiotic stress. Approximately $8 \%$ of the total number of triticale stigma proteins was predicted to contain a signal peptide which may indicate that at maturity only a small proportion of the proteins are present in readiness for pollination.

Numerous proteins with known roles in development were found in the triticale stigma including regulatory proteins such as transcription factors (TFs) and protein kinases, as well as proteins involved in various developmental processes including epigenetic mechanisms and photomorphogenesis. A significant number of triticale stigma proteins are likely to be involved in stigma cuticle formation and these include well characterized orthologs to Arabidopsis mutants affecting cuticle and epidermal cell 
development. The triticale mature stigma also expressed proteases and lipases that may facilitate pollen tube penetration. In addition, the triticale stigma proteome exhibited numerous cell wall modifying proteins including many glycosyl hydrolases, several expansins, as well as pectin modifying enzymes like pectinesterases and pectate lyase that may also enable pollen tube growth through the papillae cell wall. Pollen tube growth eventually becomes auxotrophic and reliant on nutrients and signals from the pistil, accordingly numerous proteins involved in transport were observed in the mature stigma making it the third largest functional category. There were also several examples of proteins involved in signalling although their role in pollen-stigma interaction often remains to be confirmed.

The Metabolic Process category contained a high proportion of triticale stigma proteins associated with redox processes and their role in the Triticeae stress response and pollen-stigma interactions mostly remains to be elucidated. The stigma is a critical reproductive structure that harbours the germinating pollen and the need for protection is demonstrated by numerous proteins involved in both biotic and abiotic stress responses. Almost half of the Protein Metabolic Process category was made up of proteins involved in chaperone activities, all of which may play a role in the stress response. The next largest group within this category was made up of proteins associated with the proteasome which not only mediates many developmental processes, but also plays a major role in plant responses to stress.

In this chapter, the functional distribution of triticale mature stigma proteins was also compared to that of the leaf proteome and it was found that Metabolic Process represented a larger proportion of the leaf proteome because of the contribution of 
photosynthetic proteins, while the stigma proteome was enriched in other categories including Cell Wall Modification, Cytoskeleton, Defense, Lipid, and Protein Metabolic Processes, Signalling, and Transport. Comparisons were also made to the top expressed genes in the triticale stigma and the degree of correlation seemed connected to the cellular role of the proteins. Very little correlation was found between protein and mRNA quantity which highlights the importance of post-transcriptional and post translational processes.

In Chapter 3, 2275 B. napus mature stigma proteins were reported with a distribution among the proteomics approaches being very similar to that of triticale suggesting that the number of proteins identified is independent of the source species of the dry stigmas. The proportion of proteins with a signal peptide (8.0\%) was similar to triticale and their functional distribution was like that of triticale except maybe for Signalling and Cell Wall Modification. Comparison of the B. napus stigma 2D map with that obtained for triticale also indicated clear differences in the spot pattern with most B. napus proteins occurring in a narrower $\mathrm{p} I$ range.

In the B. napus stigma, many proteins were revealed whose mutation causes a wide variety of cellular and organ developmental defects in Arabidopsis. Several proteins were identified that have been shown to play important roles in vegetative and reproductive development such as proteins associated with mutant embryo phenotypes. The B. napus mature stigma expressed proteins associated with auxin function including proteins involved in polar auxin transport. The B. napus stigma also expressed proteins with demonstrated roles in gynoecium development including proteins with functions in embryo sac, carpel and stigma development. 
Various proteins involved in cell wall modification were also identified in the $B$. napus stigma and these are likely to participate in papillar cell development or facilitate pollen tube penetration and growth through the stigma. In fact, proteins shown to be involved in pollen tube growth were also found in the B. napus stigma. Although, there were many differences in the identity of the specific proteins found within the B. napus and triticale stigma protein datasets, proteins involved in glucosinolate metabolism, isoprenoid metabolism, photosynthesis, and the SSI response were more prevalent in B. napus and appeared to reflect true biological divergence. Glucosinolates are secondary metabolites found in the Brassicales so it is not that surprising that they would be more abundant in the B. napus. Proteins involved in both isoprenoid metabolism and photosynthesis represent differences in the biology and pigmentation of the B. napus stigma when compared to that of triticale. Finally, since the Brassicaceae display SSI, the presence of related proteins is also understandable.

More than 4000 dry stigma proteins were identified in this thesis. How do these compare to proteins found in wet stigmas? Comparative proteome analyses of dry and wet stigmas might provide valuable information into their evolution and biology. Unfortunately, such a comparison is difficult since reports detailing the analysis of wet stigma proteins vary considerably in their approaches and generally focus on a small differential set of proteins as opposed to the global proteome. For example, two studies were done in the Solanaceous species Nicotiana and Solanum. Sang et al. (2012) used 2D gels to identify 47 unique proteins differentially expressed in the tobacco stigma. Chalivendra et al. (2013) used iTRAQ to identify 2534 proteins from the stigma/style of wild tomato (Solanum pennellii), but only reported the functional distribution of the top 
100 differentially expressed mature stigma proteins when compared to an earlier developmental stage. Although some similarities can be observed with the dry stigma datasets like a preponderance of proteins associated with defense and stress, such comparisons have limited value given the small wet stigma protein databases and the fact that they have been pre-selected. Informative comparisons will therefore have to wait for the global proteome analysis of a wet stigma.

\subsection{Future directions}

Many aspects of this thesis could be pursued as areas of future research. For example, although this study represents the largest inventory of Brassicaceae and Triticeae stigma proteins ever reported, the number of proteins identified still only represents a small fraction of the total number of proteins found in the stigma. To maximize the number of identified proteins, various protein extraction procedures likely to extract different proteins (e.g. membrane proteins) could be tested. The preferential enrichment of low abundance proteins, subcellular fractionation techniques, and selective labelling of proteins using CyeDye DIGE Fluor minimal dyes could also be used. The BN-PAGE method referred to as three-dimensional gel electrophoresis that separates proteins not only based on their charge to mass ratio but also their physical shape and size could be performed. To improve mass peptide spectra resolution, different protease enzymes could be used by selecting specific protein digestion enzymes such as chymotrypsin, Thermolysin, Lys-C, Arg-C or Asp-N. To increase the number of peptide spectra, more recent mass spectrometry instruments with higher resolution could be used such as Orbitrap FTMS (Fourier Transform Mass Spectrometer) mass analyser (Thermo Fisher), High- 
Performance 3D Ion Trap, or Autoflex III and AB Sciex TOF/TOF 5800 (Bruker Amazon) could be used.

This study focused on the mature stage of stigma development and future work could make use of differential analytical techniques such as iTRAQ or DIGE to compare the proteome of the mature stigma to that of younger developmental stages or to the mature stigma post-pollination.

Post-translational modifications are known to affect protein function and these modifications are likely to also play a significant role in stigma development and function. A general detection of phosphorylated or glycosylated proteins was performed in this study using fluorescent stains, but the post-translational modifications could not be confirmed by MS likely due to the complexity of the samples and the low stoichiometry of phosphorylation. Therefore, further experiments aiming to identify phosphorylation and glycosylation sites in stigma proteins will likely have to rely on selective enrichment techniques $\left(\mathrm{TiO}_{2}\right.$ or IMAC) coupled with MS. Lastly, with the advent of next generation sequencing it is likely that more gene sequence data will become available for triticale and B. napus enabling the identification of specific protein isoforms.

In conclusion, this thesis described a comprehensive inventory of dry stigma proteins and their biological roles. Future research will hopefully increase this inventory and allow comparisons to wet and dry stigmas from different species, thus providing insight into the biological role of this critical reproductive structure. 


\section{References}

Abdalleh C, Dumas-Gaudot E, Renaut J, Sergent K. 2012. Gel-Based and Gel-Free Quantitative Proteomics Approaches at a Glance. IJPG 2012, 1-17.

Acosta IF, Laparra H, Romero SP, Schmelz E, Hamberg M, Mottinger JP, Moreno MA, Dellaporta SL. 2009. tasselseed1 is a lipoxygenase affecting jasmonic acid signaling in sex determination in maize. Science 323, 262-265.

Aebersold R, Mann M. 2003. Mass spectrometry-based proteomics. Nature 422, 198-207.

Andème-Onzighi C, Sivaguru M, Judy-March J, Baskin TI, Driouich A. 2002. The reb1-1 mutation of Arabidopsis alters the morphology of trichoblasts, the expression of arabinogalactan-proteins and the organization of cortical microtubules. Planta 215, 949958.

Apuya NR, Yadegari R, Fischer RL, Harada JJ, Zimmerman JL, Goldberg RB. 2001. The Arabidopsis embryo mutant schlepperless has a defect in the chaperonin-60 $\alpha$ gene. Plant Physiol 126, 717-730.

Bateman AJ. 1955. Self-incompatibility systems in angiosperms III. Cruciferae. Hered 9 , 52-68.

Berg A, Meza TJ, Mahić M, Thorstensen T, Kristiansen K, Aalen RB. 2003. Ten members of the Arabidopsis gene family encoding methyl-CpG-binding domain proteins are transcriptionally active and at least one, AtMBD11, is crucial to normal development. Nucleic Acids Res 31, 5291-5304. 


\section{Bessire M, Borel S, Fabre G, Carraça L, Efremova N, Yephremov A, Cao Y, Jetter R,} Jacquat A, Métraux J, Nawrath C. 2011. A member of the PLEIOTROPIC DRUG RESISTANCE family of ATP binding cassette transporters is required for the formation of a functional cuticle in Arabidopsis. Plant Cell 23, 1958-1970.

\section{Bienvenut WV, Déon C, Pasquarello C, Campbells JM, Sanchez JC, Vestals ML,}

Hochstrasser DF. 2002. Matrix-assisted laser desorption/ionization-tandem mass spectrometry with high resolution and sensitivity for identification and characterization of proteins. Proteomics 2, 868-876.

BLAKESLEE AF, AVERY AG. 1937. Methods of inducing chromosome doubling in plants by treatment with colchicine. Science 86, 408.

Boros D. 2006. Triticale of high end-use quality chance to increase its value on world cereal markets. In: Botes w. (ed). Proc. $6^{\text {th }}$ Int. Triticale Symp. Stellenbosch, SA.

Boss WF, Im YJ. 2012. Phosphoinositide signaling. Annu Rev. Plant Biol 63, 409-429.

Bringmann M, Li E, Sampathkumar A, Kocabek T, Hauser MT, Persson S. 2012. POMPOM2/CELLULOSE SYNTHASE INTERACTING1 is essential for the functional association of cellulose synthase and microtubules in Arabidopsis. Plant Cell 24, 163-177.

Brosch M, Swamy S, Hubbard T, Choudhary J. 2008. Comparison of Mascot and X!Tandem Performance for Low and High Accuracy Mass Spectrometry and the Development of an Adjusted Mascot Threshold. Mol Cell Proteomics 7.5 7, 962-970. Burk DH, Liu B, Zhong R, Morrison WH, Ye ZH. 2001. A katanin-like protein regulates normal cell wall biosynthesis and cell elongation. Plant Cell 13, 807-827. 
Buschmann H, Hauptmann M, Niessing D, Lloyd CW, Schäffner AR. 2009. Helical growth of the Arabidopsis mutant tortifolia2 does not depend on cell division patterns but involves handed twisting of isolated cells. Plant Cell 21, 2090-2106.

Caldelari D, Wang G, Farmer EE, Dong X. 2011. Arabidopsis lox3 lox4 double mutants are male sterile and defective in global proliferative arrest. Plant Mol Biol 75, 25-33.

Candela H, Alonso-Peral MM, Ponce MR, Micol JL. 2007. Role of HEMIVENATA and the ubiquitin pathway in venation pattern formation. Plant Signal. Behav 2, 258-259.

Cazzonelli CI. 2011. Carotenoids in nature: insights from plants and beyond. Funct. Plant Biol 38, 833-847.

Chalivendra SC, Lopez-Casado G, Kumar A, Kassenbrock AR, Royer S, Tover-Méndez A, Covey PA, Dempsey LA, Randle AM, Stack SM, Rose JKC, McClure B, Bedinger PA. 2013. Developmental onset of reproductive barriers and associated proteome changes in stigma/styles of Solanum pennellii. J Exp Bot 64, 265-279

Chapman BD, Salmon CD, Dyson D, Blackley K. 2005. Triticale production and utilization manual, spring and winter triticale for grain, forage and value-added. Alberta Agriculture, Food and Rural Development, http://www1.agric.gov.ab.ca/\$department/deptdocs.nsf/all/fcd10535.

Chapman LA, Goring DR. 2010. Pollen-pistil interactions regulating successful fertilization in the Brassicaceae. J Exp Bot 61, 1987-1999 
Chen Y, Liu H, Stone S, Callis J. 2013. ABA and the ubiquitin E3 ligase KEEP ON GOING affect proteolysis of the Arabidopsis thaliana transcription factors ABF1 and ABF3. PlantJ 75, 965-976.

Ciampolini F, Shivanna KR, Cresti M. 2001. Organization of the stigma and transmitting tissue of rice, Oryza sativa (L). Plant Biol 3, 149-155.

Collings DA, Gebbie LK, Howles PA, Hurley UA, Birch RJ, Cork AH, Hocart CH, Arioli T, Williamson RE. 2008. Arabidopsis dynamin-like protein DRP1A: a null mutant with widespread defects in endocytosis, cellulose synthesis, cytokinesis, and cell expansion. $J$ Exp Bot 59, 361-376.

\section{Coury DA, Zhang C, Ko A, Skaggs MI, Christensen CA, Drews GN, Feldmann KA,} Yadegari R. 2007. Segregation distortion in Arabidopsis gametophytic factor 1 (gfa1) mutants is caused by a deficiency of an essential RNA splicing factor. Sex Plant Reprod 20, 87-97.

Craig R, Beavis RC. 2004. TANDEM: matching proteins with tandem mass spectra. Bioinformatics 20, 1466-1467.

Cronquist A. 1988. The evolution and classification of flowering plants. Second edition. Bronx, NY: The New York Botanical Garden.

Damerval C, Vienne DD, Zivy M, Thiellement H. 1986. Technical improvements in twodimensional electrophoresis increase the level of genetic variation detected in wheatseeding protein. Electrophoresis 7, 52-54. 
Davidson RM, Hansey CN, Gowda M, Childs KL, Lin H, Vaillancourt B, Sekhon RS, de Leon N, Kaeppler SM, Jiang N, Buell CR. 2011. Utility of RNA sequencing for analysis of maize reproductive transcriptomes. Plant Genome 4, 191-203.

DeLong A, Calderon-Urrea A, Dellaporta SL. 1993. Sex determination gene TASSELSEED2 of maize encodes a short-chain alcohol dehydrogenase required for stagespecific floral organ abortion. Cell 74, 757-768.

Denison FC, Paul A, Zupanska AK, Ferl RJ. 2011. 14-3-3 proteins in plant physiology. Sem Cell Dev Biol 22, 720-727.

Ding Y, Cao J, Ni L, Zhu Y. 2013. ZmCPK11 is involved in abscisic acid-induced antioxidant defense and functions upstream of ZmMPK5 in abscisic acid signalling in maize. J Exp Bot 64, 871-884.

Dixit R, Nasrallah JB. 2001. Recognizing self in the self-incompatibility response. Plant Physiol 125, 105-108

Domon B, Aebersold R. 2006. Mass Spectrometry and Protein Analysis. Science 312, 212217.

Dongping Z, Li C, Bing LV, Jiansheng L. 2013. The scaffolding protein RACK1: a platform for diverse functions in the plant kingdom. J Plant Biol \& Soil Health 1, 1-7.

Doughty J, Hedderson F, McCubbin A, Dickinson HG. 1993. Interaction between a coating-borne peptide of the Brassica pollen grain and stigmatic S (incompatibility)-locusspecific glycoproteins. PNAS USA 90, 467-471. 
Drakakaki G, Dandekar A. 2013. Protein secretion: How many secretory routes does a plant cell have? Plant Sci 203-204, 74-78.

Dresselhaus T, Franklin-Tong N. 2013. Male-female cross-talk during pollen germination, tube growth and guidance, and double fertilization. Mol Plant 6, 1018-1036.

Dumas C, Knox RB, Gaude T. 1984. Pollen-pistil recognition: new concepts from electron microscopy and cytochemistry. Internat Rev Cytol 90, 239-272.

Dwivedi RC, Spicer V, Harder M, Antonovici M, Ens W, Standing KG, Wilkins JA, Krokhin 0V. 2008. Practical implementation of 2D HPLC scheme with accurate peptide retention prediction in both dimensions for high-throughput bottom-up proteomics. Anal Chem 80, 7036-7042.

Edstam M, Viitamen L, Salminen TA, Edqvist J. 2011. Evolutionary history of the nonspecific lipid transfer proteins. Mol Plant 4, 947-964.

Ellis M, Egelund J, Schultz CJ, Bacic A. 2010. Arabinogalactan-proteins: key regulators at the cell surface? Plant Physiol 153, 403-419.

Eng J, Mc Cormack AL, Yates III JR. 1994. An approach to correlate tandem mass spectral data of peptides with amino acid sequences in a protein database. J Am Soc Mass Spectrom 5, 976-989.

Esau K. 1965. Plant anatomy. New York, NY. John Wiley and Sons.

Eubel H, Braun HP, Millar AH. 2005. "Blue-native PAGE in plants: a tool in analysis of protein-protein interactions," Plant Methods 1, 1-11. 
Feng B, Li L, Zhou X, Stanley B, Ma H. 2009. Analysis of the Arabidopsis floral proteome: detection of over 2000 proteins and evidence for post-translational modifications. J Integr Plant Biol 51, 207-223.

Fenn JB, Mann M, Meng CK, Wong SF, Whitehouse CM. 1989. Electrospray ionization for the mass spectrometry of large biomolecules. Science 246, 64-71.

Ferjani A, Ishikawa K, Asaoka M, Ishida M, Horigochi G, Maeshima M, Tsukaya H. 2013. Enhanced cell expansion in a $K R P 2$ overexpressor is mediated by increased VATPase activity. Plant Cell Physiol 54, 1989-1998.

Food and Agriculture Organization of the United Nations. 2011. FaoStat. http://faostat.fao.org/.

Forzani C, Carreri A, de la Fuente van Bentem S, Lecourieux D, Lecourieux F, Hirt H. 2011. The Arabidopsis protein kinase Pto-interacting $1-4$ is a common target of the oxidative signal-inducible 1 and mitogen-activated protein kinases. FEBS J 278, 1126-1136.

Fournier ML, Gilmore JM, Martin-Brown SA, Washburn MP. 2007. "Multidimensional separations-based shotgun proteomics," Chem Rev 107, 3654-3686.

Foyer CH, Noctor G. 2013. Redox signaling in plants. Antiox \& Redox Signal 18, 2087-2090.

Frank A, Pevzner P. 2005. PepNovo: de novo peptide sequencing via probabilistic network modeling. Anal Chem 77, 964-973.

Free JB. 1993. Insect pollination of crops. London: Academic Press. 
Friedt W, Luhs W. 1998. Recent developments and perspectives of industrial rapeseed breeding. Fett/Lipid 100, 219-226.

Fujikura U, Horiguchi G, Ponce MR, Micol JL, Tsukaya H. 2009. Coordination of cell proliferation and cell expansion mediated by ribosome-related processes in the leaves of Arabidopsis thaliana. Plant J 59, 499-508.

Gangappa SN, Srivastava AK, Maurya JP, Ram H, Chattopadhyay S. 2013. Z-box binding transcription factors (ZBFs): a new class of transcription factors in Arabidopsis seedling development. Mol Plant 6, 1758-1768.

\section{Geer LY, Markey SP, Kowalak JA, Wagner L, Xu M, Mynard DM, Yang X, Shi W, Bryant}

SH. 2004. Open mass spectrometry search algorithm. J Proteome Res 3, 958-964.

Guerrera IC, Kleiner 0. 2005. Application of Mass Spectrometry in Proteomics. Biosci Rep 5, 71-93.

Hackenberg D, Keetman U, Grimm B. 2012. Homologous NF-YC2 subunit from Arabidopsis and tobacco is activated by photooxidative stress and induces flowering. Internat J Mol Sci 13, 3458-3477.

Haffani YZ, Gaude T, Cock JM, Goring DR. 2004. Antisense suppression of thioredoxin h mRNA in Brassica napus cv. Westar pistils causes a low level constitutive pollen rejection response. Plant Mol Biol 55, 619-630.

Harrington JF. 1970. Seed and pollen storage for conservation of plant gene resource. In Genetic resources in plants- their exploration and conservation. Frankel $\mathrm{OH}$ and Bennett E. Blackwell, Oxford. pp. 501-521 


\section{Hayashi S, Ishii T, Matsunaga T, Tominaga R, Kuromori T, Wada T, Shinozaki K,}

Hirayama T. 2008. The glycerophosphoryl diester phosphodiesterase-like proteins SHV3 and its homologs play important roles in cell wall organization. Plant Cell Physiol 49, 15221535.

Hennig L, Derkacheva M. 2009. Diversity of polycomb group complexes in plants: same rules, different players? Trends Genet 25, 414-423.

Hepler PK, Rounds CM, Winship LJ. 2013. Control of cell wall extensibility during pollen tube growth. Mol Plant 6, 998-1017.

Heslop-Harrison J, Heslop-Harrison Y, Barber J. 1975. The stigma surface in incompatibility responses. Proc Royal Soc London Series B 188, 287-297.

Heslop-Harrison J, Heslop-Harrison Y. 1982. The pollen- stigma interactions in the grasses. 4. An interpretation of the self-incompatibility response. Acta Bot Neerl 31, 429439.

Heslop-Harrison J. 1978. Recognition and response in the pollen-stigma interaction. In: Cell-cell recognition. Society for Experimental Biology Symposium Series No. 32. Curtis A, ed. Cambridge, UK, pp. 121-138.

Heslop-Harrison Y, Shivanna KR. 1977. The receptive surface of the angiosperm stigma. Ann Bot 41, 1233-1258.

Heslop-Harrison Y. 1977. The pollen-stigma interaction: pollen -tube penetration in Crocus. Ann Bot 41,913-22 


\section{Hiroi K, Sone M, Sakazono S, Osaka M, Masuko-Suzuki H, Matsuda T, Suzuki G,}

Suwabe K, Watanabe M. 2013. Time-lapse imaging of self- and cross-pollination in Brassica rapa. Ann Bot 11, 115-122.

Hiscock SJ, Allen AM. 2008. Diverse cell signalling pathways regulate pollen-stigma interactions: the search for consensus. New Phytol 179, 286-317.

Hiscock SJ, Coleman J, Dewey FM, Dickinson HG. 1994. Identification and localization of an active cutinase in the pollen of Brassica napus L. Planta 193, 377-384.

Hiscock SJ, Dickinson HG. 1993. Unilateral incompatibility within the Brassicaceae further evidence for an involvement of the selfincompatibility (S)-locus. TAG 86, 744-753. Hiscock SJ, Doughty J, Dickinson HG. 1995. Synthesis and phosphorylation of pollen proteins during the pollen-stigma interaction in self-compatible Brassica napus L. and selfincompatible Brassica oleracea L. Sex Plant Reprod 8, 345-353.

Hiscock SJ, Hoedemaekers K, Friedman WE, Dickinson HG. 2002. The stigma surface and pollen-stigma interactions in Senecio squalidus L. (Asteraceae) following cross (compatible) and self (incompatible) pollinations. Internat J Plant Sci 163, 1-16.

Hörth P, Miller CA, Preckel T, Wenz C. 2006. “Effcient fractionation and improved protein identification by peptide OFFGEL electrophoresis." Mol Cell Proteomics 5, 19681974.

Hossain Z, McGarvey B, Amyot L, Gruber M, Jung J, Hannoufa A. 2012. DIMINUTO 1 affects the lignin profile and secondary cell wall formation in Arabidopsis. Planta 235, 485498. 
Hu R, Zhu Y, Shen G, Zhang H. 2014. TAP46 plays a positive role in ABSCISIC ACID INSENSITIVE5-regulated gene expression in Arabidopsis. Plant Physiol 164, 1-14.

Huang M, Sanchez-Moreiras AM, Abel C, Sohrabi R, Lee S, Gershenzon J, Tholl D. 2012. The major volatile organic compound emitted from Arabidopsis thaliana flowers, the sesquiterpene (E)- $\beta$-caryophyllene, is a defense against a bacterial pathogen. New Phytol 193, 997-1008.

Hwa C, Yang X. 2008. The AtMKK3 pathway mediates ABA signaling in Arabidopsis. Acta Physiol Plantar 30, 277-286.

Indriolo E, Goring DR. 2014. A conserved role for the ARC1 E3 ligase in Brassicaceae selfincompatibility. Frontiers Plant Sci 5, 1-7.

\section{IqbaLMzr J, Ahmed N, Mokhdomi TA, Wafai AH, Wani SH, Bukhari SH, Amin A, Qadri}

RA. 2013. Relative expression of apocarotenoid biosynthetic genes in developing stigmas of Crocus sativus L. J Crop Sci Biotech 16, 183-188.

Ito T, Kim G, Shinozaki K. 2000. Disruption of an Arabidopsis cytoplasmic ribosomal protein S13-homologous gene by transposon-mediated mutagenesis causes aberrant growth and development. Plant J 22, 257-264.

Jang S, Lee B, Kim C, Kim S, Yim J, Han J, Lee S, Kim S, An G. 2003. The OsFOR1 gene encodes a polygalacturonase-inhibiting protein (PGIP) that regulates floral organ number in rice. Plant Mol Biol 53, 357-369. 
Ji L, Liu X, Yan Y, Wang W, Yumul RE, Kim YJ, Dinh TT, Liu J, Cui X, Zheng B, Agarwal M, Liu CH, Cao X, Chen X . 2011. ARGONAUTE1O and ARGONAUTE1 regulate the termination of floral stem cells through two microRNAs in Arabidopsis. PLoS Genet 7, e1001358.

Johri BM. 1984. Embryology of angiosperms. Springer-Verlag Berlin, Heidelberg, pp. 377443

Kagi C, Baumann N, Nielsen N, Stierhof Y, Groß-Hardt R. 2010. The gametic central cell of Arabidopsis determines the lifespan of adjacent accessory cells. PNAS 107, 22350-22355.

Kandasamy MK, Kristen U. 1987. Developmental aspects of ultrastructure, histochemistry and receptivity of the stigma of Nicotiana sylvestris. Ann Bot 60, 427-437. Kaneda M, Schuetz M, Lin BSP , Chanis C, Hamberger B, Western TL, Ehlting J, Samuels AL. 2011. ABC transporters coordinately expressed during lignification of Arabidopsis stems include a set of ABCBs associated with auxin transport. J Exp Bot 62, 2063-2077.

Kang B, Busse JS, Bednarek SY. 2003. Members of the Arabidopsis dynamin-like gene family, ADL1, are essential for plant cytokinesis and polarized cell growth. Plant Cell 15, 899-913.

Kania U, Fendrych M, Friml J. 2014. Polar delivery in plants; commonalities and differences to animal epithelial cells. Open Biol 4, 140017.

Karas M, Hillenkamp F. 1988. Laser desorption ionization of proteins with molecular mass exceeding 1000 daltons. Anal Chem 60, 2299-2301. 
Kawade K, Horiguchi G, Usami T, Hirai MY,Tsukaya H. 2013. ANGUSTIFOLIA3 signaling coordinates proliferation between clonally distinct cells in leaves. Curr Biol 23, 788-792.

Keller A, Nesvizhskii AI, Aebersold R. 2002. Empirical statistical model to estimate the accuracy of peptide identification made by MS/MS and database search. Anal Chem 74, 5383-5392.

Keller A, Nesvizhskii AI, Kolker E, Aebersold R. 2002. Empirical statistical model to estimate the accuracy of peptide identifications made by MS/MS and database search. Anal Chem 74, 5383-5392.

Kim ST, Kim HS, Kim HJ, Kim SG, Kang SY, Lim DB, Kang KY. 2003. Prefractionation of protein samples for proteome analysis by sodium dodecyl sulfate-polyacrylamide gel electrophoresis. Mol Cells 16, 316-322.

\section{Klaas M, Yang B, Bosch M, Thorogood D, Manzanares C, Armstead IP, Franklin FCH,} Barth S. 2011. Progress towards elucidating the mechanisms of self-incompatibility in the grasses: further insights from studies in Lolium. Ann Bot 108, 677-685.

Kleinow T, Himbert S, Krenz B, Jeske H, Koncz C. 2009. NAC domain transcription factor ATAF1 interacts with SNF1-related kinases and silencing of its subfamily causes severe developmental defects in Arabidopsis. Plant Sci 177, 360-370.

Kobayashi Y, Yamamoto S, Minami H, Kagaya Y, Hattori T. 2004. Differential activation of the rice sucrose nonfermenting1-related protein kinase2 family by hyperosmotic stress and abscisic acid. Plant Cell 16, 1163-1177. 


\section{Konishi T, Aohara T, Igasaki T, Hayashi N, Miyazaki Y, Takahashi A, Hirochika H, Iwai}

H, Satoh S, Ishii T. 2011. Down-regulation of UDP-arabinopyranose mutase reduces the proportion of arabinofuranose present in rice cell walls. Phytochem 72, 1962-1968.

Krogan NT, Hogan K, Long JA. 2012. APETALA2 negatively regulates multiple floral organ identity genes in Arabidopsis by recruiting the co-repressor TOPLESS and the histone deacetylase HDA19. Dev 139, 4180-4190.

Kupiec T. 2004. Quality-control Analytical methods: High-Performance liquid chromatography. IJPC 8, 223-227.

Kurepa J, Wang S, Li Y, Zaitlin D, Pierce AJ, Smalle JA. 2009. Loss of 26 S proteasome function leads to increased cell size and decreased cell number in Arabidopsis shoot organs. Plant Physiol 150, 1780-1789.

Laemmli UK. 1970. Cleavage of structural proteins during the assembly of the head of bacteriophage T4. Nature 227, 680-685.

Langridge P, Baumann U. 2008. Self-Incompatibility in the grasses. In: SelfIncompatibility in Flowering Plants- Evolution, Diversity and Mechanisms. Berlin, Springer, pp. 275-287.

Larsson E, Franks RG, Sundberg E. 2013. Auxin and the Arabidopsis thaliana gynoecium. J Exp Bot 64, 2619-2617.

Larter EN, Gustofson JP. 1980. Triticale. In; Hybridization of crop plants. Am Soc Agron. Fehr WR and Hadley HH, ends. Madison, Wisconsin, pp 681-694. 
Larter EN. 1977. Unpublished data. Dept. of Plant Science, Univ. of Manitoba, Winnipeg, Manitoba, Canada, R2T2N2.

Lausser A, Dresselhaus T. 2010. Sporophytic control of pollen tube growth and guidance in grasses. Biochem Soc Trans 38, 631-634.

Lee BH, Wynn AN, Franks RG, Hwang Y, Lim J, Kim JH. 2014. The Arabidopsis thaliana GRF-INTERACTING FACTOR gene family plays an essential role in control of male and female reproductive development. Dev Biol 386, 12-24.

Li CH, Fu SX, Chen XJ, Qi CK. 2012c. Phenotypic characterization and genetic analysis of a partially female-steile mutant in Brassica napus. Plant Sci 185-186, 112-117.

Li H, Chen H, Yang Z, Gong J. 2012b. Cdi gene is required for pollen germination and tube growth in Arabidopsis. FEBS Lett 586, 1027-1031.

Li H, Liang W, Yin C, Zhu L, Zhang D. 2011. Genetic interaction of OsMADS3, DROOPING $L E A F$, and OSMADS13 in specifying rice floral organ identities and meristem determinacy. Plant Physiol 156, 263-274.

Li M, Xu W, Yang W, Kong Z, Xue Y. 2007. Genome-wide gene expression profiling reveals conserved and novel molecular functions of the stigma of rice. Plant Physiol 144, 17971812.

Li S, Lei L, Somerville CR, Gu Y. 2012a. Cellulose synthase interactive protein 1 (CSI1) links microtubules and cellulose synthase complexes. PNAS USA 109, 185-190.

Li W, Perry PJ, Prafulla NN, Schmidt W. 2010. Ubiquitin-specific protease 14 (UBP14) is involved in root responses to phosphate deficiency in Arabidopsis. Mol Plant 3, 212-223. 
Lichter R. 1982. Induction of haploid plants from isolated pollen of B. napus. $Z$ Pflanzenphysiol 105, 427-434

Lim M, Kim J, Kim Y, Chung K, Seo Y, Lee I, Kim J, Hong CHB, Kim H, Park CH. 2004. A new Arabidopsis gene, FLK, encodes an RNA binding protein with $\mathrm{K}$ homology motifs and regulates flowering time via FLOWERING LOCUS C. Plant Cell 16, 731-740.

Lindner H, Müller LM, Boisson-Dernier A, Grossniklaus U. 2012. CrRLK1L receptor-like kinases: not just another brick in the wall. Curr. Opin. Plant Biol 15, 1-11.

Liu ZN,Yu XL, Wang FZ, Hu S, Liu YP, Lu G. 2012. Physiological, biochemical, and molecular characterization of a new female sterile mutant in turnip. Plant Growth Regul 68, 239-248.

Löfke C, Luschnig C, Kleine-Vehn J. 2013. Post-translational modification and trafficking of PIN auxin efflux carriers. Mech Dev 130, 82-94.

Lolle SJ, Cheung AY. 1993. Promiscuous germination and growth of wildtype pollen from Arabidopsis and related species on the shoot of the Arabidopsis mutant, fiddlehead. Dev Biol 155, 250-258.

Lü S, Song T, Kosma DK, Parsons EP, Rowland O, Jenks MA. 2009. Arabidopsis CER8 encodes LONG-CHAIN ACYL-COA SYNTHETASE 1 (LACS1) that has overlapping functions with LACS2 in plant wax and cutin synthesis. Plant J 59, 553-564.

Lucas JR, Courtney S, Hassfurder M, Dhingra S, Bryant A, Shaw SL. 2011. Microtubuleassociated proteins MAP65-1 and MAP65-2 positively regulate axial cell growth in etiolated Arabidopsis hypocotyls. Plant Cell 23, 1889-1903. 
Lum G, Min XJ. 2011. Plant secretomes: current status and future perspectives. Plant Omics J 4, 114-119.

Lundgren DH, Hwang SI, Wu L, Han DK. 2010. "Role of spectral counting in quantitative proteomics." Expert Review of Proteomics 7, 39-53.

Luu D, Marty-Mazars D, Trick M, Dumas C, Heizmann P. 1999. Pollen-stigma adhesion in Brassica spp involves SLG and SLR1 glycoproteins. Plant Cell 11, 251-262.

Lyzenga WJ, Stone SL. 2012. Abiotic stress tolerance mediated by protein ubiquitination. J. Exp Bot 63, 599-616.

Ma B, Zhang k, Hendrie C, Liang C, Li M, Doherty-Kirby A, Lajoie G. 2003. PEAKS: powerful software for peptide de novo sequencing by tandem mass spectrometry. Rapid Commun Mass Spectrom 17, 2337-2342.

Ma H. 2005. Molecular genetics analyses of microsporogenesis and microgametogenesis in flowering plants. Plant Biol 56, 393-434.

Ma XF, Gustafson JP. 2008. Allopolyploidization-accommodated genomic sequence changes in triticale. Ann Bot 101, 825-832.

Maluszynski M, Ahloowalia BS, Sigurbjornsson B. 1995. Application of in vivo and in vitro mutation techniques for crop improvement. Euphyt 85, 303-315

Manadas B, Mendes VM, English J, Dunn MJ. 2010. “Peptide fractionation in proteomics approaches," Expert Rev Proteomics 7, 655-663. 
Mann M. 2006. "Functional and quantitative proteomics using SILAC." Nat Rev Mol Cell Biol 7, 952-958.

Mattsson O, Knox RB, Heslop-Harrison J, Heslop-Harrison Y. 1974. Protein pellicle of stigmatic papillae as a probable recognition site in incompatibility reactions. Nature $\mathbf{2 4 7}$, 298-300.

McInnis SM, Desikan R, Hancock JT, Hiscock SJ. 2006. Production of reactive oxygen species and reactive nitrogen species by angiosperm stigmas and pollen: potential signalling crosstalk? New Phytol 172, 221-228.

Molloy MP, Herbert BR, Walsh, BJ, Tyler MI, Trani M, Sanchez JC, Hochstrasser DF, Williams KL, Goodley AA. 1998. Extraction of membrane proteins by differential solubilisation for separation using 2-D electrophoresis. Electrophoresis 19, 837-844.

Monaghan J, Li X. 2010. The HEAT repeat protein ILITYHIA is required for plant immunity. Plant Cell Physiol 51, 742-553.

Morrison RA, Evans DA. 1988. Haploid plants from tissue culture: new plant varieties in a short ened time frame. Bio/technology 6, 684-690

Mulekar JJ, Huq E. 2014. Expanding roles of protein kinase CK2 in regulating plant growth and development. J Exp Bot 65, 2883-2893

Mussury RM, Fernandes W. 2000. Studies of the Floral Biolgy and Reproductive System of Brassica napus L. (Cruciferae). Brazil Arch Biol Technol 43, 111-117. 
Myouga F, Motohashi R, Kuromori T, Nagata N, Shinozaki K. 2006. An Arabidopsis chloroplast-targeted Hsp101 homologue, APG6, has an essential role in chloroplast development as well as heat-stress response. Plant J 48, 249-260.

Nakasone A, Fujiwara M, Fukao Y, Biswas KK, Rahman A, Kawai-Yamada M, Narumi I, Uchimiya H, Oono Y. 2012. SMALL ACIDIC PROTEIN1 acts with RUB modification components, the COP9 signalosome, and AXR1 to regulate growth and development in Arabidopsis. Plant Physiol 160, 93-105.

Nakata M, Okada K. 2013. The leaf adaxial-abaxial boundary and lamina growth. Plants 2 , 174-202.

Neilson KA1, Ali NA, Muralidharan S, Mirzaei M, Mariani M, Assadourian G, Lee A, van Sluyter SC, Haynes PA. 2011. "Less label, more free: approaches in label-free quantitative mass spectrometry." Proteomics 11, 535-553.

Nishimura T, Wada T, Yamamoto KT, Okada K. 2005. The Arabidopsis STV1 protein, responsible for translation reinitiation, is required for auxin-mediated gynoecium patterning. Plant Cell 17, 2940-2953.

O'Farrell PH. 1975."High resolution two dimensional electrophoresis of proteins". J Bio Chem 250, 4007-4021.

Ogura T, Wilkinson AJ. 2001. AAA+ superfamily ATPases: common structure - diverse function. Genes to Cells 6, 575-597. 
Okamoto S, Odashima M, Fujimoto R, Sato Y, Kitashiba H, Nishio T. 2007. Selfcompatibility in Brassica napus is caused by independent mutations in S-locus genes. Plant J 50, 391-400.

Osaka M, Matsuda T, Sakazono S, Masuko-Suzuki H, Maeda S, Sewaki M, Sone M, Takahashi H, Nakazono M, Iwano M, Takayama S, Shimizu KK, Yano K, Lim YP, Suzuki G, Suwabe K, Watanabe M. 2013. Cell type-specific transcriptome of Brassicaceae stigmatic papilla cells from a combination of laser microdissection and RNA sequencing. Plant Cell Physiol 54, 1894-1906.

\section{Pagant S, Bichet A, Sugimoto K, Lerouxel O, Desprez T, McCann M, Lerouge P,} Vemhettes S, Höfte H. 2013. KOBITO1 encodes a novel plasma membrane protein necessary for normal synthesis of cellulose during cell expansion in Arabidopsis. Plant Cell 14, 2001-2013.

Pagnussat GC, Yu H, Sundaresan V. 2007. Cell-fate switch of synergid to egg cell in Arabidopsis oestre mutant embryo sacs arises from misexpression of the BEL1-like homeodomain gene BLH1. Plant Cell 19, 3578-3592.

Pandey AK. 1997. Introduction to Embryology of Angiosperms. CBC Publishers\& Distributers, New Delhi.

Panikashvili D, Shi JX, Schreiber L, Aharoni A. 2009. The Arabidopsis $D C R$ encoding a soluble BADH acyltransferase is required for cutin polyester formation and seed hydration properties. Plant Physiol 151, 1773-1789. 
Park S, Rancour DM, Bednarek SY. 2008. In planta analysis of the cell cycle-dependent localization of AtCDC48A and its critical roles in cell division, expansion, and differentiation. Plant Physiol 148, 246-258.

Peer LA. 2014. Self-incompatibility patterns and signal transduction In: Plant signaling: understanding the molecular crosstalk. Rehman Hakeem K, Rehman RU, Tahir I, eds. Springer, India, pp. 327-343.

Pejin DJ, Mojović LV, Pejin JD, Grujić OS, Markov SL, Nikolić SB, Marković MN. 2012. Increase in bioethanol production yield from triticale by simultaneous saccharification and fermentation with application of ultrasound. J Chem Technol Biotechnol 87, 170-176.

Pérez-Pérez JM, Rubio-Díaz S, Dhondt S, Hernández-Romero D, Sánchez-Soriano J, Beemster GTS, Ponce MR, Micol JL. 2011. Whole organ, venation and epidermal cell morphological variations are correlated in the leaves of Arabidopsis mutants. Plant Cell Environ 34, 2200-2211.

Perkins DN, Pappin DJ, Creasy DM, Cottrell JS. 1999. Probability-based protein identification by searching sequence database using mass spectrometry data. Electrophoresis 20, 3551-3567.

Prenni JE, Vidal M, Olver CS. 2012. Preliminary characterization of the murine membrane reticulocyte proteome. Blood Cells Molec Dis 49, 74-82.

\section{Qin Y, Leydon AR, Manziello A, Pandey R, Mount D, Denic S, Vasic B, Johnson MA,} Palanivelu R. 2009. Penetration of the stigma and style elicits a novel transcriptome in pollen tubes, pointing to genes critical for growth in a pistil. PLoS Genet 5, e1000621. 
Qing L, Aoyama T. 2012. Pathways for epidermal cell differentiation via the homeobox gene GLABRA2: update on the roles of the classic regulator. J Integr Plant Biol 54, 729-737.

Radlowski M. 2005. Proteolytic enzymes from generative organs of flowering plants (Angiospermae). J. Applied Genet 46, 247-257.

Rampitsch C, Day J, Subramaniam R, Walkowiak S. 2013. Comparative secretomes analysis of Fusarium graminearum and two of its non-pathogenic mutants upon deoxynivalenol induction in vitro. Proteomics 13, 1913-1921.

Rappsilber J, Ishiham Y, Mann M. 2003. Stop and go extraction tip for matrix- assisted laser desorption /ionization, nanoelectrospray, and LC/MS sample preparation in proteomics. Anal Chem 75, 663-670.

Rappsilber J, Mann M, Ishihama Y. 2007. Protocol for micro-purification, enrichment, pre-fractionation and storage of peptides for proteomics using Stage Tips. Nature Protocols 2, 1896-1906.

Rehman RUI, Di Sansebastiano G. 2014. Plant Rab GTPases in membrane trafficking and signalling. In: Plant signaling: understanding the molecular crosstalk, Rehman Hakeem K, Rehman, RUI, Tahir I. eds. Springer, pp. 51-73.

Rejón JD, Delalande F, Schaeffer-Reiss C, Carapito C, Zienkiewicz K, de Dios Alché J, Rodrìguez-Garcia MI, Van Dorsselaer A, Castro AJ. 2013. Proteomics profile reveals novel proteins and functions of the plant stigma exudate. J Exp Bot 64, 5695-5705. 
Richmond TA, Bleecker AB. 1999. A defect in $\beta$-oxidation causes abnormal inflorescence development in Arabidopsis. Plant Cell 11, 1911-1923.

Ringli C, Bigler L, Kuhn BM, Leiber R, Diet A, Santelia D, Frey B, Pollmann S, Klein M. 2008. The modified flavonol glycosylation profile in the Arabidopsis rol1 mutants results in alterations in plant growth and cell shape formation. Plant Cell 20, 1470-1481.

Ripoll JJ, Ferrándiz C, Martínez-Laborda A, Vera A. 2006. PEPPER, a novel K-homology domain gene, regulates vegetative and gynoecium development in Arabidopsis. Dev Biol 289, 346-359.

Roberts IN, Stead AD, Ockendon DJ, Dickinson HG. 1980. Pollen-stigma interactions in Brassica oleracea. TAG 58, 241-246.

Rodrigo-Peiris T, Xu XM, Zhao Q, Wang H, Meier I. 2011. RanGAP is required for postmeiotic mitosis in female gametophyte development in Arabidopsis thaliana. J Exp Bot 62, 2705-2714.

Ross PL1, Huang YN, Marchese JN, Williamson B, Parker K, Hattan S, Khainovski N, Pillai S, Dey S, Daniels S, Purkayastha S, Juhasz P, Martin S, Bartlet-Jones M, He F, Jacobson A, Pappin DJ. 2004. "Multiplexed protein quantitation in Saccharomyces cerevisiae using amine-reactive isobaric tagging reagents." Mol Cell Proteomics 3, 11541169.

Russell SD, Dumas Ch. 1992. Sexual reproduction in flowering plants. Academic Press. San Diego; New York. 
Saijo Y, Hata S, Kyozuka J, Shimamoto K, Izui K. 2000. Over-expression of a single $\mathrm{Ca}^{2+}{ }_{-}$ dependent protein kinase confers both cold and salt/drought tolerance on rice plants. Plant J 23, 319-327.

Samuel MA, Tang W, Jamshed M, Northey J, Patel D, Smith D, Siu KWM, Muench DG, Wang Z, Goring DR. 2011. Proteomic analysis of Brassica stigmatic proteins following the self- incompatibility reaction reveals a role of microtubule dynamics during pollen responses. Mol Cell Proteomics 10, M111

Sang YL, Xu M, Ma FF, Chen H, Xu XH, Gao X, Zhang XS. 2012. Comparative proteomics analysis reveals similar and distinct features of proteins in dry and wet stigma. Proteomics 12, 1983-1998.

\section{Sankaranarayanan S, Jamshed M, Deb S, Chatfield-Reed K, Kwon EG, Chua G, Samuel}

MA. 2013a. Deciphering the stigmatic transcriptional landscape of compatible and selfincompatible pollinations in Brassica napus reveals a rapid stigma senescence response following compatible pollination. Mol Plant 6, 1988-1991.

Sankaranarayanan S, Jamshed M, Samuel MA. 2013b. Proteomics approaches advance our understanding of plant self-incompatibility response. J Proteome Res 12, 4717-4726.

Sarker RH, Elleman CJ, Dickinson HG. 1988. Control of pollen hydration in Brassica requires continued protein synthesis, and glycosylation is necessary for intraspecific incompatibility. PNAS USA 85, 4340-4344.

Schulze WX, Usadel B. 2010. "Quantitation in mass-spectrometry-based proteomics," Ann Rev Plant Biol 61, 491-516. 
Searle BC. 2010. Scaffold: A bioinformative tool for validating MS/MS based proteomics studies. Proteomics 10, 1265-1269.

Seo J, Wu J, Lii Y, Li y, Jin H. 2013. Contribution of small RNA pathway components in plant immunity. Mol Plant-Microbe Interact 26, 617-625.

Shi JX, Malitsky S, De Oliveira S, Branigan C, Franke RB, Schreiber L, Aharoni A. 2011. SHINE transcription factors act redundantly to pattern the archetypal surface of Arabidopsis flower organs. PLoS One 7.e1001388.

Shivanna KR, Ciampolini F, Cresti M.1989. The structure and cytochemistry of the pistil of Hypericum calycinum: The stigma. Ann Bot 63, 613-620.

\section{Silva JC1, Denny R, Dorschel CA, Gorenstein M, Kass IJ, Li GZ, McKenna T, Nold MJ, Richardson K, Young P, Geromanos S. 2005. "Quantitative proteomic analysis by accurate mass retention time pairs." Anal Chem 77, 2187-2200.}

Sjögren LLE, MacDonald TM, Sutinen S, Clarke AK. 2004. Inactivation of the clpC1 gene encoding a chloroplast Hsp100 molecular chaperone causes growth retardation, leaf chlorosis, lower photosynthetic activity, and a specific reduction in photosystem content. Plant Physiol 136, 4114-4126.

Sønderby IE, Geu-Flores F, Halkier BA. 2010. Biosynthesis of glucosinolates - gene discovery and beyond. Trends Plant Sci 15, 283-290.

Sørmo CG, Brembu T, Winge P, Bones AM. 2011. Arabidopsis thaliana MIRO1 and MIRO2 GTPases are unequally redundant in pollen tube growth and fusion of polar nuclei during female gametogenesis. PLoS One 6, e18530. 
Ståldal V, Sundberg E. 2009. The role of auxin in style development and apical-based patterning of the Arabidopsis thaliana gynoecium. Plant Signal Behav 4, 83-85.

Stein JC, Howett B, Boyes DC, Nasrallah ME, Nasrallah JB. 1991. Molecular cloning of putative receptor protein kinase gene encoded at the self-incompatibility locus of Brassica oleracea. PNAS USA $\mathbf{8 8}, 8816-8820$

Steinborn K, Maulbetsch C, Priester B, Trautmann S, Pacher T, Geiges B, Küttner F, Lepiniec L, Stierhof YD, Schwarz H, Jürgens G, Mayer U. 2002. The Arabidopsis PILZ group genes encode tubulin-folding cofactor orthologs required for cell division but not cell growth. Genes Dev 16, 959-971.

Stratmann JW, Gusmaroli G. 2011. Many jobs for one good cop - the COP9 signalosome guards development and defense. Plant Sci 185-6, 50-64.

Swanson R, Clark T, Preuss D. 2005. Expression profiling of Arabidopsis stigma tissue identifies stigma-specific genes. Sex Plant Reprod 18, 163-171.

Swanson R, Edlund A, Preuss D. 2004. Species specificity in pollen-pistil interactions. Annu Rev Genet 38, 793-818.

Szakonyi D, Byrne ME. 2011. Involvement of ribosomal protein RPL27a in meristem activity and organ development. Plant Signal Behav 6, 712-714.

Takahashi K, Shimada T, Kondo M, Tamai A, Mori M, Nishimura M, Hara-Nishimura I. 2010. Ectopic expression of an esterase, which is a candidate for the unidentified plant cutinase, causes cuticular defects in Arabidopsis thaliana. Plant Cell Physiol 51, 123-131. 
Takatsuka H, Ohno R, Umeda M. 2009. The Arabidopsis cyclin-dependent kinaseactivating kinase CDKF; 1 is a major regulator of cell proliferation and cell expansion but is dispensable for CDKA activation. Plant J 59, 475-487.

Takayama S, Shimosato H, Shiba H, Funato M, Che FS, Watanabe M, Iwano M, Isoqai A. 2001. Direct ligand-receptor complex interaction controls Brassica self-incompatibility. Nature 413, 534-538.

Taylor JA, Johnson RS. 1997. Sequence database searches via de novo peptide sequencing by tandem mass spectrometry. Rapid Commun Mass Spectrom11, 1067-1075.

Tran F, Penniket C, Patel RV, Provart NJ, Laroche A, Rowland O, Robert LS. 2013. Developmental transcriptional profiling reveals key insights into Triticeae reproductive development. Plant J 74, 971-988.

Traverso JA, Pulido A, Rodríguez-Garía MI, Alché JD. 2013. Thiol-based redox regulation in sexual plant reproduction: new insights and perspectives. Front Plant Sci 4, doi:10.3389/fpls.00465.

Treu R, Emberlin J. 2000. Pollen dispersal in the crops Maize (Zea mays), Oilseed rape (Brassica napus ssp. Oleifera), Potatoes (Solanum tuberosum), Sugar beet (Beta vulgaris ssp. vulgaris) and wheat (Triticum aestivum). Soil Association, Bristol, UK

Tsai AY, Gazzarrini S. 2012. AKIN10 and FUSCA3 interact to control lateral organ development and phase transitions in Arabidopsis. Plant J 69, 809-821. 
Tung CW, Dwyer KG, Nasrallah ME, Nasrallah JB. 2005. Genome-wide identification of genes expressed in Arabidopsis pistils specifically along the path of pollen tube growth. Plant Physiol 138, 977-989.

Ünlü M, Morgan ME, Minden JS. 1997. Difference gel electrophoresis: a single gel method for detecting changes in protein extract". Electrophoresis 18, 2071-2077.

Vishnyakova MA, Willemse MTM. 1994. Pollen-pistill interaction in wheat. Acta Bot Neerl 43, 51-64

Vivian-Smith A, Luo M, Chaudhury A, Koltunow A. 2001. Fruit development is actively restricted in the absence of fertilization in Arabidopsis. Dev 128, 2321-2331.

Vogel C, Marcotte EM. 2012. Insights into the regulation of protein abundance from proteomic and transcriptomic analyses. Nature Rev Genet 13, 227-232.

Waduwara-Jayabahu I, Oppermann Y, Wirtz M, Hull ZT, Schoor S, Plotnikov AN, Hell R, Sauter M, Moffatt BA. 2012. Recycling of methylthioadenosine is essential for normal vascular development and reproduction in Arabidopsis. Plant Physiol 158, 1728-1744.

Wang H, Boavida LC, Ron M, McCormick S. 2008. Truncation of a protein disulfide isomerase, PDIL2-1, delays embryo sac maturation and disrupts pollen tube guidance in Arabidopsis thaliana. Plant Cell 20, 3300-3311.

Wang J, Howles PA, Cork AH, Birch RJ, Williamson RE. 2006. Chimeric proteins suggest that the catalytic and/or C-terminal domains give CesA1 and CesA3 access to their specific sites in the cellulose synthase of primary walls. Plant Physiol 142, 685-695. 
Wang X, Guo L, Wang G, Li M. 2014. PLD: phospholipase Ds in plant signaling. In:

Phospholipases in plant signaling, Wang X. ed. Springer, Heidelberg, pp. 3-26.

Wasiak S, Legendre-Guillemin V, Puertollano R, Blondeau F, Girard M, de Heuvel E,

Boismenu D, Bell AW, Bonifacino JS, McPherson PS. 2002. Enthoprotin : a novel

clathrin-associated protein identified through subcellular proteomics. J Cell Biol 158, 855-

862.

Wheeler MJ, Franklin-Tong VE, Franklin FCH. 2001. The molecular and genetic basis of pollen-pistil interactions. New Phytol 151, 565-584.

Wilkins MR, Sachez JC, Gooley AA, Appel RD, Humphery-Smith I, Hochstrasser DF, Willams KL. 1996. Progress with proteome projects: why all proteins expressed by a genome should be identified and how to do it". Biotechnol Genet Eng Rev 13, 19-50.

Wilson AS. 1876. On wheat and rye hybrids. Trans. a. Proc. Bot. Sco. Edinburg. 12, 286-288.

Wiśniewski JR, Zougman A, Mann M. 2009. Combination of FASP and stage tip-based fractionation allows in-depth analysis of the hippocampal membrane proteome. J Proteome Res 8, 5674-5678.

Wiśniewski JR, Zougman A, Nagaraj N, Matthias M. 2009. Universal sample preparation method for proteome analysis. Nat Meth 6, 362-359.

Wolters-Arts M, Lush WM, Mariani C. 1998. Lipids are required for directional pollentube growth. Nature 392, 818-821. 
Wu R, Li S, He S, Waßmann F, Yu C, Qin G, Schreiber L, Qu L, Gu H. 2011. CFL1, a WW domain protein, regulates cuticle development by modulating the function of HDG1, a class IV homeodomain transcription factor, in rice and Arabidopsis. Plant Cell 23, 3392-3411.

Xu XH, Chen H, Sang YL, Wang F, Ma JP, Gao X, Zhang XS. 2012. Identification of genes specifically or preferentially expressed in maize silk reveals similarity and diversity in transcriptabundance of different dry stigmas. BMC Genomics 13, 294-311.

Xu XH, Wang F, Chen H, Sun W, Zhang XS. 2013. Transcript profile analyses of maize silks reveal effective activation of genes involved in microtubule-based movement, ubiquitindependent protein degradation, and transport in the pollination process. PLoS One $\mathbf{8}$, e0053545.

Yamatani H, Sato Y, Masuda Y, Kato Y, Morita R, Fukunaga K, Nagamura Y, Nishimura M, Sakamoto W, Tanaka A, Kusaba M. 2013. NYC4, the rice ortholog of Arabidopsis THF1, is involved in the degradation of chlorophyll-protein complexes during leaf senescence. Plant J 74, 652-662.

Yeung KC, Larter EN. 1972. Pollen production and dissemination properties of triticale relative to wheat. Can J Plant Sci 52, 569-574.

Zhou H, Nussbaumer C, Chao Y, DeLong A. 2004. Disparate roles for the regulatory A subunit isoforms in Arabidopsis protein phosphatase 2A. Plant Cell 16, 709-722.

Zinkl GM, Zweibel BI, Grier DG, Preuss D. 1999. Pollen-stigma adhesion in Arabidopsis: a species-specific interaction mediated by hydrophobic molecules in the pollen exine. Dev 126, 5431-5440 